ORNL/TM-13693

Neutron and Gamma Fluxes and dpa Rates for HFIR Vessel Beltline Region (Present and Upgrade Designs)

\author{
E. D. Blakeman
}




\section{DOCUMENT AVAILABILITY}

Reports produced after January 1, 1996, are generally available free via the U.S. Department of Energy (DOE) Information Bridge.

Web site http://www.osti.gov/bridge

Reports produced before January 1, 1996, may be purchased by members of the public from the following source.

National Technical Information Service

5285 Port Royal Road

Springfield, VA 22161

Telephone 703-605-6000 (1-800-553-6847)

TDD 703-487-4639

Fax 703-605-6900

E-mail info@ntis.fedworld.gov

Web site http://www.ntis.gov/support/ordernowabout.htm

Reports are available to DOE employees, DOE contractors, Energy Technology Data Exchange (ETDE) representatives, and International Nuclear Information System (INIS)

representatives from the following source.

Office of Scientific and Technical Information

P.O. Box 62

Oak Ridge, TN 37831

Telephone 865-576-8401

Fax 865-576-5728

E-mail reports@adonis.osti.gov

Web site http://www.osti.gov/contact.html

This report was prepared as an account of work sponsored by an agency of the United States Government. Neither the United States Government nor any agency thereof, nor any of their employees, makes any warranty, express or implied, or assumes any legal liability or responsibility for the accuracy, completeness, or usefulness of any information, apparatus, product, or process disclosed, or represents that its use would not infringe privately owned rights. Reference herein to any specific commercial product, process, or service by trade name, trademark, manufacturer, or otherwise, does not necessarily constitute or imply its endorsement, recommendation, or favoring by the United States Government or any agency thereof. The views and opinions of authors expressed herein do not necessarily state or reflect those of the United States Government or any agency thereof. 
ORNL/TM-13693

Computational Physics and Engineering Division

\title{
Neutron and Gamma Fluxes and dpa Rates for HFIR Vessel Beltline Region (Present and Upgrade Designs)
}

\author{
E. D. Blakeman
}

Date published: November 2000

Prepared by the

OAK RIDGE NATIONAL LABORATORY

Oak Ridge, TN 37831-6363

Managed by

UT-BATTELLE, LLC,

for the

U.S. DEPARTMENT OF ENERGY

under contract DE-AC05-00OR22725 



\section{CONTENTS}

Page

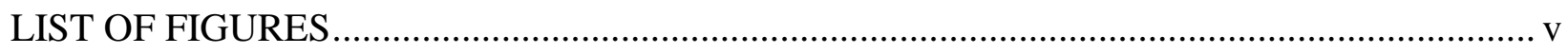

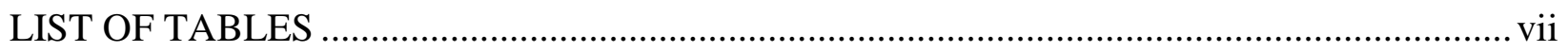

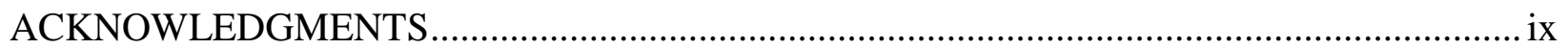

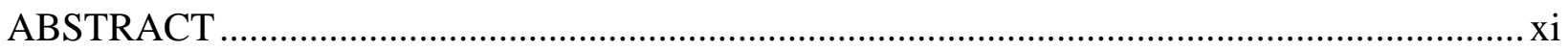

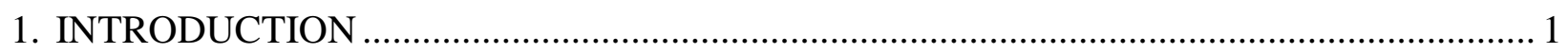

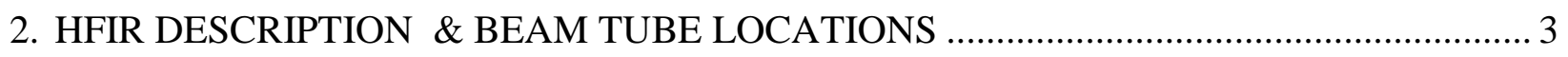

3. LOCATIONS FOR DPA RATE CALCULATIONS ……………........................................ 7

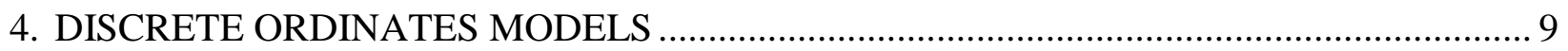

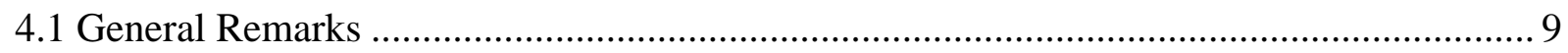

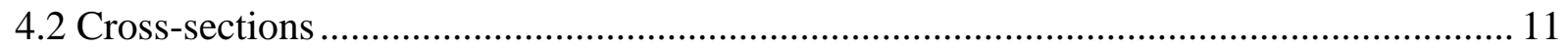

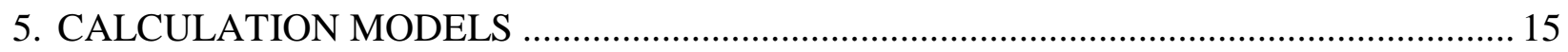

5.1 HFIR Core and Vessel Region Models .................................................................. 15

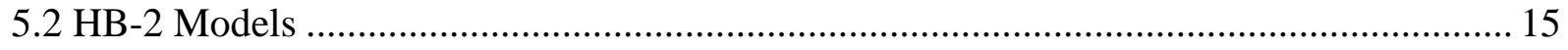

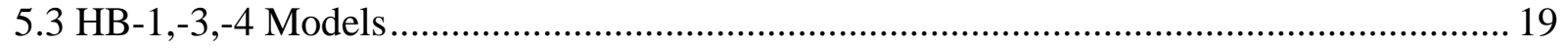

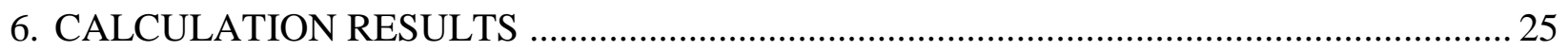

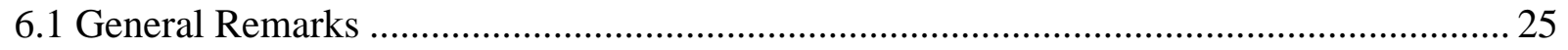

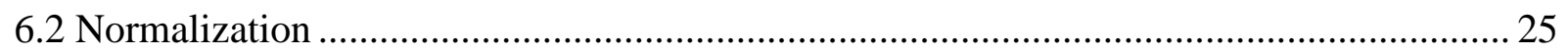

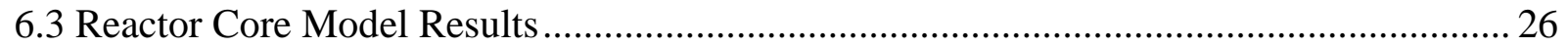

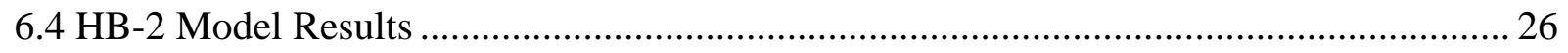

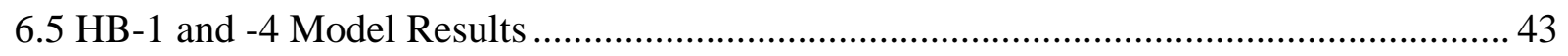

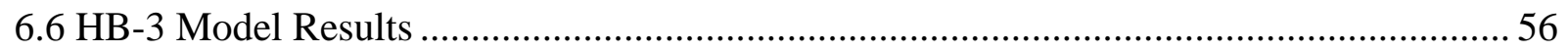

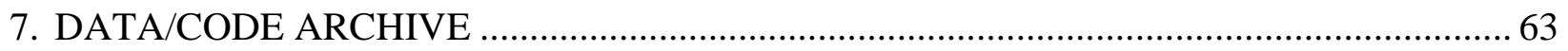

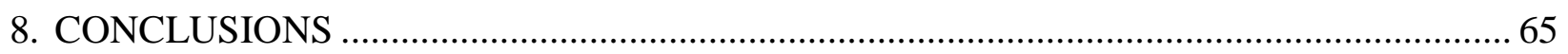

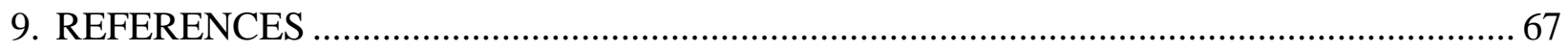

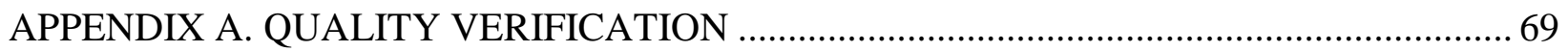

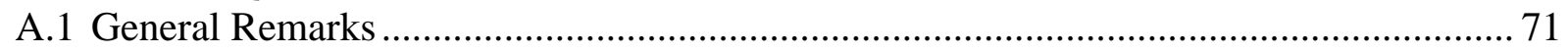

A.2 Validation of Models.............................................................................................. 72

A.2.1 Validation of HB-2 Models ............................................................................ 72 
A.2.2 Validation of HB-4 (HB-1) Models

A.2.3 Validation of HB-3 Model

APPENDIX B. CALCULATIONS USING BOC CONTROL PLATE POSITIONS ................ 79

APPENDIX C. MATERIAL COMPOSITION ATOMIC DENSITIES FOR HFIR MODELS .. 87

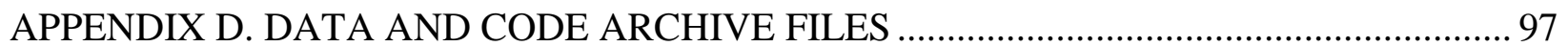

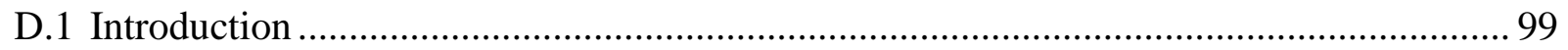

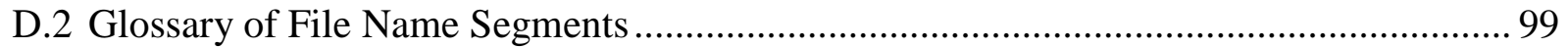

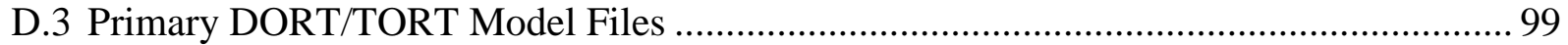

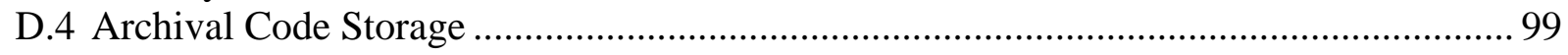

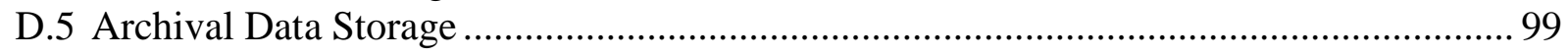




\section{LIST OF FIGURES}

Figure $\quad$ Page

1. Vertical section of HFIR vessel and core........................................................................ 4

2. Cross section of HFIR vessel showing locations of surveillance capsules.......................... 5

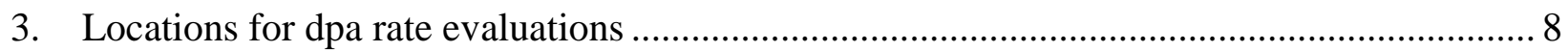

4. Geometry/material model for HFIR reactor core ............................................................ 16

5. Geometry/material model for HB-2 (present design) .................................................... 17

6. Geometry/material model for HB-2 (new design) .................................................. 18

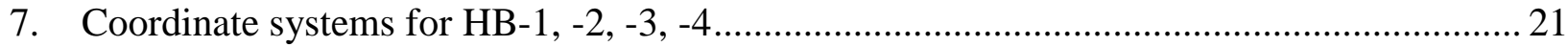

8. Geometry/material model for HB-1 and HB-4 (present design)..................................... 22

9. Geometry/material model for HB-4 (new design) .................................................... 23

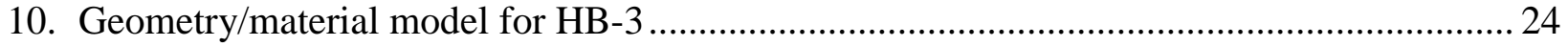

11. Neutron iso-dpa rate (displacements/atom/s) for HFIR core fixed source model ................ 28

12. Gamma iso-dpa rate (displacements/atom/s) for HFIR core fixed source model ................. 29

13. Total (neutron + gamma) iso-dpa rate (displacements/atom/s) for HFIR core fixed source model. 30

14. Neutron iso-flux (neutrons $\left./ \mathrm{cm}^{2} / \mathrm{s}\right)(\mathrm{E}>1 \mathrm{MeV})$ for HFIR core fixed source model............. 31

15. Gamma iso-flux (photons $\left./ \mathrm{cm}^{2} / \mathrm{s}\right)(\mathrm{E}>1 \mathrm{MeV})$ for HFIR core fixed source model .............. 32

16. Neutron iso-dpa rate (displacements/atom/s) for HB-2 (present design) ........................... 33

17. Gamma iso-dpa rate (displacements/atom/s) for HB-2 (present design) ............................ 34

18. Total (neutron + gamma) iso-dpa rate (displacements/atom/s) for HB-2 (present design) ... 35

19. Neuton iso-flux (neutrons $\left./ \mathrm{cm}^{2} / \mathrm{s}\right)(\mathrm{E}>1 \mathrm{MeV})$ for HB-2 (present design) ........................... 36

20. Gamma iso-flux (photons $\left./ \mathrm{cm}^{2} / \mathrm{s}\right)(\mathrm{E}>1 \mathrm{MeV})$ for HB-2 (present design) ............................... 37

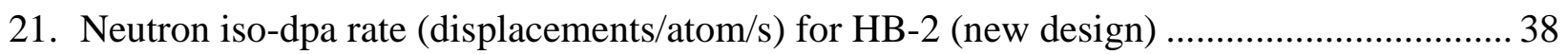

22. Gamma iso-dpa rate (displacements/atom/s) for HB-2 (new design) ............................... 39

23. Total (neuton + gamma) iso-dpa rate (displacements/atom/s) for HB-2 (new design) ........ 40

24. Neutron iso-flux (neutrons $\left./ \mathrm{cm}^{2} / \mathrm{s}\right)(\mathrm{E}>1 \mathrm{MeV})$ for HB-2 (new design) ............................ 41

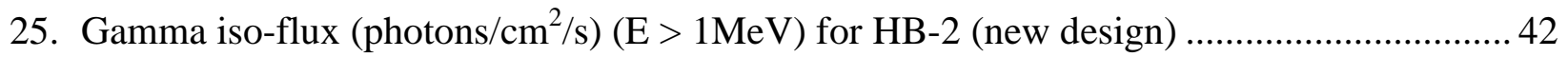

26. Neutron iso-dpa rate (neutrons $/ \mathrm{cm}^{2} / \mathrm{s}$ ) for HB-1 and HB-4 (present design; HB-4 shown ; HB-1 is mirror image). 
27. Gamma iso-dpa rate (displacements/atom/s) for HB-1 and HB-4 (present design; HB-4 shown; HB-1 is mirror image).

28. Total (neutron + gamma) iso-dpa rate (displacements/atom/s) for HB-1 and HB-4 (present design; HB-4 shown; HB-1 is mirror image).

29. Neutron iso-flux (neutrons $\left./ \mathrm{cm}^{2} / \mathrm{s}\right)(\mathrm{E}>1 \mathrm{MeV})$ for $\mathrm{HB}-1$ and $\mathrm{HB}-4$ (present design; HB-4 shown; HB-1 is mirror image).

30. Gamma iso-flux (photons $\left./ \mathrm{cm}^{2} / \mathrm{s}\right)(\mathrm{E}>1 \mathrm{MeV})$ for HB-1 and HB-4 (present design; HB-4 shown; HB-1 is mirror image).

31. Neutron iso-dpa rate (displacements/atom/s) for HB-4 (new design).

32. Gamma iso-dpa rate (displacements/atom/s) for HB-4 (new design).............................. 52

33. Total (neutron + gamma) iso-dpa rate (displacements/atom/s) for HB-4 (new design) ........53

34. Neutron iso-flux (neutrons $\left./ \mathrm{cm}^{2} / \mathrm{s}\right)(\mathrm{E}>1 \mathrm{MeV})$ for HB-4 (new design) ..............................5 54

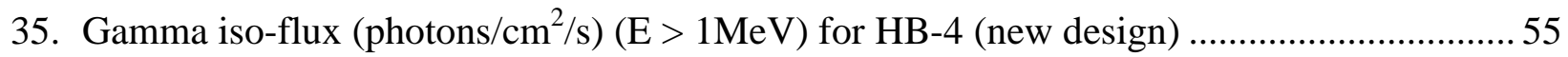

36. Neutron iso-dpa rate (displacements/atom/s) for HB-3 .............................................. 57

37. Gamma iso-dpa rate (displacements/atom/s) for HB-3 ................................................58

38. Total (neutron +gamma) iso-dpa rate (displacements/atom/s) for HB-3 .......................... 59

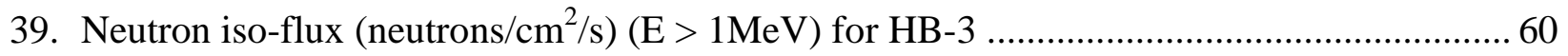

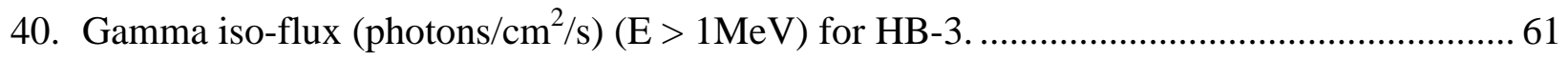

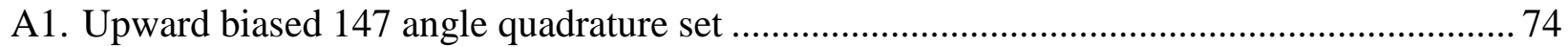

A2. Total (neutron + gamma) iso-dpa rate (displacements/atom/s) for HB-4 (new design) with fine mesh on beam tube $(\mathrm{X})$ axis

B1. Total (neutron + gamma) iso-dpa rate (displacements/atom/s) for HFIR core fixed source model with BOC rod position.

B2. Total iso-dpa rate (displacements/atom/s) for HB-2 (present design) for BOC control plate positions

B3. Total (neutron + gamma) iso-dpa rate (displacements/atom/s) for HB-2 (new design) for BOC control plate positions

D1. Directory structure for beam line calculations for HFIR vessel life extension analysis ...... 100 


\section{LIST OF TABLES}

Table

Page

1. Summarization of code sequence for beam tube calculations ….................................... 11

2. VELM neutron group boundaries and Fe dpa cross sections........................................... 12

3. VELM gamma group boundaries and Fe dpa cross sections ........................................ 13

4. Comparison of dpa rates in the HB-2 present and proposed designs................................ 43

5. Determination of HB-4 (HB-1) normalization factors................................................... 44

6. Comparison of normalized dpa rates for HB-4 (HB-1) present and proposed

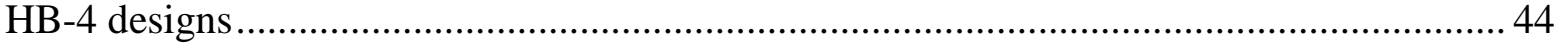

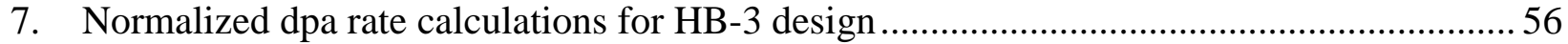

A1. Internal validation of HB-2 models by comparison of dpa rates calculated at approximately equivalent points near the reactor vessel inside surface .......................... 73

A2. Internal validation of HB-4 (HB-1) models by comparison of dpa rates calculated at approximately equivalent points at the reactor vessel inside surface

A3. Internal validation of HB-3 Model by comparison of dpa rates calculated at approximately equivalent points at the reactor vessel inside surface ..............................76

B1. Comparison of HB-2 models for BOC and EOC control plate positions ........................... 85

C1. Atomic Densities for HFIR Model Mixtures ...................................................................... 89

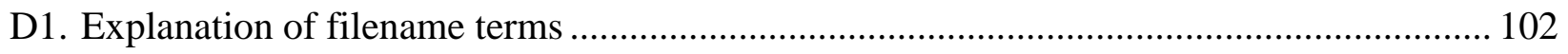

D2. List of main DORT/TORT code inputs by beam tube design ..................................... 104 



\section{ACKNOWLEDGMENTS}

The author wishes to acknowledge the technical assistance from R. A. Lillie, R. D. Cheverton, J. V. Pace III, J. A. Bucholz, I. Remec, and C.O.Slater. R. A. Lillie and J. V. Pace III provided technical guidance on the discrete ordinates method and R. A. Lillie performed considerable cross section processing during the early part of the project. J. V. Pace III also provided material composition data. R. D. Cheverton contributed extensive technical advice and knowledge of the HFIR reactor. Particular appreciation is extended to him for his guidance, patience, and support for the duration of this project. J. A. Bucholz is also thanked for his advice and assistance with regard to the HFIR beam tubes and modeling the cold source in HB-4. C.O. Slater provided help on several occasions with debugging discrete ordinates input files.

The author also wishes to extend his appreciation to I. Remec for providing results from the analysis of dosimetry data.

Appreciation is extended to M. R. Whittenbarger for help in preparing the manuscript. 



\begin{abstract}
The Oak Ridge National Laboratory (ORNL) High Flux Isotope Reactor (HFIR) is currently undergoing an upgrading program, a part of which is to increase the diameters of two of the four radiation beam tubes (HB-2 and HB-4). This change will cause increased neutron and gamma radiation dose rates at and near locations where the tubes penetrate the vessel wall. Consequently, the rate of radiation damage to the reactor vessel wall at those locations will also increase. This report summarizes calculations of the neutron and gamma flux (particles $/ \mathrm{cm}^{2} / \mathrm{s}$ ) and the dpa rate (displacements/atom/s) in iron at critical locations in the vessel wall. The calculated dpa rate values have been recently incorporated into statistical damage evaluation codes used in the assessment of radiation induced embrittlement.

Calculations were performed using models based on the discrete ordinates methodology and utilizing ORNL two-dimensional and three-dimensional discrete ordinates codes. Models for present and proposed beam tube designs are shown and their results are compared. Results show that for HB-2, the dpa rate in the vessel wall where the tube penetrates the vessel will be increased by $\sim 10$ by the proposed enlargement. For HB-4, a smaller increase of $\sim 2.6$ is calculated.
\end{abstract}





\section{INTRODUCTION}

The Oak Ridge National Laboratory (ORNL) High Flux Isotope Reactor (HFIR) is currently undergoing an extensive upgrading process, a part of which is to increase the diameters of two of the four radiation beam tubes. In addition to increasing the radiation streaming area, these modifications will also reduce the amount of shielding at locations where the tubes penetrate the vessel wall. As a result, the neutron and gamma radiation dose rates received at and near these locations will be significantly increased. A major concern is the additional radiation damage to the reactor vessel wall that will result from these modifications. The damage parameter used in the evaluation is displacements/atom (dpa) in iron (the major constituent in the vessel wall) which results from neutron and gamma radiation. Radiation induced embrittlement that could result in a loss of integrity of the vessel wall has been an ongoing issue of considerable interest. An assessment ${ }^{1}$ for the present HFIR design describes the HFIR pressure vessel design, the integrity evaluation concepts, and the vessel surveillance monitoring program in detail.

This report summarizes calculations of the neutron and gamma flux (particles $/ \mathrm{cm}^{2} / \mathrm{s}$ ) and the dpa rate (displacements/atom/s) at critical locations in the vessel beltline region near the four radiation beam tubes. (The beltline region refers to the general area of the reactor vessel near the core midplane where radiation dose rates are relatively high.) A recent evaluation has shown that gamma contributions are significant and must be included in the vessel damage assessment. ${ }^{2}$

The motivation for the calculations is two-fold. First, it is necessary to specifically assess the impact of the enlargement of HB-2 and HB-4. Second, the models provide updated capabilities to determine the dpa rates and fluxes for all of the beam tube designs as required by the lifetime extension analysis.

Results from models of the reactor core and each beam tube are presented. Models for present and proposed beam tube designs are shown and their results compared. Values obtained from these calculations have been recently incorporated into statistical damage evaluation codes and details of these evaluations are reported in an updated assessment. ${ }^{3}$

The current calculation models are similar to earlier models used previously to calculate neutron and gamma fluxes and activities for the existing HFIR beam tube designs. ${ }^{4}$ In some cases the new models are revisions of these earlier models that have been changed to incorporate proposed beam tube modifications. Additional changes incorporated in the newer models are also described later in this report. 



\section{HFIR DESCRIPTION \& BEAM TUBE LOCATIONS}

The HFIR is a pressurized water research reactor used to perform neutron scattering and nuclear physics research, isotope production, and material irradiation studies. The maximum reactor operating power is 100MWth. The $239 \mathrm{~cm}$ (94 in.) [id] reactor vessel, shown in vertical crosssection in Figure 1, is located in a water pool. Figure 2 shows a horizontal cross-section at the vertical reactor mid-plane. The core consists of two annular regions surrounded by removable and permanent beryllium reflector sections. Figure 2 also shows the four horizontal radiation beam tubes, labeled HB-1,-2,-3, and -4 , used to direct radiation out of the reactor core. Each tube has a unique orientation to the reactor core. HB-2 lies along a radial vector of the reactor core, and is consequently referred to as a "radial" tube. HB-3 is a "tangential" tube because its axis is nearly tangential to the reactor core. HB-1 and HB-4 are, in the present design, symmetrical and identical, and are located in a tubular region that extends entirely through the reactor vessel. Consequently, $\mathrm{HB}-1$ and $\mathrm{HB}-4$ are referred to as "thru tubes". 


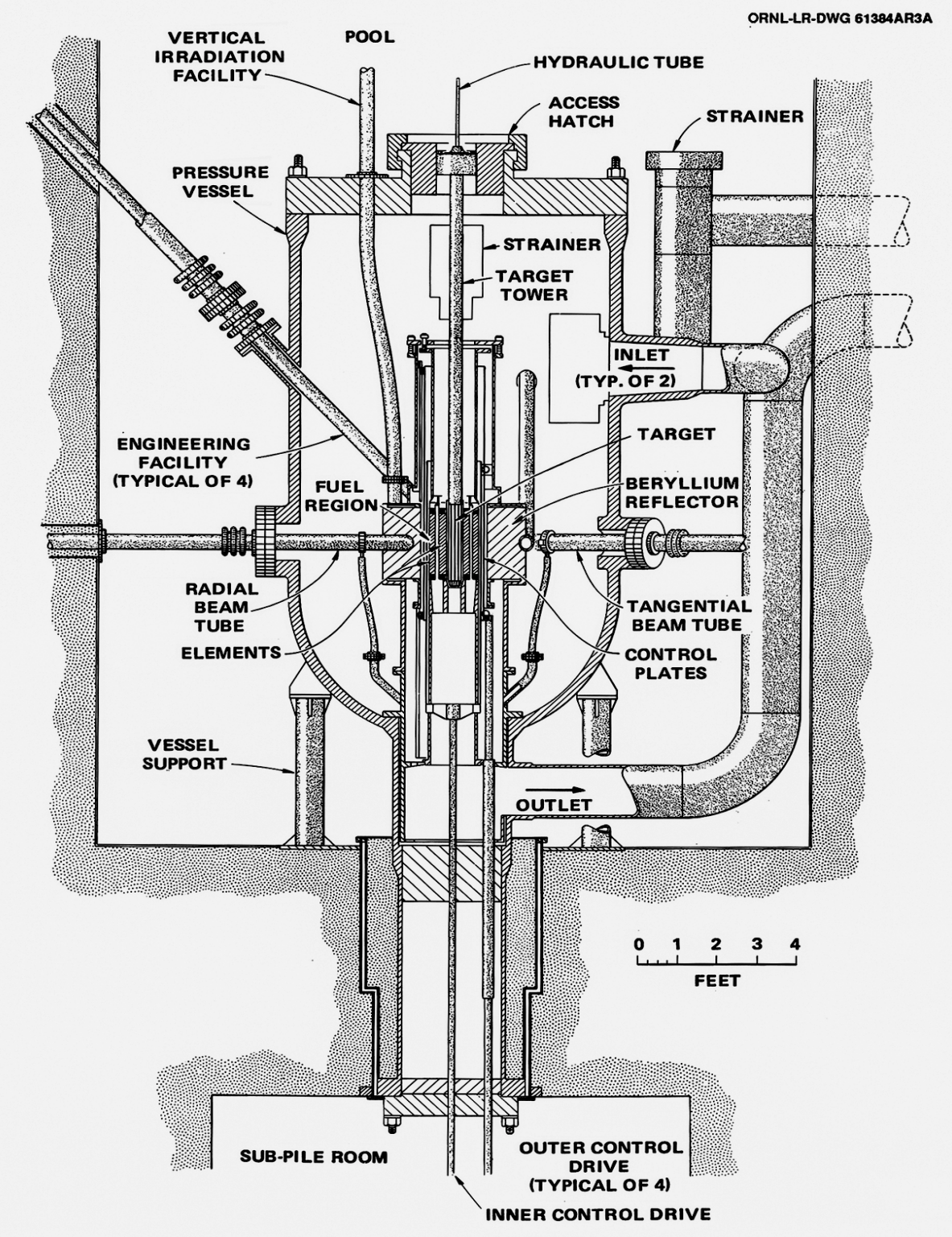

VERTICAL SECTION OF REACTOR VESSEL AND CORE

Figure 1. Vertical section of HFIR vessel and core. 


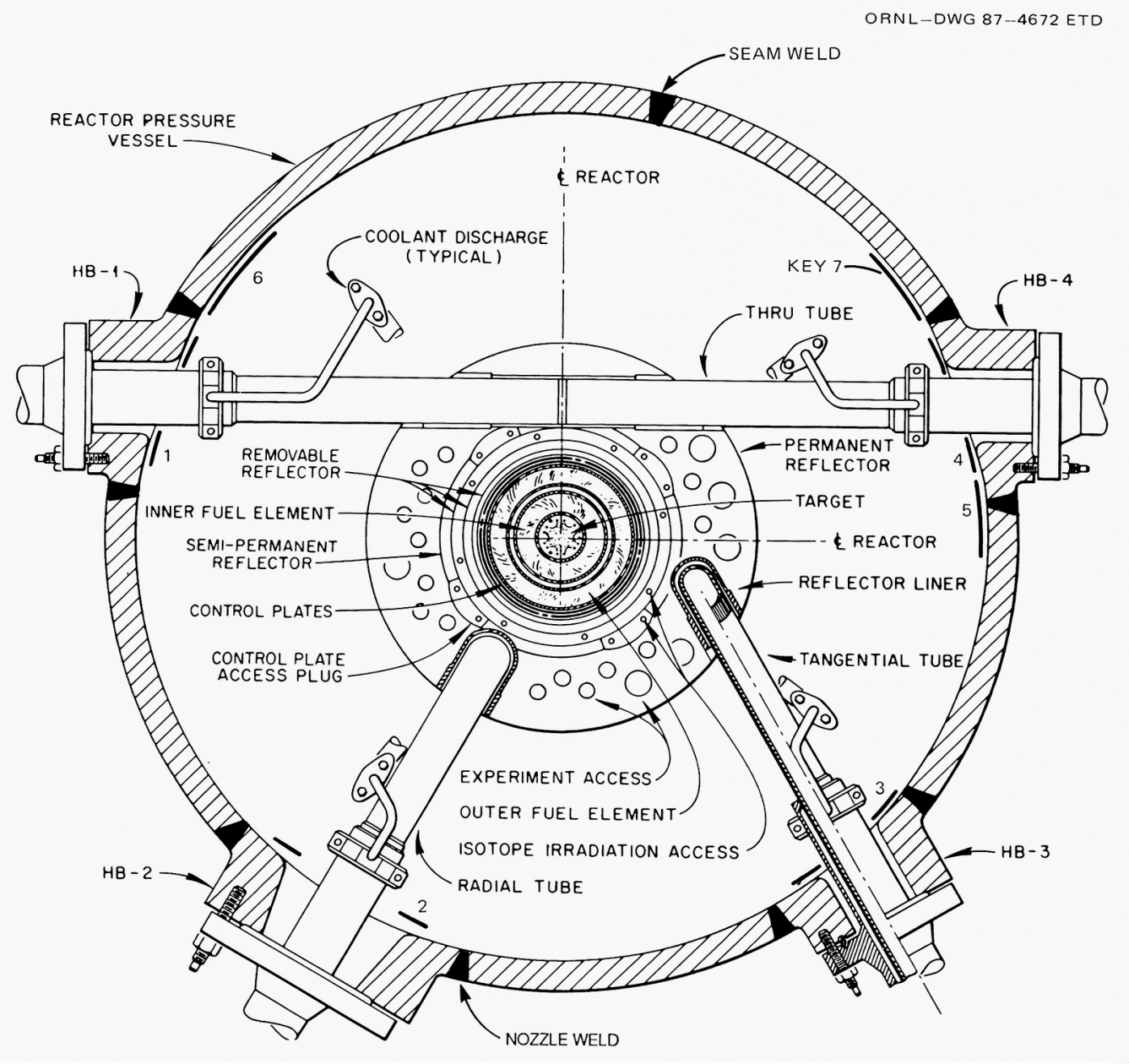

Figure 2. Cross section of HFIR vessel showing locations of surveillance capsules. 



\section{LOCATIONS FOR dPa RATE CALCULATIONS}

The locations in the vessel wall at which it is most crucial to evaluate the dpa rates are those at which radiation levels are elevated because of proximity to a beam tube and/or at which, because of material properties, radiation damage is more likely to occur. It is not within the scope of this report to address these issues in detail. The reader is referred to References 1 and 3 for a detailed analysis. The primary areas of concern are the slightly rounded inside surface of the vessel where each beam tube penetrates the vessel wall (nozzle corner) and the inside surface of the seam weld where the nozzle structure is joined to the vessel wall (nozzle weld). Also, of concern is the annulus region defined by the inside surface of the vessel wall between the corner and the weld. Figure 3 is a conceptual drawing of a beam tube penetration; its purpose is to clarify these locations. Figure 3 is applicable to each of the beam tubes. 


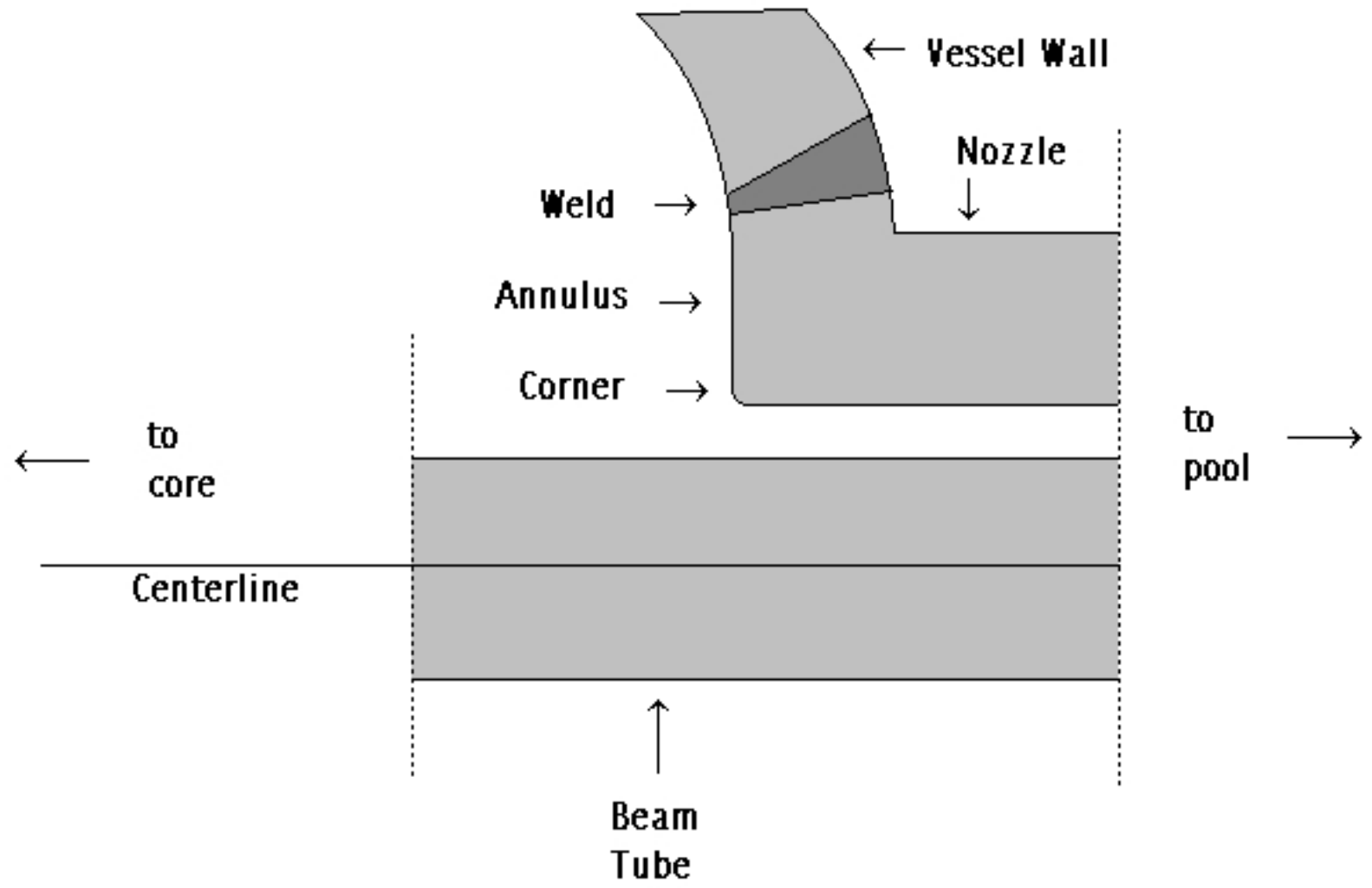

Figure 3. Locations for dpa rate evaluations 


\section{DISCRETE ORDINATES MODELS}

\subsection{General Remarks}

All transport calculations for these analyses were performed with the discrete ordinates ${ }^{5,6}$ methodology utilizing either two- or three-dimensional models. Codes used are from the DOORS transport code system ${ }^{7}$ developed at ORNL and distributed by the ORNL Radiation Safety Information Computational Center (RSICC). Because the central axis of HB-2 projects along the core radius, a two-dimensional RZ geometry using the DORT two-dimensional transport code was used for this beam-tube model. Beam tubes HB-1, -3 , and -4 are not aligned with a core radius vector and cannot be adequately modeled with two-dimensional geometry. Therefore, these beam tubes were modeled with a three-dimensional XYZ geometry using the TORT three-dimensional discrete ordinates transport code.

All calculations were performed using $\mathrm{P}_{3}$ Legendre expansions and a quadrature order of at least $\mathrm{S}_{10}$. A biased quadrature set of 147 angles was used for HB-2 to accommodate particle streaming in the beam tube. Also, a quadrature set with 20 additional angles was used for HB-3 and HB-4 for similar reasons. The expansion order determines the degree of scattering anisotropy and the quadrature order determines angular resolution. Appendix A addresses further quality verification of the models used.

Neutron and gamma sources for all beam tube calculations were obtained from fixed source calculations of the HFIR core utilizing beginning-of-cycle (BOC) fuel conditions, but with control plates withdrawn to the end-of-cycle (EOC) location. This approach was convenient and was assumed at the outset to represent the most conservative situation since it results in the largest flux to the vessel wall. Additional calculations were later performed with actual BOC conditions in which the control plates were inserted to the BOC position; these results are discussed in Appendix B.

The general approach used was to first perform a two-dimensional cylindrical (RZ) calculation of the HFIR core to obtain a two-dimensional distribution of the fission source in the fuel. This source was then used in a second enlarged two-dimensional cylindrical reactor model which included the vessel and the surrounding water. The neutron and gamma flux distribution from this latter model was then used as a boundary source for two-dimensional or three-dimensional beam tube models.

The procedure used to perform these calculations is summarized below. More details and descriptions of specific models are given in Section 5.

\section{Step 1:}

A forward eigenvalue $\left(\mathrm{k}_{\mathrm{eff}}\right)$ discrete ordinates calculation was performed using a twodimensional cylindrical DORT model of the HFIR core without beam tubes. This model concentrated on the fuel region and extended in radius far enough $(25.4 \mathrm{~cm})$ into the water region beyond the outer Be reflector to provide essentially infinite neutron reflection. The purpose of 
this calculation was to calculate a fission source spatial distribution in the fuel that could be used in subsequent calculations.

\section{Step 2:}

The fission source produced in Step 1 was incorporated into a fixed source two-dimensional DORT model to calculate boundary sources to be used in all the subsequent beam tube calculations. The reactor model used in the Step 2 calculation was similar to that used for the Step 1 calculation, except that the radius was enlarged to include the reactor vessel wall and the water beyond. The fixed source, which has a fission energy distribution, was normalized to the maximum reactor power of $100 \mathrm{MW}$ in this calculation. An advantage of this two-step process is that only a single outer iteration was required for the latter calculation that used the larger model.

\section{Step 3:}

Auxiliary codes from the DOORS system, including VISA and TORSED, and a separate code, $\mathrm{DTD}^{8}$, were used to map the fluxes calculated in Step 2 to the boundaries of the beam tube models; this produced boundary sources for the subsequent two-dimensional and threedimensional beam-tube calculations. The VISA code was used to reorder the directional fluxes from the Step 2 DORT calculation into a more useable format, select an appropriate subset of the data, and normalize the directional flux so that weighted directional sums matched those of the corresponding scalar fluxes. The TORSED code used the VISA output to produce a boundary source for the three-dimensional beam tube calculations with the TORT code. In summary, TORSED couples a DORT two-dimensional geometry to a TORT three-dimensional geometry, performing the necessary translations and rotations between the two coordinate frames. The auxiliary code, DTD, performs an analogous task coupling two geometrically dissimilar DORT models. Thus, DTD was used to calculate a boundary source for the DORT-based HB-2 models.

\section{Step 4:}

Beam tube calculations were performed using two-dimensional (DORT) or three-dimensional (TORT) models. Sources from Step 3 were input as external boundary sources. Table 1 summarizes the overall calculation sequence. 
Table 1. Summarization of code sequence for beam tube calculations

\begin{tabular}{|c|l|c|c|}
\hline Step & \multicolumn{1}{|c|}{ Process } & \multicolumn{2}{|c|}{ DOORS Code } \\
\hline 1 & $\begin{array}{l}\text { Core eigenvalue (keff } \\
\text { calculation }\end{array}$ & \multicolumn{2}{|c|}{ DORT } \\
\hline 2 & $\begin{array}{l}\text { Fixed source extended core } \\
\text { calculation }\end{array}$ & \multicolumn{2}{|c|}{ DORT } \\
\hline 3 & Flux ordering/normalization & \multicolumn{2}{|c|}{ VISA } \\
\hline \multicolumn{2}{|l|}{$\begin{array}{l}\text { Two-dimensional } \\
\text { Models }\end{array}$} & $\begin{array}{l}\text { Three-dimensional } \\
\text { models }\end{array}$ \\
\hline 4 & $\begin{array}{l}\text { Boundary source calculation } \\
\text { for beam tube model }\end{array}$ & DTD & TORSED \\
\hline 5 & $\begin{array}{l}\text { Calculation of beam-tube } \\
\text { fluxes and dpa rates }\end{array}$ & DORT & TORT \\
\hline
\end{tabular}

\subsection{Cross-sections}

All calculations were performed using the VELM61 ${ }^{9}$ broad-group cross-section library. This library, which is collapsed from the fine-group 212-group Vitamin-E library, contains 61 neutron groups and 23 gamma groups. Recent studies have shown that gamma degradation is significant. Thus, it was necessary to include gamma dpa cross sections and to include gamma production and transport in the transport calculations. The selected neutron group structure contains only one thermal neutron group; thus, neutron energy upscattering is not treated. Group boundaries in the epi-thermal and fast groups are sufficiently fine-spaced and therefore considered adequate for HFIR dpa activity calculations, which are not heavily influenced by thermal groups. Tables 2 and 3 show the neutron and gamma group boundaries as well as the iron $(\mathrm{Fe})$ dpa cross-sections. Neutron and gamma dpa cross section values were obtained from References 10 and 11 respectively, and were subsequently converted to the VELM energy groups. From Table 2 it is observed that the neutron dpa cross section decreases monotonically with energy from $\sim 15 \mathrm{MeV}$ to about $100 \mathrm{eV}$, below which it begins to increase slightly. From Table 3, the gamma dpa cross section decreases monotonically from $\sim 14 \mathrm{MeV}$ to about $1 \mathrm{MeV}$, below which it is negligible. 
Table 2. VELM neutron group boundaries and Fe dpa cross sections

\begin{tabular}{|ccc|lll|}
\hline Group & $\begin{array}{l}\text { Upper Energy } \\
(\mathrm{eV})\end{array}$ & $\begin{array}{c}\text { Fe dpa } \\
\left(\mathrm{cm}^{2}\right)\end{array}$ & Group & $\begin{array}{l}\text { Upper Energy } \\
(\mathrm{eV})\end{array}$ & $\begin{array}{l}\text { Fe dpa } \\
\left(\mathrm{cm}^{2}\right)\end{array}$ \\
\hline 1 & $1.4918 \mathrm{e}+7$ & $2.744 \mathrm{e}-21$ & 31 & $1.2277 \mathrm{e}+5$ & $1.075 \mathrm{e}-22$ \\
2 & $1.2214 \mathrm{e}+7$ & $2.446 \mathrm{e}-21$ & 32 & $8.6517 \mathrm{e}+4$ & $1.100 \mathrm{e}-22$ \\
3 & $1.0000 \mathrm{e}+7$ & $2.213 \mathrm{e}-21$ & 33 & $5.6562 \mathrm{e}+4$ & $7.913 \mathrm{e}-23$ \\
4 & $8.1873 \mathrm{e}+6$ & $2.037 \mathrm{e}-21$ & 34 & $5.2475 \mathrm{e}+4$ & $6.693 \mathrm{e}-23$ \\
5 & $6.7032 \mathrm{e}+6$ & $1.874 \mathrm{e}-21$ & 35 & $3.4307 \mathrm{e}+4$ & $2.042 \mathrm{e}-22$ \\
6 & $5.4881 \mathrm{e}+6$ & $1.718 \mathrm{e}-21$ & 36 & $2.8501 \mathrm{e}+4$ & $4.334 \mathrm{e}-22$ \\
7 & $4.4933 \mathrm{e}+6$ & $1.539 \mathrm{e}-21$ & 37 & $2.7000 \mathrm{e}+4$ & $6.080 \mathrm{e}-23$ \\
8 & $3.6788 \mathrm{e}+6$ & $1.371 \mathrm{e}-21$ & 38 & $2.6058 \mathrm{e}+4$ & $2.889 \mathrm{e}-23$ \\
9 & $3.0119 \mathrm{e}+6$ & $1.272 \mathrm{e}-21$ & 39 & $2.4788 \mathrm{e}+4$ & $3.810 \mathrm{e}-24$ \\
10 & $2.4660 \mathrm{e}+6$ & $1.161 \mathrm{e}-21$ & 40 & $2.3579 \mathrm{e}+4$ & $7.355 \mathrm{e}-24$ \\
11 & $2.3457 \mathrm{e}+6$ & $1.042 \mathrm{e}-21$ & 41 & $1.5034 \mathrm{e}+4$ & $1.194 \mathrm{e}-23$ \\
12 & $2.2313 \mathrm{e}+6$ & $1.047 \mathrm{e}-21$ & 42 & $9.1188 \mathrm{e}+3$ & $2.400 \mathrm{e}-23$ \\
13 & $2.0190 \mathrm{e}+6$ & $8.667 \mathrm{e}-22$ & 43 & $5.5308 \mathrm{e}+3$ & $6.707 \mathrm{e}-24$ \\
14 & $1.6530 \mathrm{e}+6$ & $8.127 \mathrm{e}-22$ & 44 & $3.7074 \mathrm{e}+3$ & $4.857 \mathrm{e}-24$ \\
15 & $1.3534 \mathrm{e}+6$ & $5.900 \mathrm{e}-22$ & 45 & $3.0354 \mathrm{e}+3$ & $4.156 \mathrm{e}-24$ \\
16 & $1.1080 \mathrm{e}+6$ & $4.302 \mathrm{e}-22$ & 46 & $2.6126 \mathrm{e}+3$ & $3.666 \mathrm{e}-24$ \\
17 & $9.0718 \mathrm{e}+5$ & $4.658 \mathrm{e}-22$ & 47 & $2.2487 \mathrm{e}+3$ & $3.245 \mathrm{e}-24$ \\
18 & $7.4274 \mathrm{e}+5$ & $3.612 \mathrm{e}-22$ & 48 & $2.0347 \mathrm{e}+3$ & $2.426 \mathrm{e}-24$ \\
19 & $6.0810 \mathrm{e}+5$ & $2.747 \mathrm{e}-22$ & 49 & $1.2341 \mathrm{e}+3$ & $3.410 \mathrm{e}-24$ \\
20 & $5.2340 \mathrm{e}+5$ & $3.605 \mathrm{e}-22$ & 50 & $7.4852 \mathrm{e}+2$ & $2.234 \mathrm{e}-25$ \\
21 & $4.9787 \mathrm{e}+5$ & $3.946 \mathrm{e}-22$ & 51 & $4.5400 \mathrm{e}+2$ & $9.134 \mathrm{e}-26$ \\
22 & $3.8774 \mathrm{e}+5$ & $2.480 \mathrm{e}-22$ & 52 & $2.7536 \mathrm{e}+2$ & $1.173 \mathrm{e}-25$ \\
23 & $3.0197 \mathrm{e}+5$ & $1.638 \mathrm{e}-22$ & 53 & $1.6702 \mathrm{e}+2$ & $1.506 \mathrm{e}-25$ \\
24 & $2.9849 \mathrm{e}+5$ & $1.921 \mathrm{e}-22$ & 54 & $1.0130 \mathrm{e}+2$ & $2.038 \mathrm{e}-25$ \\
25 & $2.9721 \mathrm{e}+5$ & $1.921 \mathrm{e}-22$ & 55 & $4.7851 \mathrm{e}+1$ & $2.966 \mathrm{e}-25$ \\
26 & $2.9452 \mathrm{e}+5$ & $2.077 \mathrm{e}-22$ & 56 & $2.2603 \mathrm{e}+1$ & $4.315 \mathrm{e}-25$ \\
27 & $2.7324 \mathrm{e}+5$ & $1.754 \mathrm{e}-22$ & 57 & $1.0677 \mathrm{e}+1$ & $6.278 \mathrm{e}-25$ \\
28 & $2.2371 \mathrm{e}+5$ & $2.196 \mathrm{e}-22$ & 58 & $5.0435 \mathrm{e}+0$ & $9.135 \mathrm{e}-25$ \\
29 & $1.8316 \mathrm{e}+5$ & $1.399 \mathrm{e}-22$ & 59 & $2.3824 \mathrm{e}+0$ & $1.326 \mathrm{e}-24$ \\
30 & $1.4996 \mathrm{e}+5$ & $1.781 \mathrm{e}-22$ & 60 & $1.1253 \mathrm{e}+0$ & $2.031 \mathrm{e}-24$ \\
& & & 61 & $4.1399 \mathrm{e}-1$ & $5.296 \mathrm{e}-24$ \\
\hline
\end{tabular}


Table 3. VELM gamma group boundaries and Fe dpa cross sections

\begin{tabular}{|lll|lll|}
\hline Group & $\begin{array}{l}\text { Upper Energy } \\
(\mathrm{eV})\end{array}$ & $\begin{array}{l}\text { Fe dpa } \\
\left(\mathrm{cm}^{2}\right)\end{array}$ & Group & $\begin{array}{l}\text { Upper Energy } \\
(\mathrm{eV})\end{array}$ & $\begin{array}{l}\text { Fe dpa } \\
\left(\mathrm{cm}^{2}\right)\end{array}$ \\
\hline 1 & $1.4000 \mathrm{e}+7$ & $7.600 \mathrm{e}-24$ & 13 & $1.0000 \mathrm{e}+6$ & $4.333 \mathrm{e}-27$ \\
2 & $1.0000 \mathrm{e}+7$ & $6.249 \mathrm{e}-24$ & 14 & $7.0000 \mathrm{e}+5$ & 0 \\
3 & $8.0000 \mathrm{e}+6$ & $4.677 \mathrm{e}-24$ & 15 & $6.0000 \mathrm{e}+5$ & 0 \\
4 & $7.5000 \mathrm{e}+6$ & $4.111 \mathrm{e}-24$ & 16 & $5.1000 \mathrm{e}+5$ & 0 \\
5 & $7.0000 \mathrm{e}+6$ & $3.314 \mathrm{e}-24$ & 17 & $4.0000 \mathrm{e}+5$ & 0 \\
6 & $6.0000 \mathrm{e}+6$ & $2.388 \mathrm{e}-24$ & 18 & $3.0000 \mathrm{e}+5$ & 0 \\
7 & $5.0000 \mathrm{e}+6$ & $1.585 \mathrm{e}-24$ & 19 & $1.5000 \mathrm{e}+5$ & 0 \\
8 & $4.0000 \mathrm{e}+6$ & $9.269 \mathrm{e}-25$ & 20 & $1.0000 \mathrm{e}+5$ & 0 \\
9 & $3.0000 \mathrm{e}+6$ & $5.278 \mathrm{e}-25$ & 21 & $7.0000 \mathrm{e}+4$ & 0 \\
10 & $2.5000 \mathrm{e}+6$ & $3.133 \mathrm{e}-25$ & 22 & $4.5000 \mathrm{e}+4$ & 0 \\
11 & $2.0000 \mathrm{e}+6$ & $1.456 \mathrm{e}-25$ & 23 & $2.0000 \mathrm{e}+4$ & 0 \\
12 & $1.5000 \mathrm{e}+6$ & $4.030 \mathrm{e}-26$ & & & \\
\hline
\end{tabular}





\section{CALCULATION MODELS}

\subsection{HFIR Core and Vessel Region Models}

The HFIR reactor was modeled in a two-dimensional cylindrical (RZ) geometry using the DORT two-dimensional transport code. The reactor model omits the beam tubes. As was mentioned in Section 4.1, the reactor calculations were performed in two steps. First, an eigenvalue $\left(\mathrm{k}_{\mathrm{eff}}\right)$ calculation for the reactor core was performed. The model for this calculation was limited in the radial dimension to a distance of $25.4 \mathrm{~cm}$ (10 in.) beyond the Beryllium reflector region that was sufficient to assure an essentially infinite reflector in the water region beyond the core. Because neutron multiplication was included, this calculation required outer (source) iterations as well as inner iterations to achieve convergence. The calculated fission source was subsequently input as a fixed source in a radially expanded model that extended $30.48 \mathrm{~cm}$ (12 in.) beyond the vessel wall. The source strength was normalized to the HFIR maximum operating power level (100 $\mathrm{MW}$ ), which resulted in a neutron source strength of $7.56 \times 10^{18} \mathrm{n} / \mathrm{s}$. In this second, fixed-source calculation, no outer (source) iterations were required. The two-step process avoids the longer calculation times and potential calculation convergence problems that would result had the entire core and vessel been modeled in one step. If the calculation were performed in one step, it would be necessary to have a relatively small multiplying region (the core) within a large transport region (the vessel and some water beyond). In general, such a situation can cause numerical convergence problems in discrete ordinates calculations and is to be avoided if possible. Figure 4 shows the reactor core fixed source geometry model. Appendix C lists material atom densities, which are also applicable to other models. Reference 12 provides additional information on HFIR material compositions. Note that there are two water regions within the vessel and outside of the reflector region. The boundary between the two regions is the outer boundary for the $\mathrm{k}_{\text {eff }}$ reactor core model.

\subsection{HB-2 Models}

Because HB-2 is aligned with the cylindrical core radius, it has symmetry along bisecting planes either parallel to the vertical core axis or through the core midplane. For this reason it was also modeled as a two-dimensional cylindrical geometry using the DORT code. Two models were developed; one was developed for the present $10.16 \mathrm{~cm}$ (4 in.) diameter tube and another for the proposed expanded $22.86 \mathrm{~cm}$ (9 in.) diameter tube. ${ }^{*}$ In each of these models, shown in Figures 5 and 6 , the $\mathrm{X}$ dimension is aligned along the long axis of symmetry of the beam tube. The $\mathrm{Y}$ axis is shown as negative so that, assuming the system is right-handed and cartesian, the positive $\mathrm{Z}$ axis, if shown, would point out from the figure toward the reader and would be aligned with the vertical axis of the reactor core. Thus, with this orientation, the reader has the perspective of looking down on the beam-tube from above the reactor. This choice of axis coordinates is consistent with three-dimensional models discussed in the following section. However, for the two-dimensional HB-2 models, the $-\mathrm{Y}$ axis is a radial axis and thus arbitrary; that is, the model is the same in any direction perpendicular to the axis of symmetry.

\footnotetext{
* The present and proposed designs for HB-2 are conveniently referred to as the 4 in. and the 9 in. diameter tubes throughout the report.
} 


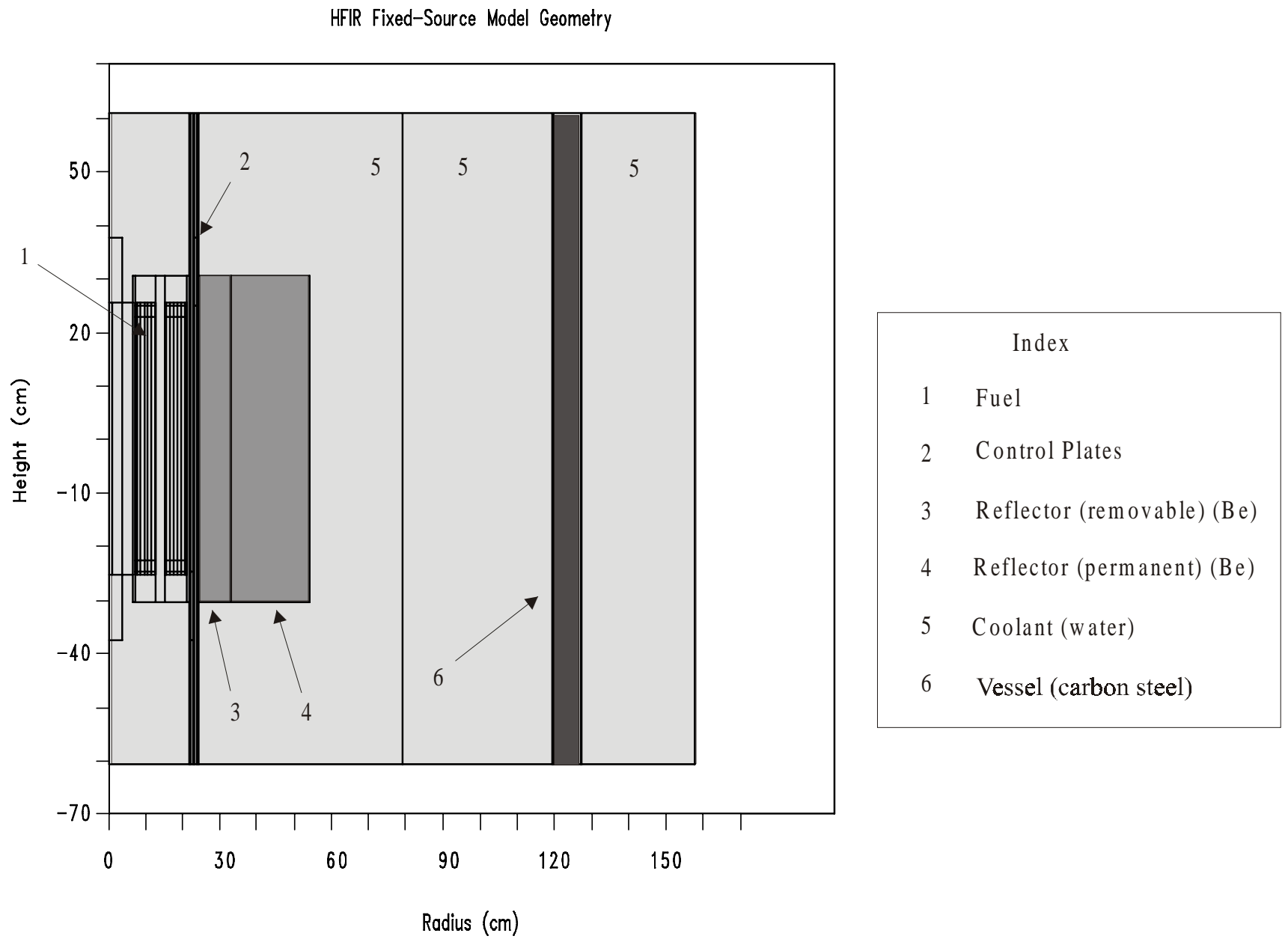

Figure 4. Geometry/material model for HFIR reactor core

A two-dimensional approach properly models the cylindrical shape of HB-2. However, an unavoidable approximation that occurs with these two-dimensional models is that the Beryllium reflector and the vessel wall are symmetric around the beam tube axis, whereas in actuality, there is no curvature in these structures in the vertical (with respect to the core axis) direction.

The overall effects from using this approximation are judged to be minimal under the conditions in which the model is used. The primary locations of interest are close to the beam tube axis where the largest contribution to the dpa rate is the result of particles streaming along the beam tube. Effects from the outer radial boundary which would be affected by the curvature approximation have been shown to be small (see Appendix A, Section A.2.1).

Figure 5 shows a numerical index of the material regions. This index is assumed for subsequent figures showing the beam-tube models, but is not shown on the subsequent figures. Also, it should be noted that each model does not necessarily contain all of the regions. An approximate location of the weld where the beam tube joins the vessel wall is shown in each case. The weld, however, was not modeled as a separate material region. Figure 5 also shows the source boundaries which are not repeated on subsequent figures. 


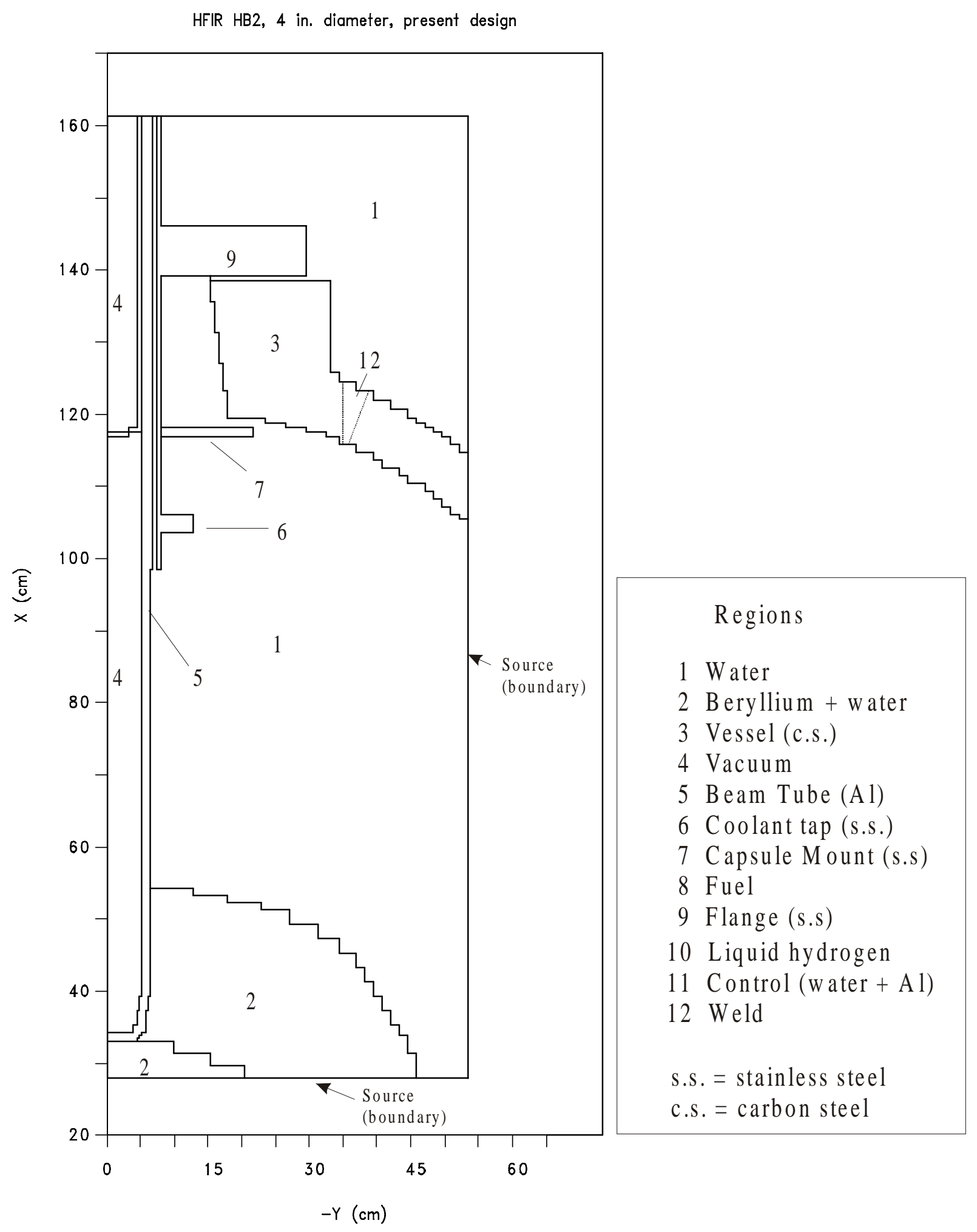

Figure 5. Geometry/material model for HB-2 (present design) 
HFIR HB2, 9 in. dia., modified design

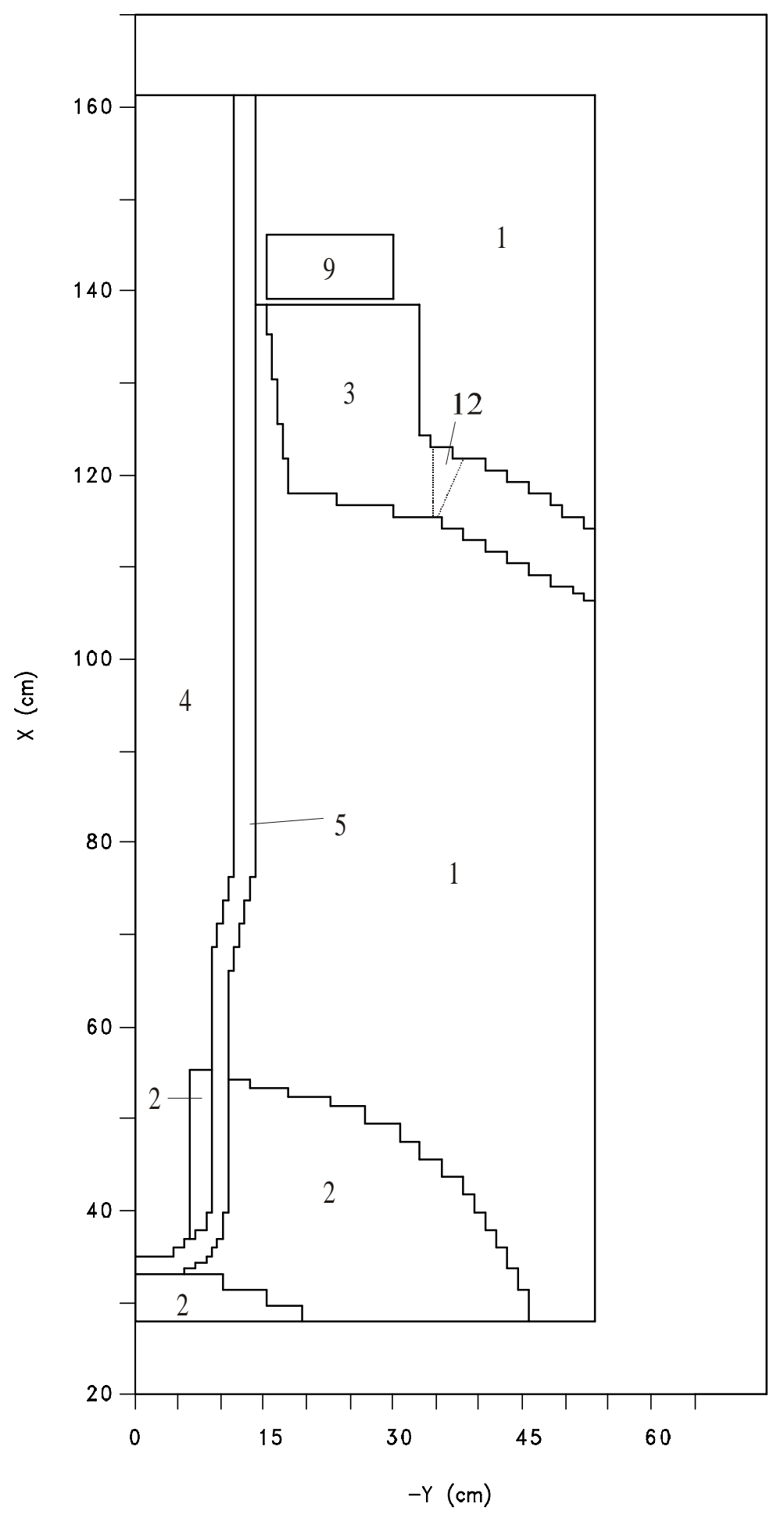

Figure 6. Geometry/material model for HB-2 (new design) 
The base core model for the present design of HB-2 shown in Figure 5 has 95 axial intervals and 77 radial intervals. The model for the upgraded design of the HB-2 has 91 axial and 66 radial intervals.

\subsection{HB-1,-3,-4 Models}

Axes of the remaining beam tubes are all non-parallel to the core radius vector. In these cases, because two-dimensional models were not appropriate, the beam tubes were modeled using the TORT three-dimensional transport code in the XYZ cartesian coordinate system. For consistency with the two-dimensional models, the $\mathrm{X}$ axis in each case was located along the axial centerline of the tube and the $\mathrm{Z}$ axis parallel to the vertical core axis. In each model the origin was selected on the beam tube axis at the point closest to the reactor core center. (Thus, for each model the origin was located at a point such that a core radial vector through the model origin is perpendicular to the beam tube $\mathrm{X}$-axis.) This situation is shown conceptually in Figure 7 . The $X^{\prime} Y$ ' coordinates are used for HB-3, and the X' $Y$ ', coordinates for HB-4 (HB-1). In each case the model origin O' or O' 'is located at the intersection of the coordinates axes, resulting in a $90^{\circ}$ angle between either the $X^{\prime} Y^{\prime}$ axes or the $X^{\prime}$ 'Y' axes. Also, the model origin is located at the vertical reactor midplane, which is also the vertical center of the beam tube. In the case of HB-2, represented by the XY axes, the beam tube axis is aligned with the core radius vector and the model origin is simply the radial center of the core in the core axial midplane.

A conceptual approach that helps to identify regions around the asymmetric beam tubes is to refer to any region outside of the beam tubes as either a "sunny side" or "shady side" region. The sunny side refers to regions in the negative $\mathrm{Y}$ half-plane and the shady side to regions in the positive half-plane. The reason for these names becomes clear if one visualizes the core as analogous to a light source and the beam tube an opaque object; it can be seen that the sunny side would receive direct light and, on the shady side the light would be blocked by the tube.

In the present (unmodified) HFIR design, HB-1 and HB-4 are opposite but otherwise identical configurations. Therefore, a model for the present HB-4 design also suffices for HB-1. In the model of the upgraded (modified) design, the HB-4 inner diameter has been increased from 9.68 $\mathrm{cm}$ to $13.335 \mathrm{~cm}$ and a region of liquid hydrogen, simulating a neutron cold source, has been added at the reactor end of the tube. Figures 8 and 9 show TORT models of the present HB- 4 (HB-1) configuration and the upgraded HB-4 configuration, respectively. The model for the present configuration has 66, 57, and 15 intervals in the $\mathrm{X}, \mathrm{Y}$, and $\mathrm{Z}$ dimensions. Similarly the model for the upgraded configuration has 71, 69, and 23 intervals in the $\mathrm{X}, \mathrm{Y}$, and $\mathrm{Z}$ dimensions. The cold neutron source in this design is approximated by hydrogen at the density of liquid hydrogen $\left(0.0762 \mathrm{~g} / \mathrm{cm}^{3}\right)$, but at normal room temperature because the VELM cross section set does not contain cross-sections for low-temperature hydrogen. This approximation is valid since the temperature variation of the total neutron cross-section for hydrogen is small except at very low neutron energies at which there is insufficient neutron density to contribute significantly to the dpa rate.

Figure 10 shows a TORT model for the present HB-3 configuration. HB-3 will not be modified in the upcoming reactor upgrade. The HB-3 model has 59, 52, and 15 intervals in the $\mathrm{X}$, Y, and $\mathrm{Z}$ dimensions respectively. 
Geometry models for the present HB-3 and HB-4 unmodified designs are based on earlier models ${ }^{4}$ but with several modifications included. The HB-4 model has been extended in height (Z) from $15.24 \mathrm{~cm}(6 \mathrm{in}$.) to $25.4 \mathrm{~cm}(10 \mathrm{in}$.). Both models have been extended in the $-\mathrm{Y}$ dimension (perpendicular to the beam-tube in the core midplane) to incorporate the entire nozzle weld region into the calculation. Because the boundary flux was obtained from a core calculation that did not include the beam tubes, it is important that the model boundaries be located far enough from the beam tubes so that perturbations from the presence of the beam tubes are minimized. Ideally, the flux at the model boundary should be approximately the same as if the beam tube were not present. The increased model height and the extension in the $-Y$ dimension reduce these perturbations. A complication introduced by extending the model to include the sunny side weld, however, is that a section of the fuel region must be included in the TORT models for HB-3 and HB-4. This necessitates the inclusion of a source in this region to account for fissions in the fuel in addition to the boundary source produced by the core fixed source calculation. The procedure used to incorporate the additional source was to map the location of each fuel cell in the TORT geometry to the equivalent cell location in the fixed source two-dimensional core calculation and to insert that source at the TORT location. Sources were normalized to the source strength at the maximum 100MW power level. Separate calculations were performed for the prompt neutrons and gammas and for the delayed fission product gammas. 


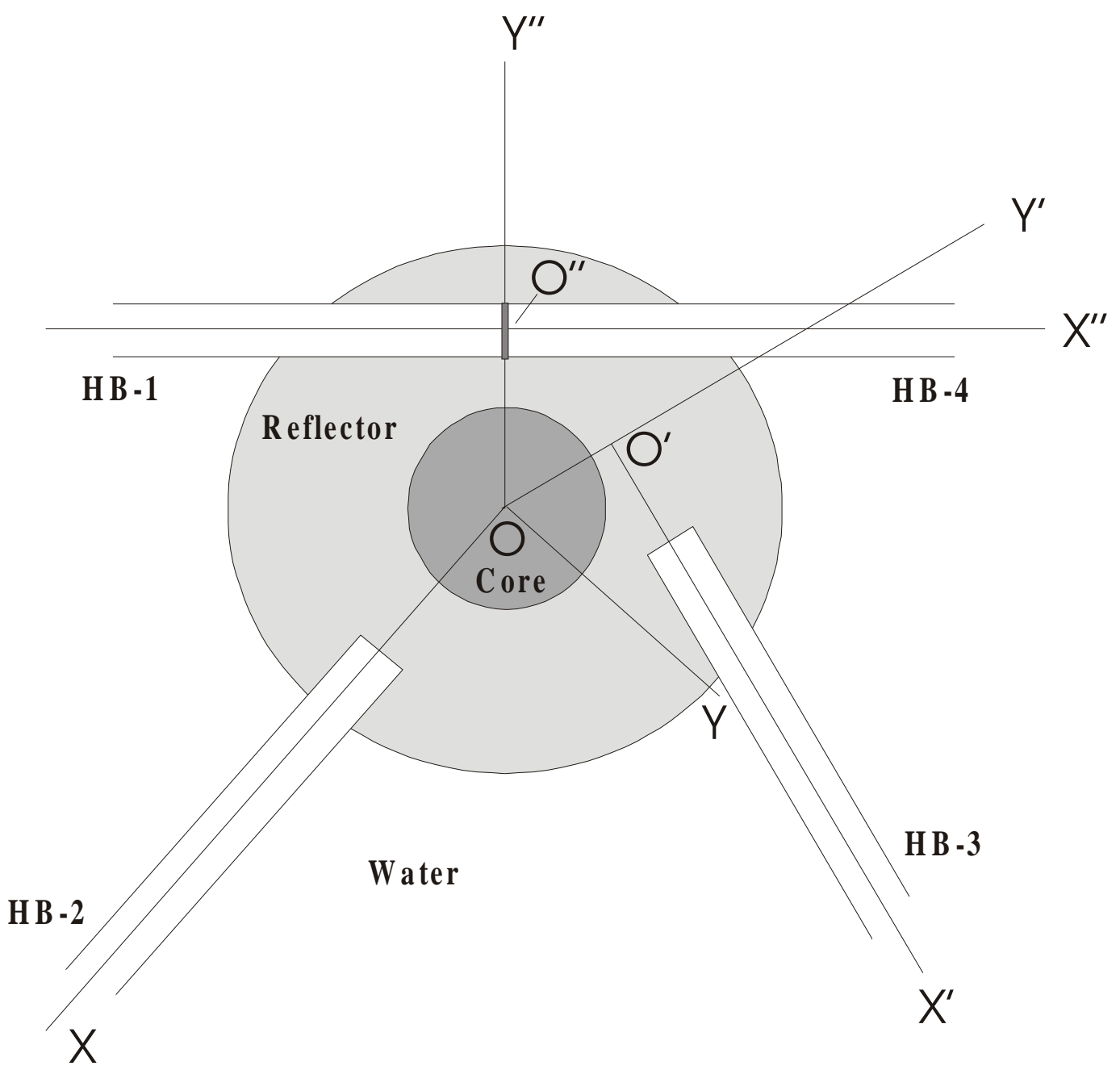

Figure 7. Coordinate systems for HB-1, -2, -3, -4 


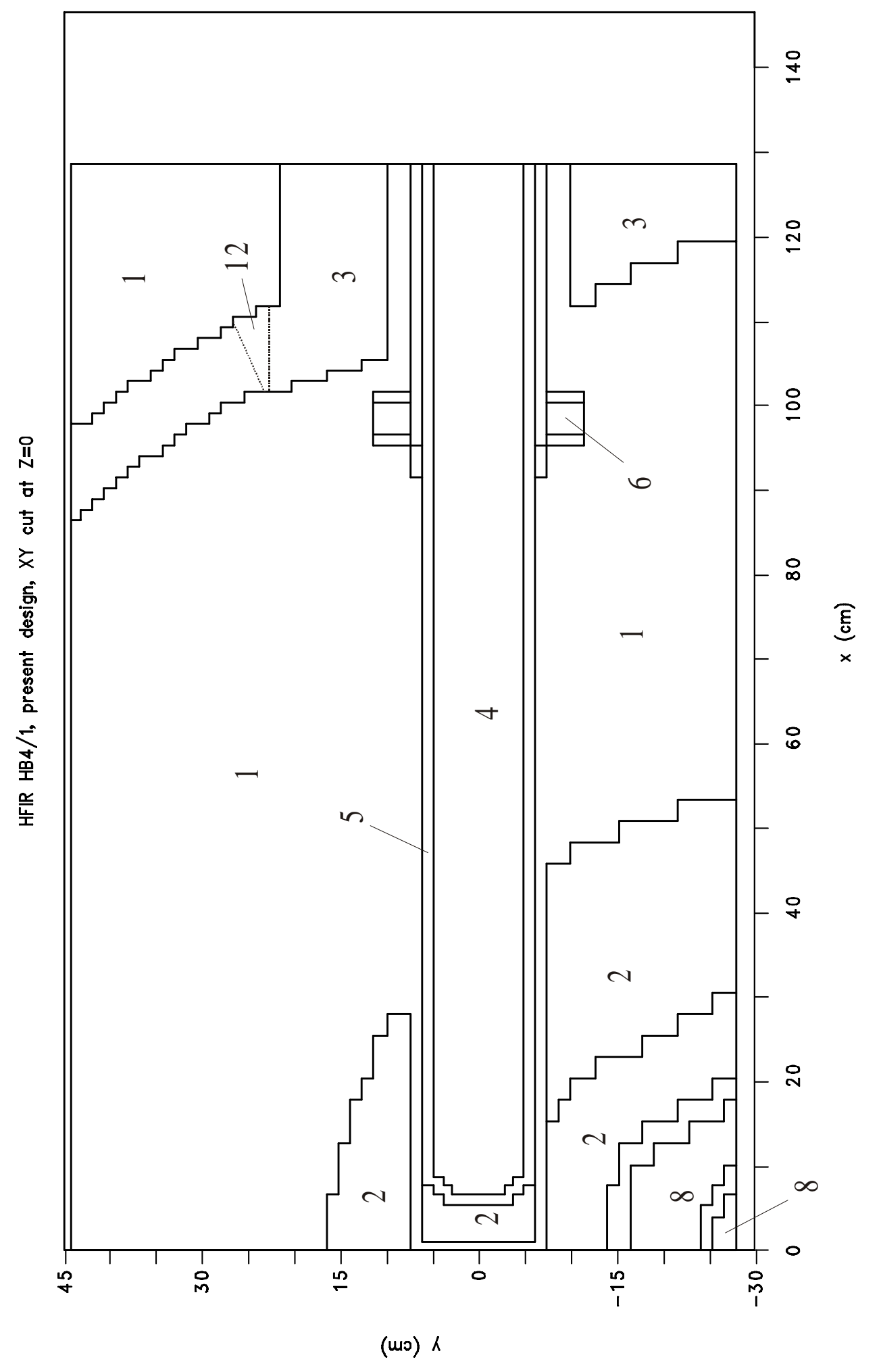

Figure 8. Geometry/material model for HB-1 and HB-4 (present design) 


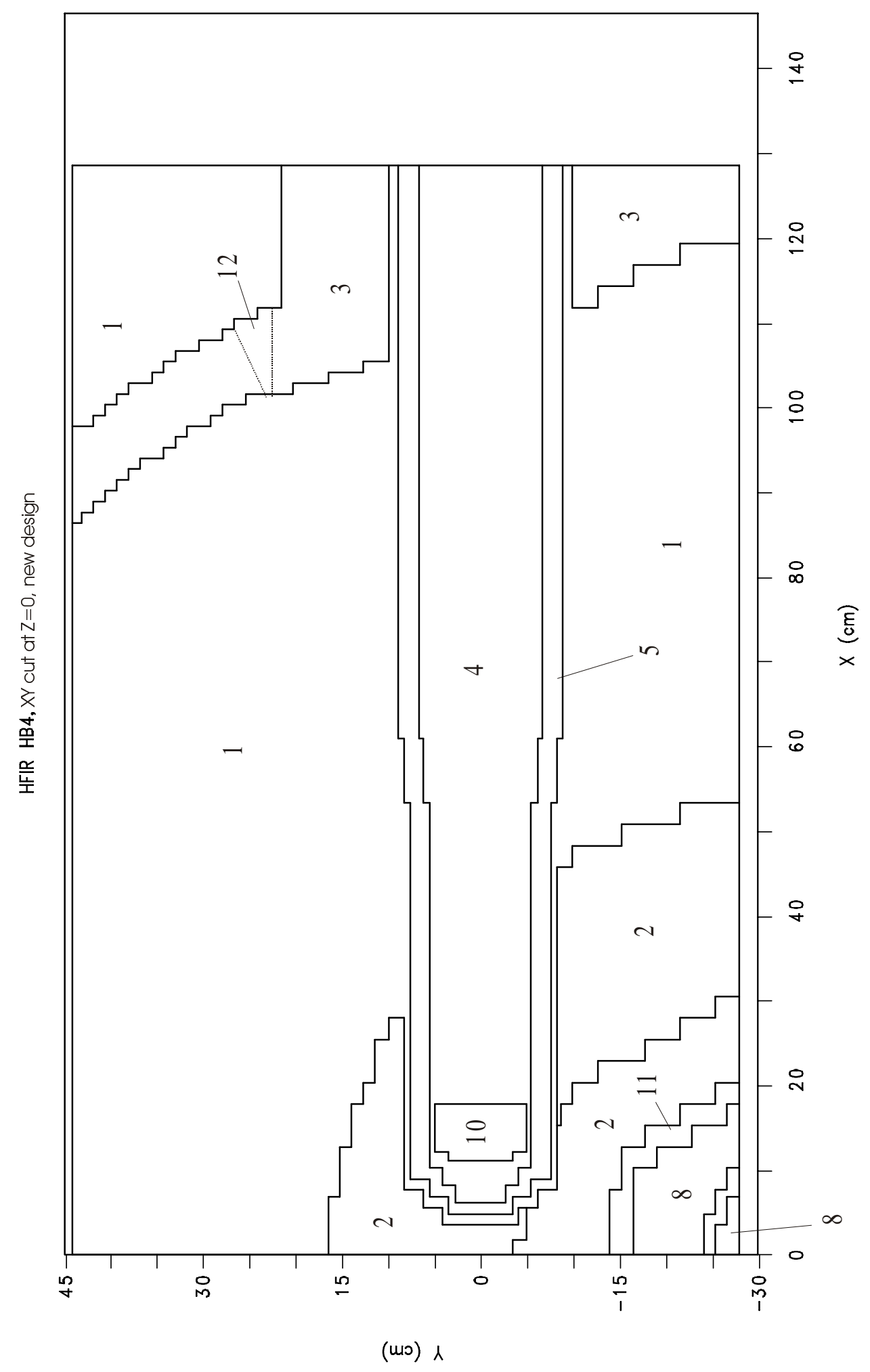

Figure 9. Geometry/material model for HB-4 (new design) 


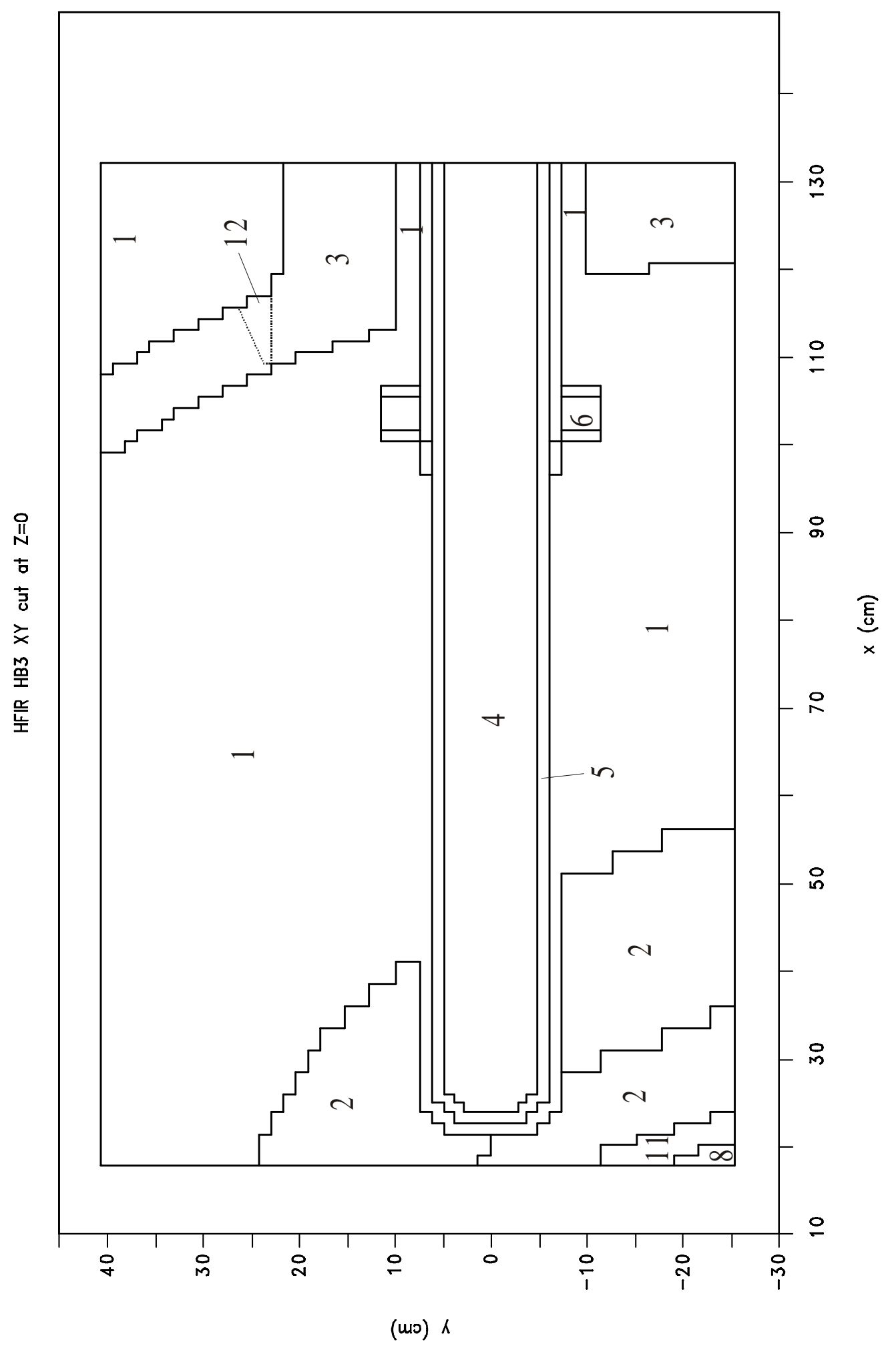

Figure 10. Geometry/material model for HB-3 


\section{CALCULATION RESULTS}

\subsection{General Remarks}

Calculational results are presented in this section for the beam tube models. The result of interest was primarily dpa rates, which were determined at all locations in the model. Since only the dpa cross-sections for iron are used, these values are only of significance in locations where iron is present; however, they show the effects that would occur at any location if iron were present. Since dpa rates depend primarily on the fast flux, the plotted dpa rate values are similar in appearance to plots of fast flux and serve as an indicator of flux trends. For the three dimensional TORT models, plots of beam tube regions along planes through the reactor core vertical midplane ( $\mathrm{Z}$ cut) and through the beam tube long axis center parallel to the reactor $\mathrm{Z}$ axis (Y cut) are shown. In each case, gamma values include combined results from prompt and delayed gamma sources. Results from delayed gammas, which are emitted from the decay of fission products, were determined from separate gamma source calculations. A calculated value of 12.9 photons per fission was used. ${ }^{13}$ For the reactor fixed source model, the resulting total delayed gamma source strength was $4.01 \times 10^{19}$ photons/s. In this analysis dpa contributions from delayed gammas were seen to be in general relatively small $(<10 \%)$.

\subsection{Normalization}

As part of the ongoing reactor surveillance program, dosimetry measurements utilized in the determination of neutron and gamma dpa rates were performed at Key 2 and 4 locations near the vessel wall as shown in Figure 1. The evaluation procedure is discussed in detail in references 2 and 14 and is briefly summarized here. At each key radial position, specimen capsules are mounted at different angular positions around a beam tube. A three step procedure was used to determine the flux and hence the dpa rates at the specimen locations: 1) calculate the flux at each specimen location, 2) determine reaction rates, and 3) combine the measurements and calculations using a least squares code to adjust the calculated flux spectrum. A methodology that combines measurements and calculations is required for dpa evaluation since dpa is not a directly measured quantity. Nonethless, the analysis is based on measured data.

In this analysis, the published dpa rates from the above measure-based analyse ${ }^{2}$ were used to normalize the calculated dpa rates at the appropriate key and position locations. The normalization factor, which is the ratio of the measured to the calculated value, is used as a correction factor to obtain the best estimate dpa rate at any location. This best estimate is thus equal to the product of the normalization factor and the calculated dpa rate. It can reasonably be assumed that the normalization factor does not change appreciably for short distances from the location of measurement. Thus, this procedure should result in an accurate determination of the dpa rate at points of interest close to the appropriate key. For locations distant to the point of normalization, such as on the model periphery, this assumption has less validity.

Another parameter of interest is the calculated-to-experimental-value $(\mathrm{C} / \mathrm{E})$ ratio. This parameter is the reciprocal of the normalization factor. 


\subsection{Reactor Core Model Results}

Figures 11,12, and 13 show iso-plots of the neutron, gamma, and total dpa rates respectively for the fixed source calculation for the two-dimensional reactor core model. The prefix "-iso" is used to refer to equivalue contour lines in these plots and is used with the quantity of interest in some cases, e.g. iso-dpa rate and iso-flux. (In labels on the these plots, the symbol "•" is placed over the letters "dpa" to indicate dpa rate as in earlier reports.) Figures 14 and 15 show similar plots for the neutron and gamma fluxes above $1 \mathrm{MeV}$. Note that the iso-flux lines in Figures 14 and 15 are similar to the neutron and gamma iso-dpa rate lines in Figures 11 and 12; thus, isodpa rate plots can in general be used interchangeably with either neutron or gamma fast flux plots for trend assessment. As was discussed earlier, the source for this calculation was obtained from the eigenvalue $\left(\mathrm{k}_{\mathrm{eff}}\right)$ calculation and normalized to a reactor power of $100 \mathrm{MW}$. As can be observed from the plots, the neutron dpa rate and fast flux are reduced by the water shielding by approximately 4.5 orders of magnitude radially from the outer edge of the Be reflector to the inner edge of the vessel wall. However, since water is a poor shield for energetic gamma rays, gamma dpa rates are reduced by only two orders of magnitude. Thus, at the surface of the vessel wall away from perturbation effects of the beam tubes, the neutron dpa rate is only $~ 10 \%$ of the total dpa rate and the primary contribution to the dpa rate is from gamma rays!

In Figure 12 some small lobes are observed in the gamma iso-dpa rate plot, which are most pronounced in the area outside of the reactor vessel. These lobes are the result of quadrature ray effects and typically occur in discrete ordinates calculations when the source radiation emanates from a relatively small volume and there is a small amount of scattering and absorption (e.g a a point source in an evacuated tube is an extreme case). In this case the highest flux values are observed along discrete angles associated with the selected quadrature. Since the lobes are nonphysical, they are the cause of some concern. One way to address this concern is to increase the level of quadrature so that there are more discrete angles over which source particles are distributed. Accordingly, the above gamma calculations were repeated with the quadrature level increased from $S_{10}$ to $S_{16}$ (symmetric). Although the ray effects were reduced, the overall changes in gamma dpa rate were only $\sim 1 \%$ in the regions of interest. Thus, it was judged that the $\mathrm{S}_{10}$ results were sufficient for these calculations.

\subsection{HB-2 Model Results}

Figures 16 to 20 show similar neutron, gamma, and total iso-dpa rate plots and neutron and gamma iso-flux (> $1 \mathrm{MeV}$ ) plots for the present 4 in. diameter HB-2 beam tube. Figures 21 to 25 show analogous plots for the 9 in. diameter proposed new HB-2 design. Values in both sets of plots have been normalized to measured dpa rates as discussed earlier. The normalization factors determined by the ratio of the measured to the calculated values are 0.638 for neutron dpa rate and 1.76 for gamma dpa rate. These values represent revisions to previously calculated values of 0.560 and 1.09 and result from a modification in the total neutron source strength and a correction in the delayed gamma spectrum that significantly reduces the delayed gamma contribution. Results reported in Reference 3 are based on the earlier normalizations; however, the calculated dpa rates using the new normalizations represent at most a few percent increase and do not significantly change the reported results. 
Several conclusions are drawn from examination and comparison of these plots. First, since the beam tube displaces the water, which is an effective neutron shield, neutrons are readily transported along the tube's length, but are heavily attenuated as they travel in a direction transverse to the tube axis. This effect is much less pronounced in the gamma iso-dpa rate plots, however, since water is a poor shield for gamma rays. Consequently, the attenuation of gamma rays is observed more in the outward direction along the core radius (iso-lines are more perpendicular to the core radial direction). Also, the gamma attenuation in the water is seen to be less overall than the neutron attenuation. Strong gamma attenuation is localized near bulk metal components.

Another observation is that most of the dpa rate contribution at the nozzle corner is from neutrons, whereas, at points on the vessel wall remote to the beam tube, most of the dpa contribution is from gamma rays, which is consistent with the core model calculations. The reason for the higher neutron contribution at the corner is that the neutron source from the core is much greater than the gamma ray source and there is little shielding between the tube and the corner. However, at increasing distances from the tube, the neutron attenuation drops off drastically, whereas the gamma attenuation is minimal.

It is also evident from these plots that an increase in the tube diameter significantly increases the dpa rate at points such as the nozzle corner that are near to the tube. This is because the larger tube is a conduit for more neutrons streaming from the core and because of the reduced shielding between the tube outer wall and the vessel nozzle wall in the larger diameter opening. Table 4 summarizes a comparison of normalized dpa rate values at the nozzle corner and nozzle weld for the two models.

From Table 4 it is observed that the total dpa rate at the nozzle corner is increased by an order of magnitude as the beam tube diameter is increased from $10.16 \mathrm{~cm}$ (4 in.) to $22.86 \mathrm{~cm}$ (9 in.). The neutron dpa rate is increased by a factor of $\sim 18$ because of the dramatic reduction in neutron shielding, but the gamma dpa rate only by a factor of 2.7. Thus the combined normalized increase in dpa rate is by a factor of 10.5. At the weld location, the increase in total dpa rate is only 2.13 because the relative difference in the neutron shielding between the two cases at this location is not as great. 
HFIR fixed source 84gp 100MW neutron dpa (unnorm)

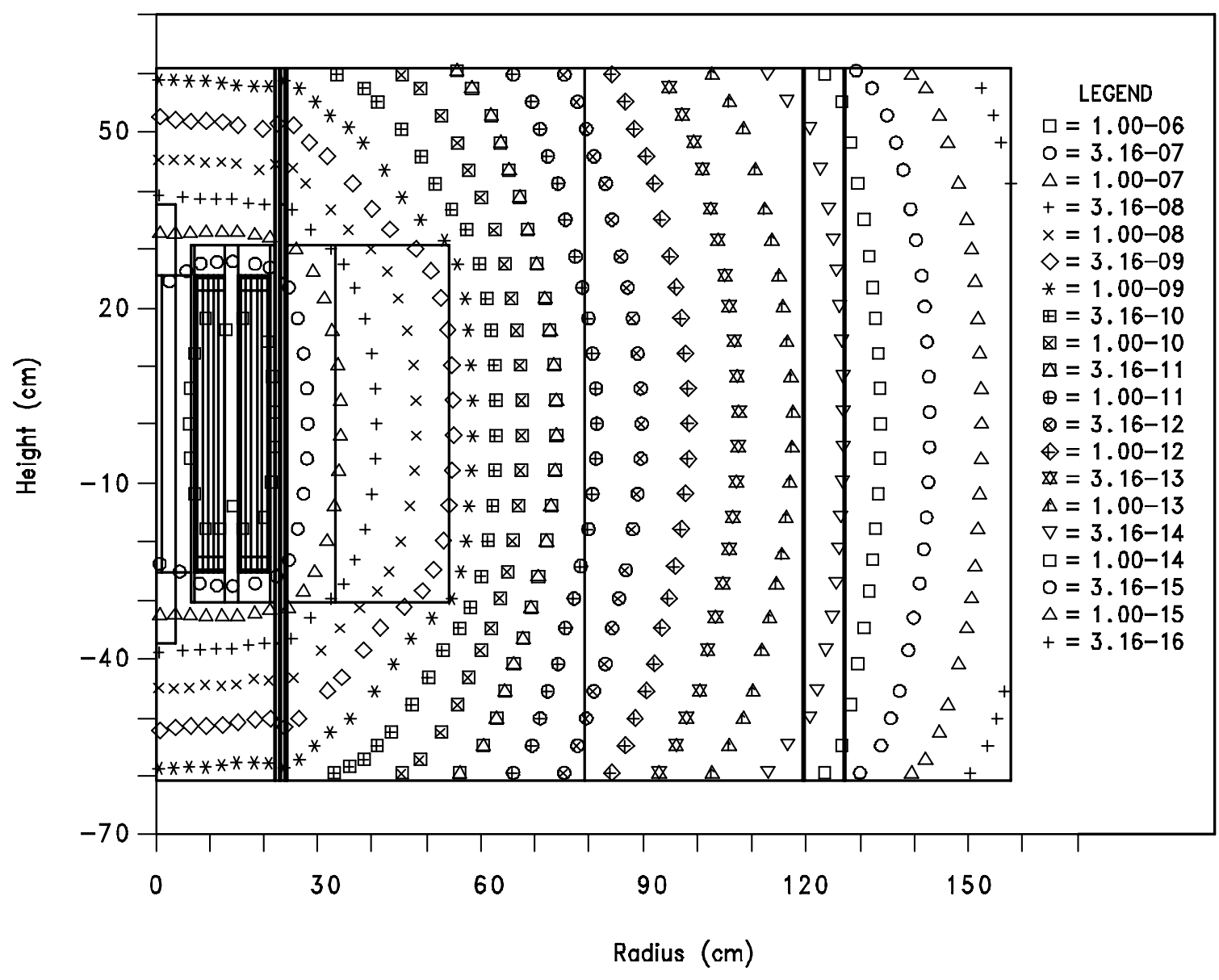

Figure 11. Neutron iso-dpa rate (displacements/atom/s) for HFIR core fixed source model 


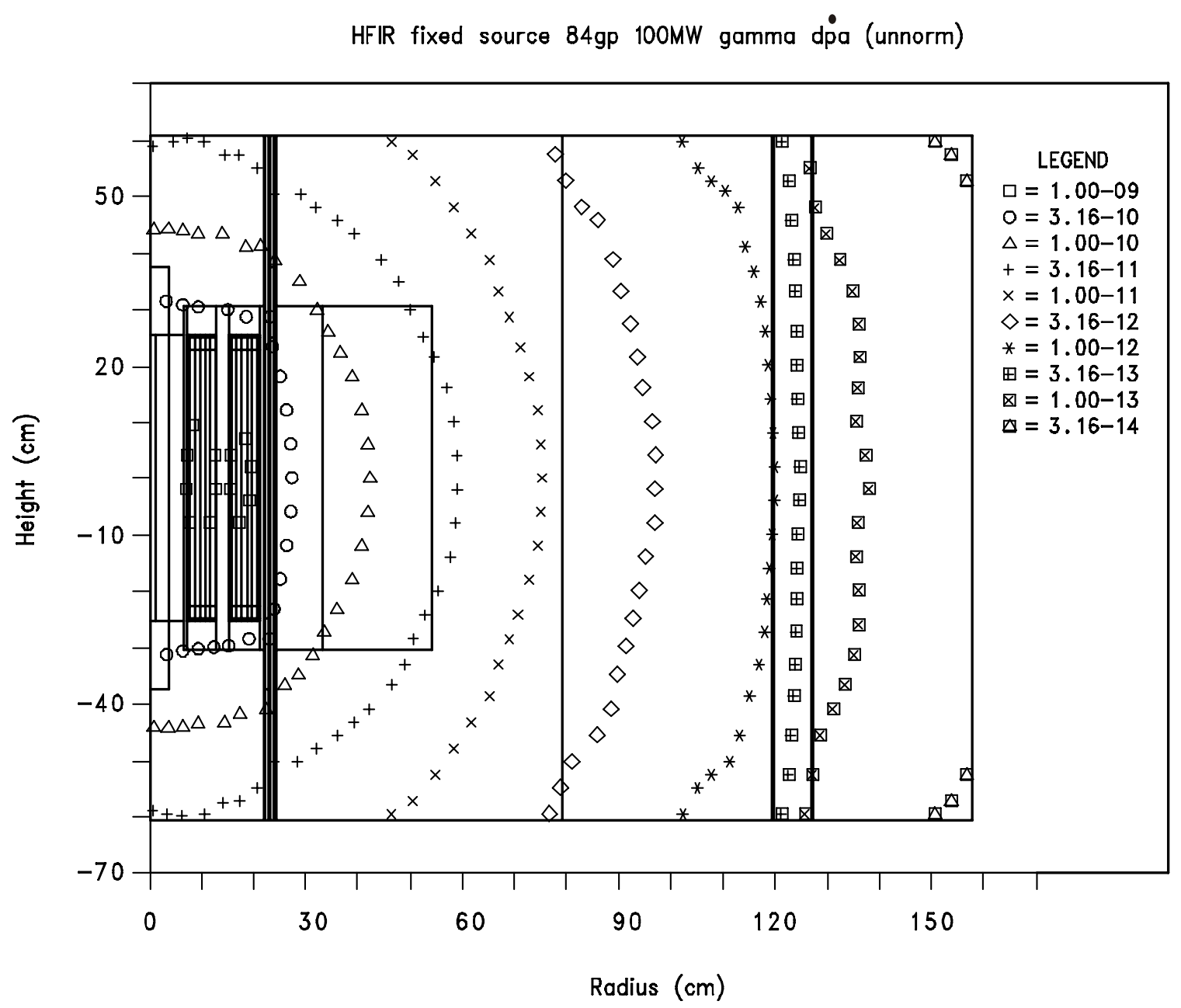

Figure 12. Gamma iso-dpa rate (displacements/atom/s) for HFIR core fixed source model 
HFIR fixed source $84 \mathrm{gp} 100 \mathrm{MW}$ total dpa (unnorm)

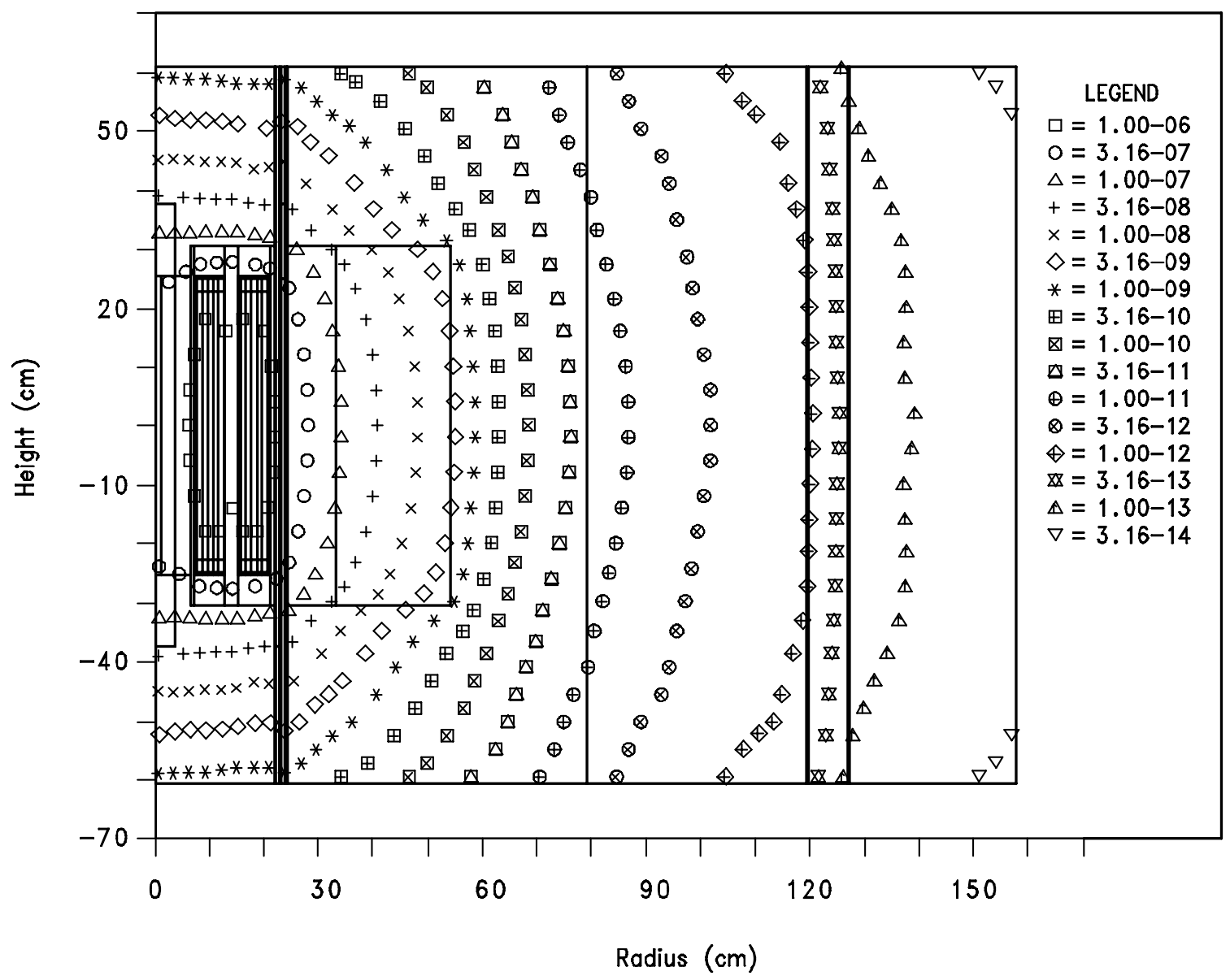

Figure 13. Total (neutron + gamma) iso-dpa rate (displacements/atom/s) for HFIR core fixed source model 
HFIR fixed source $84 \mathrm{gp}$ 100MW neutron flux $>1 \mathrm{MeV}$ (unnorm)

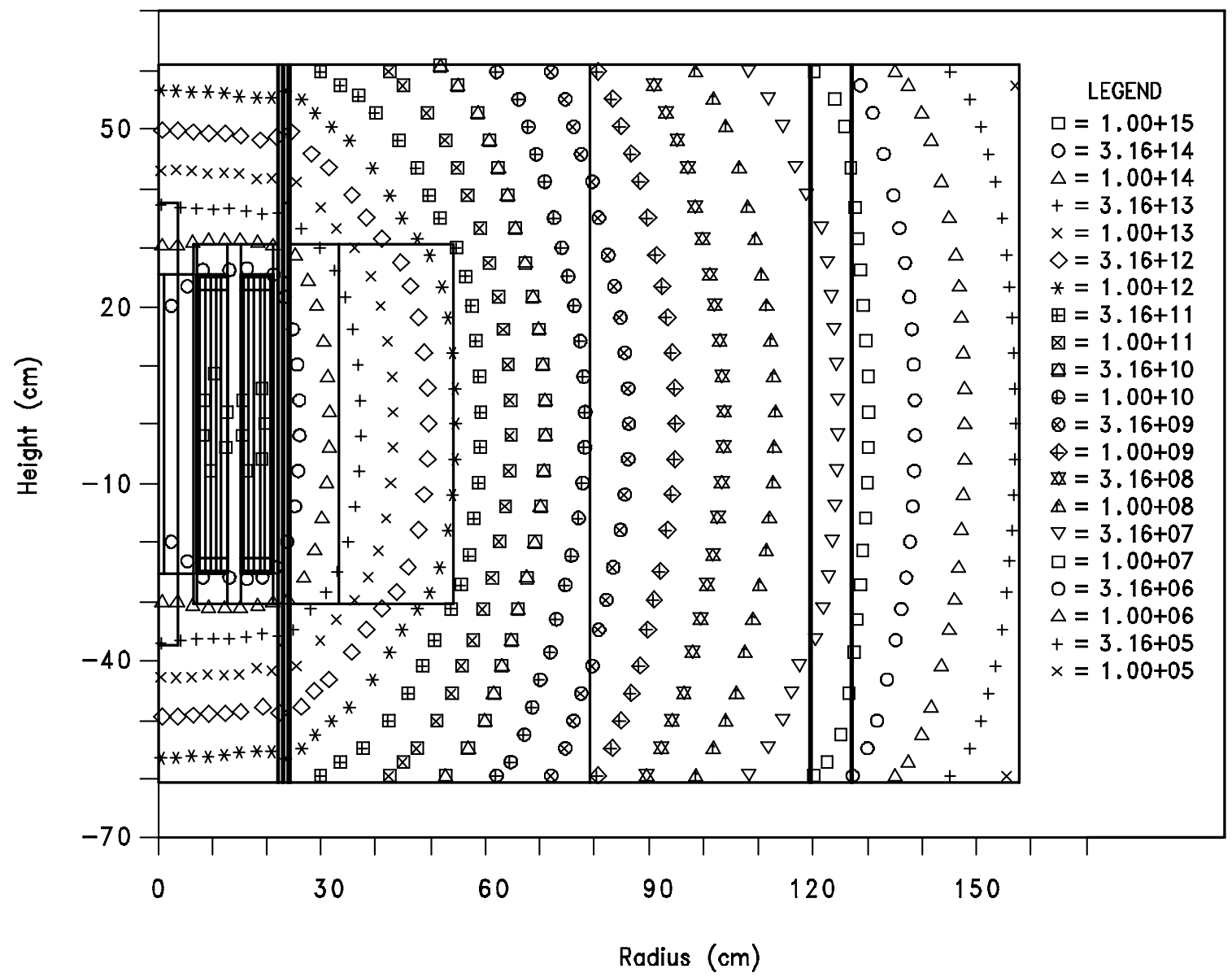

Figure 14. Neutron iso-flux (neutrons $\left./ \mathrm{cm}^{2} / \mathrm{s}\right)(\mathrm{E}>1 \mathrm{MeV}$ ) for HFIR core fixed source model 
HFIR fixed source $84 \mathrm{gp} 100 \mathrm{MW}$ gamma flux $>1 \mathrm{MeV}$ (unnorm)

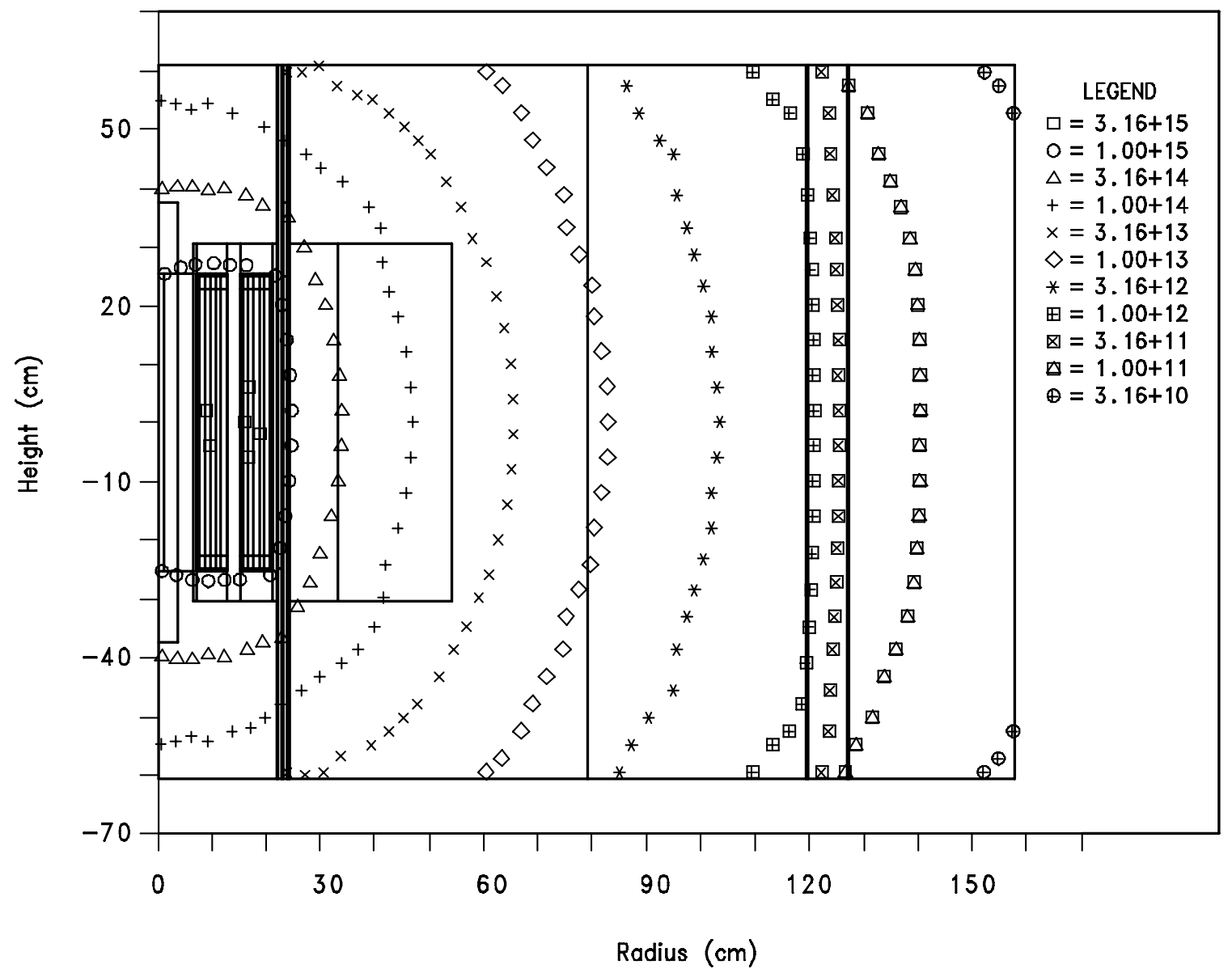

Figure 15. Gamma iso-flux (photons $\left./ \mathrm{cm}^{2} / \mathrm{s}\right)(\mathrm{E}>1 \mathrm{MeV})$ for HFIR core fixed source model 


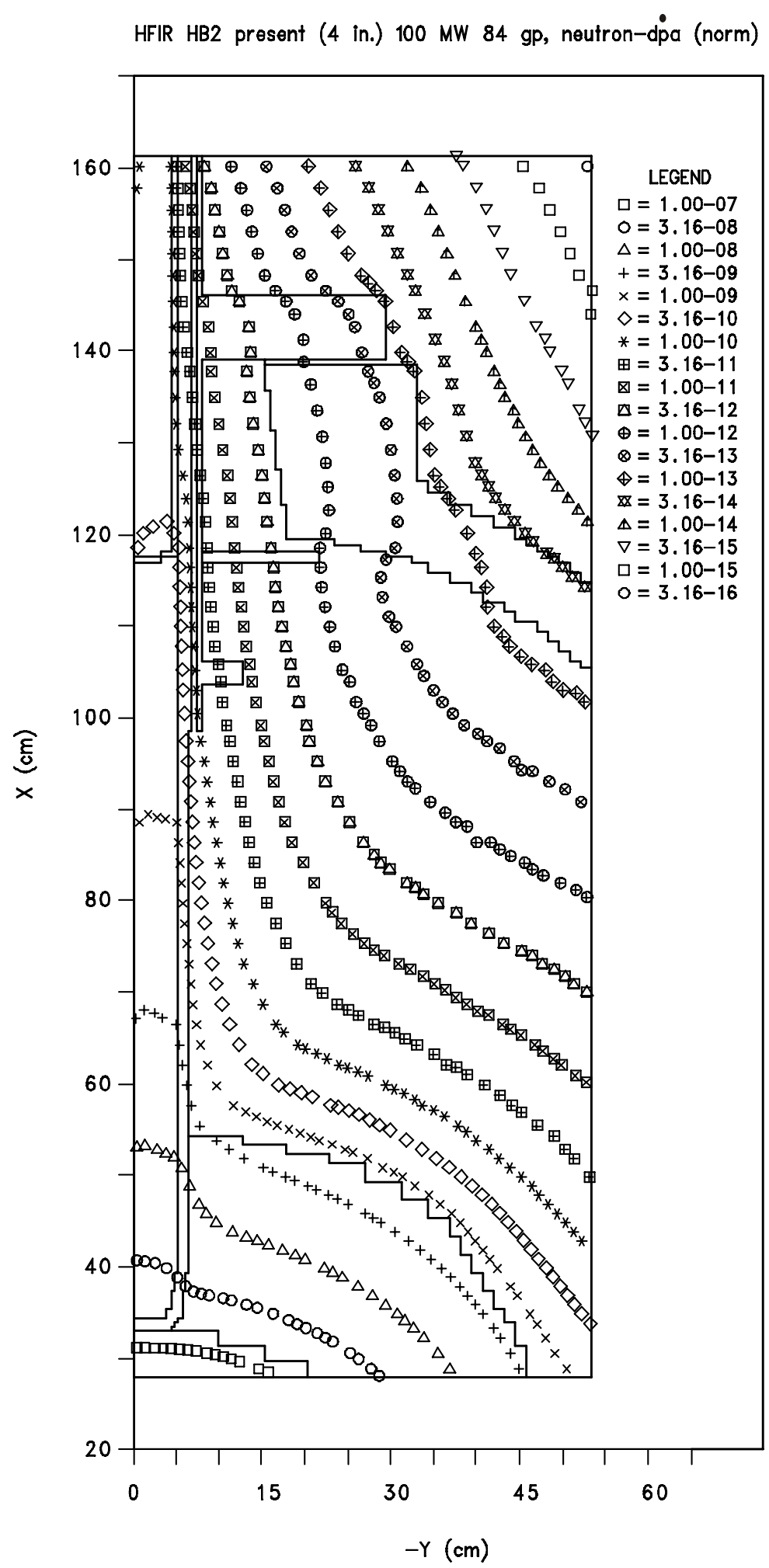

Figure 16. Neutron iso-dpa rate (displacements/atom/s) for HB-2 (present design) 


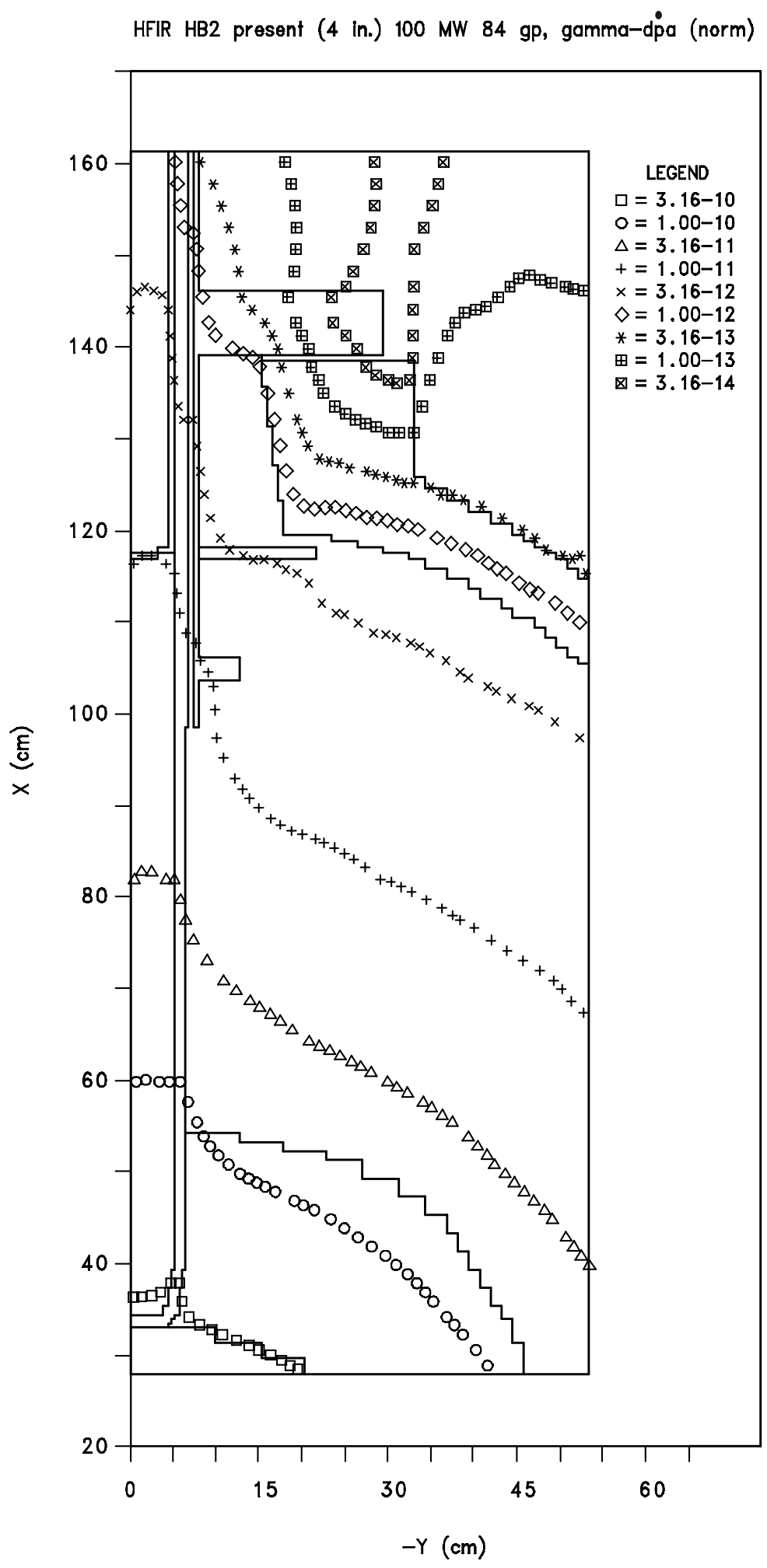

Figure 17. Gamma iso-dpa rate (displacements/atom/s) for HB-2 (present design) 


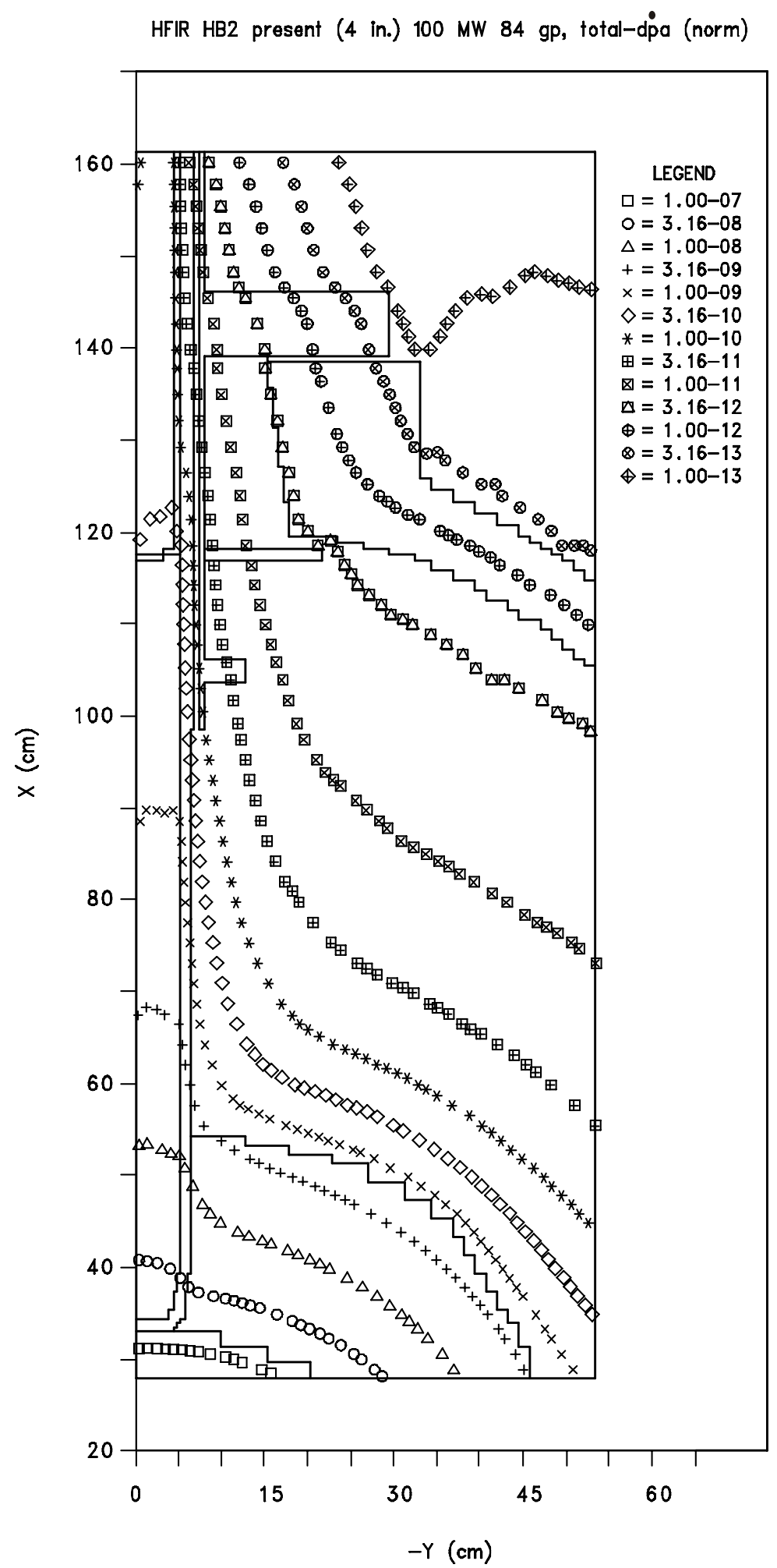

Figure 18. Total (neutron + gamma) iso-dpa rate (displacements/atom/s) for HB-2 (present design) 


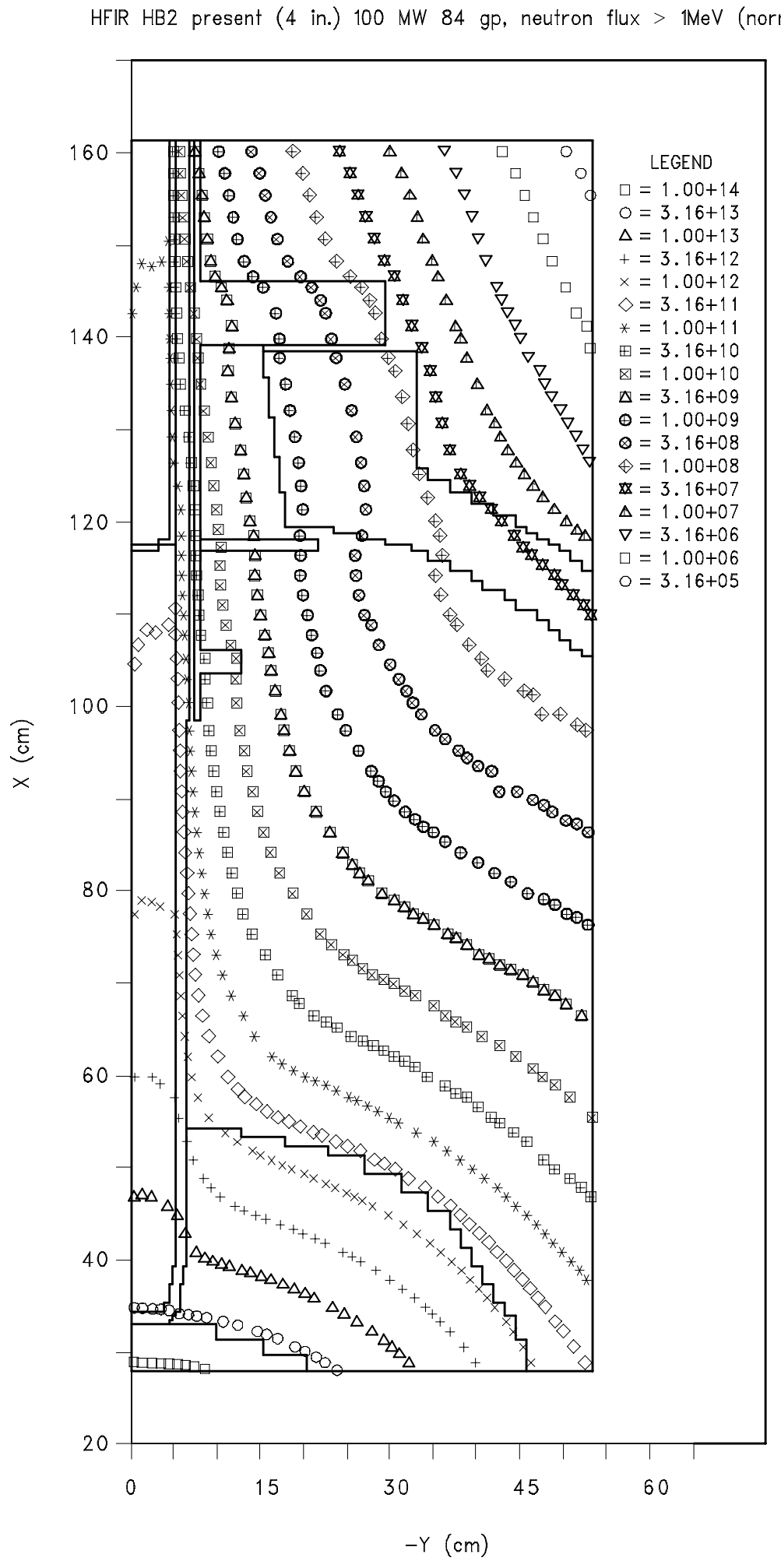

Figure 19. Neutron iso-flux (neutrons $\left./ \mathrm{cm}^{2} / \mathrm{s}\right)(\mathrm{E}>1 \mathrm{MeV})$ for $\mathrm{HB}-2$ (present design) 
HFIR HB2 present (4 in.) $100 \mathrm{MW} 84 \mathrm{gp}$, gamma flux > $1 \mathrm{MeV}$ (norm)

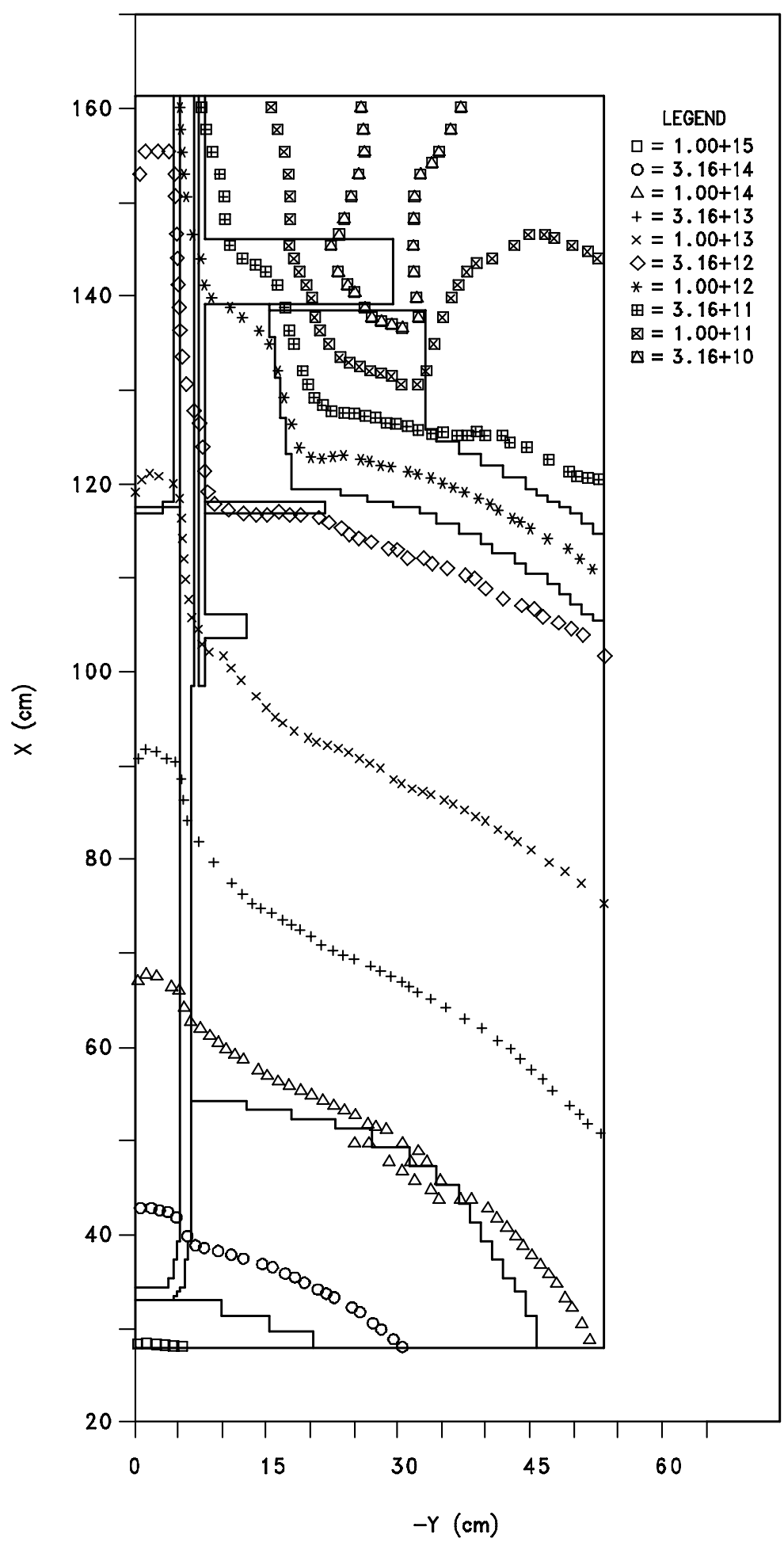

Figure 20. Gamma iso-flux (photons $\left./ \mathrm{cm}^{2} / \mathrm{s}\right)(\mathrm{E}>1 \mathrm{MeV})$ for HB-2 (present design) 
HFIR HB2 upgraded (9 in.), 100 MW 84 gp, neutron-dpa (norm)

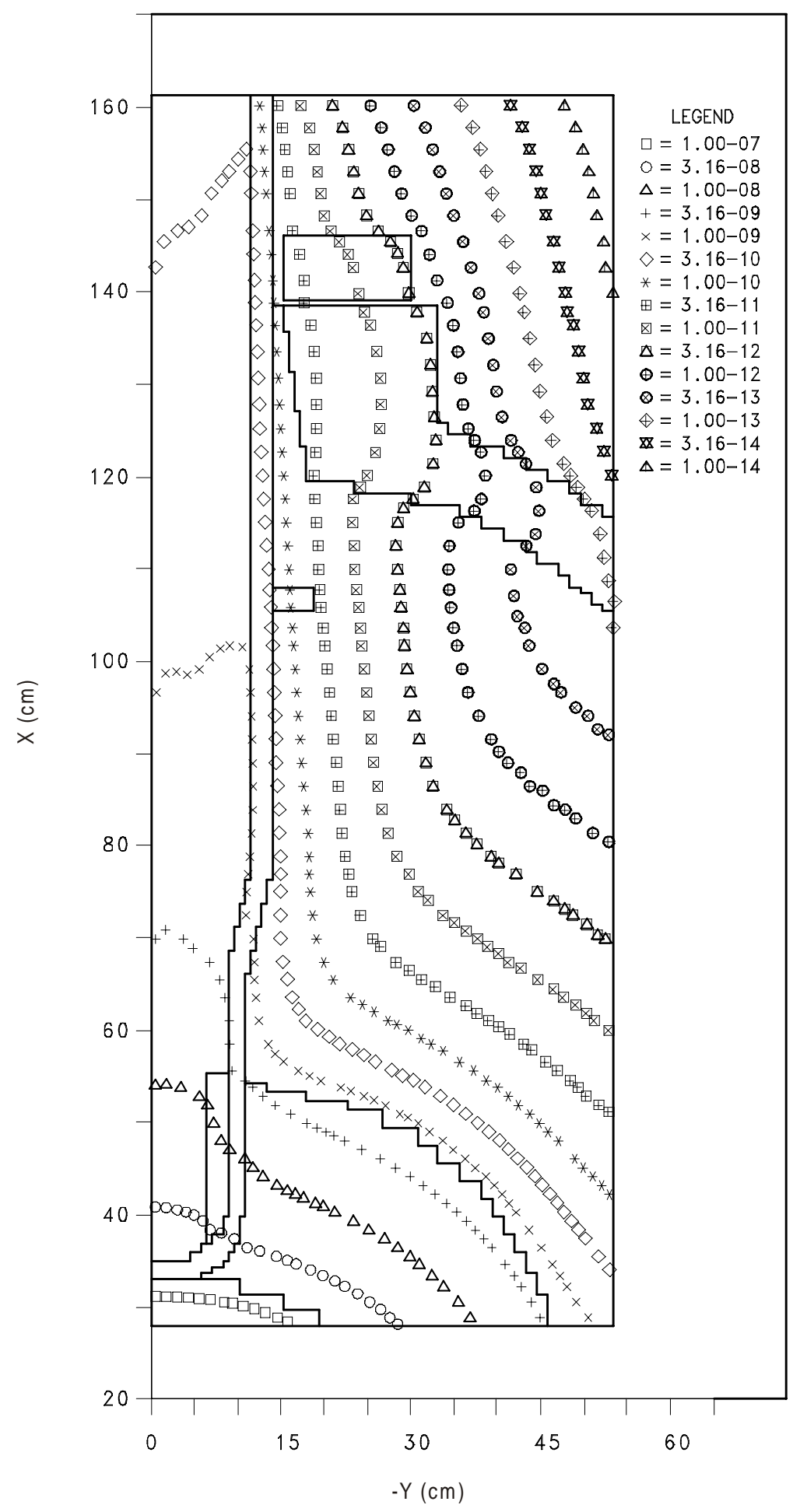

Figure 21. Neutron iso-dpa rate (displacements/atom/s) for HB-2 (new design) 


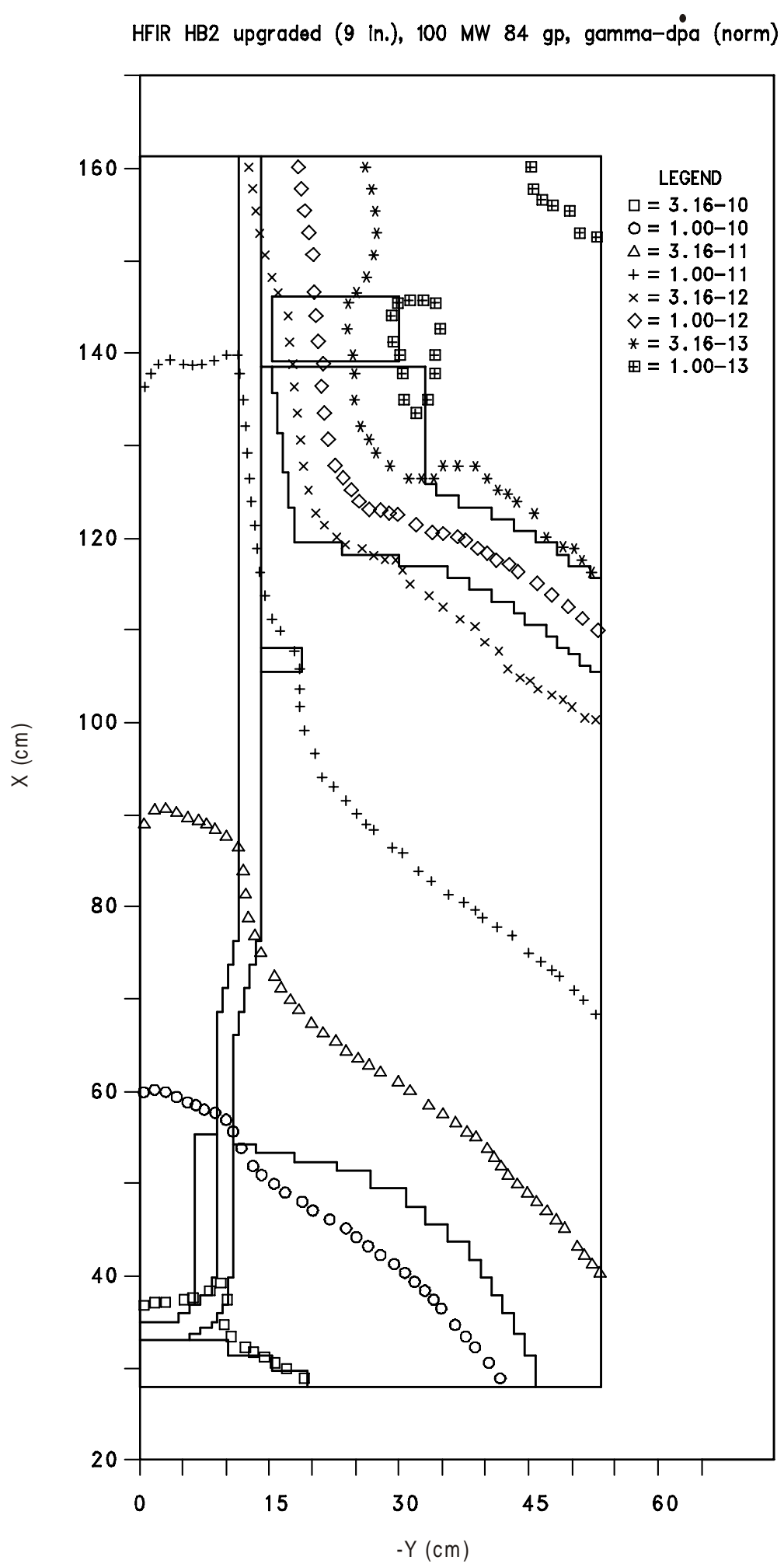

Figure 22. Gamma iso-dpa rate (displacements/atom/s) for HB-2 (new design) 
HFIR HB2 upgraded (9 in.), $100 \mathrm{MW} 84 \mathrm{gp}$, total-dpa (norm)

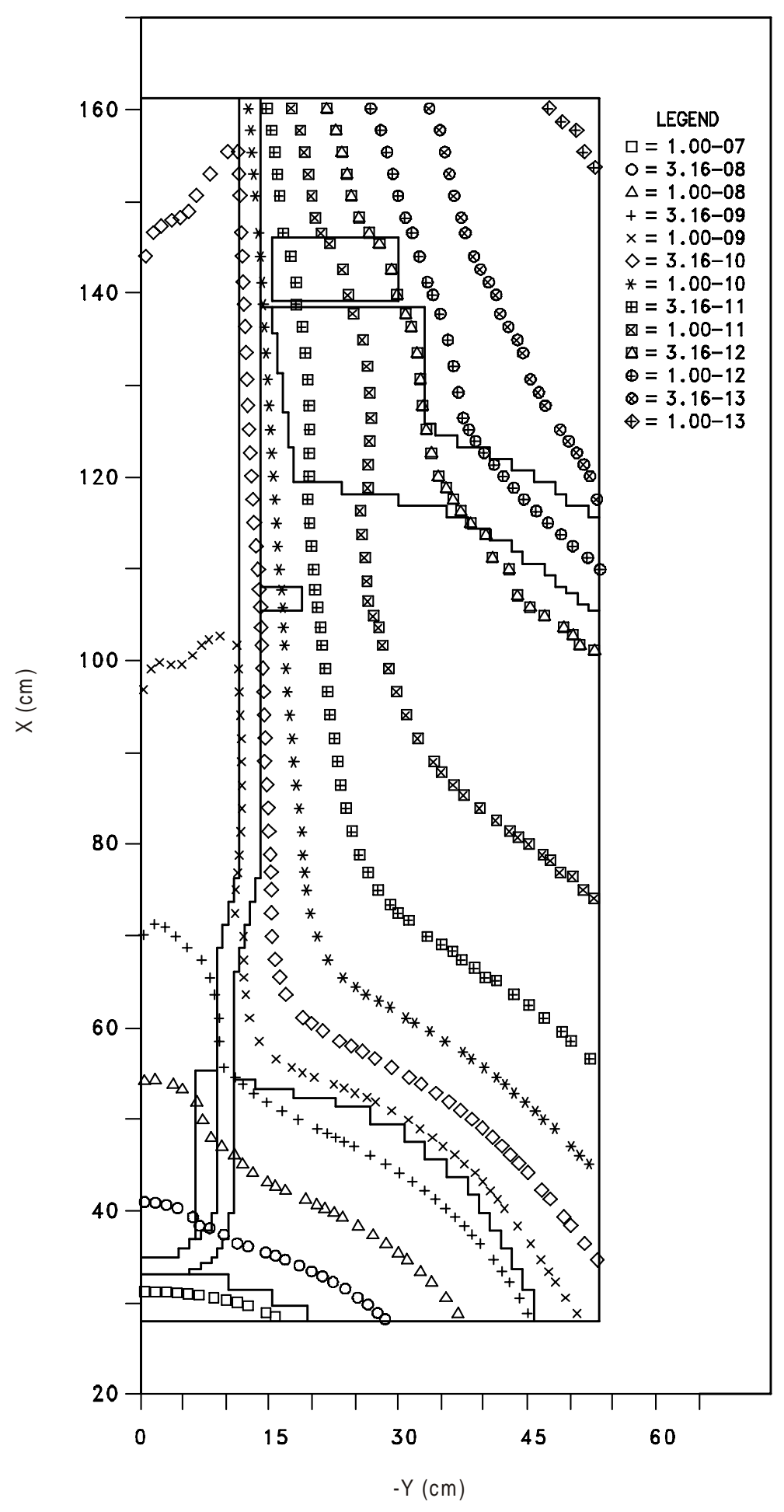

Figure 23. Total (neutron + gamma) iso-dpa rate (displacements/atom/s) for HB-2 (new design) 


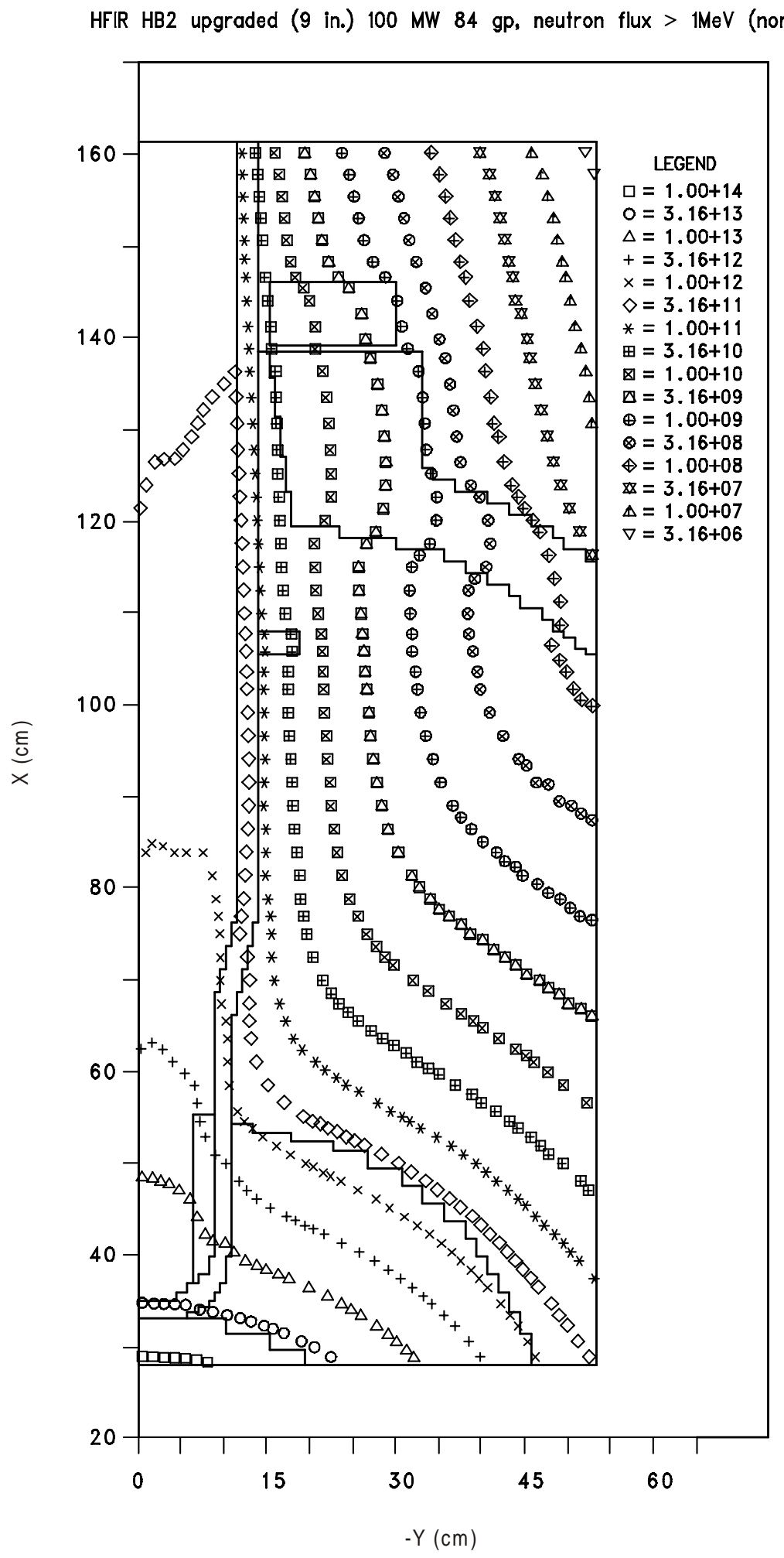

Figure 24. Neutron iso-flux (neutrons $\left./ \mathrm{cm}^{2} / \mathrm{s}\right)(\mathrm{E}>1 \mathrm{MeV})$ for HB-2 (new design) 


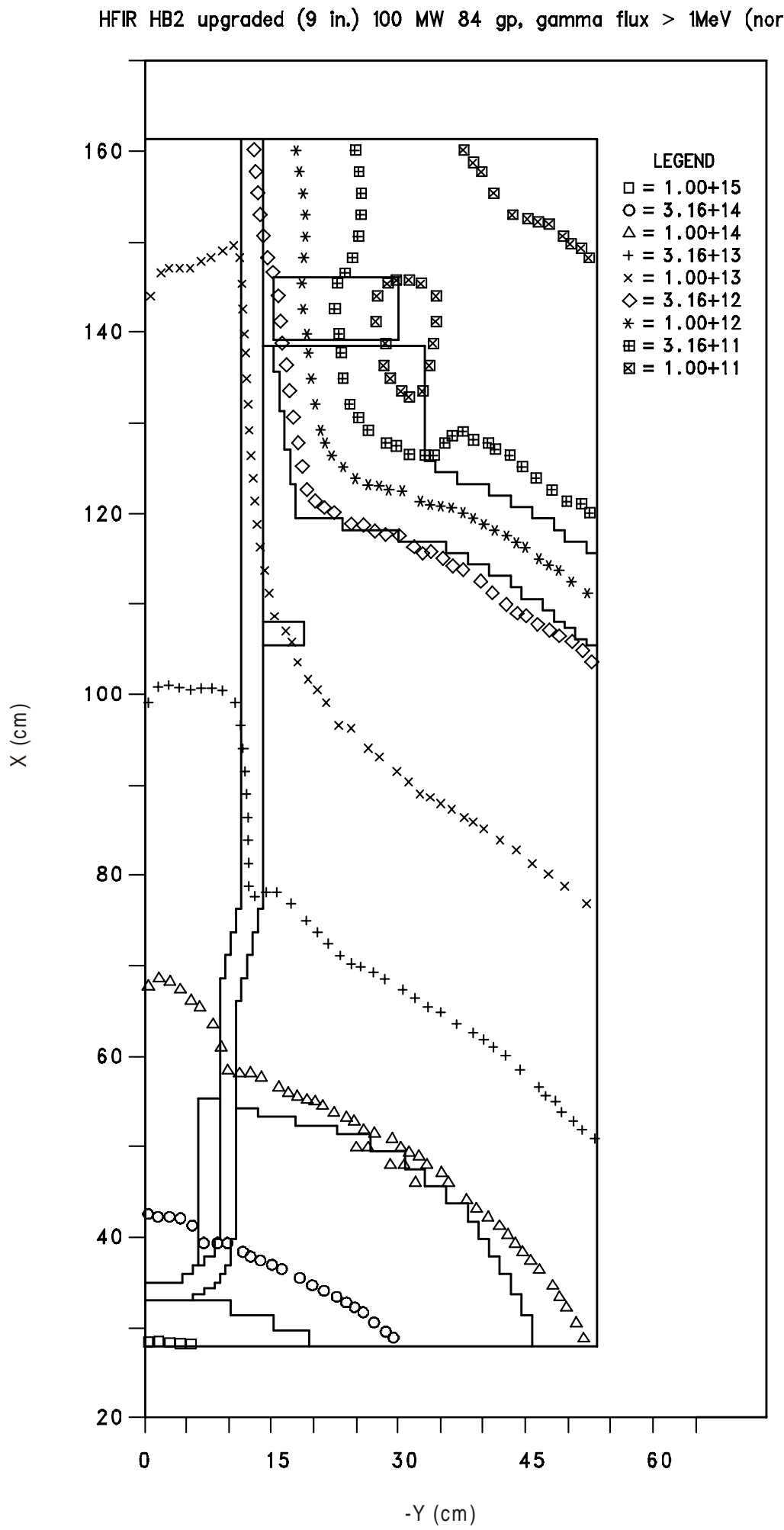

Figure 25. Gamma iso-flux (photons $\left./ \mathrm{cm}^{2} / \mathrm{s}\right)(\mathrm{E}>1 \mathrm{MeV})$ for $\mathrm{HB}-2$ (new design) 
Table 4. Comparison of dpa rates in the HB-2 present and proposed designs

\begin{tabular}{|l|l|l|l|l|l|}
\hline Design & \multicolumn{3}{|l|}{ HB-2 Present 4 in. Diam. } & HB-2 New 9 in. Diam. \\
\hline Location & $\begin{array}{l}\text { Key } 2 @ \\
\mathrm{R} \sim 18.5 \mathrm{~cm} \\
\mathrm{X} \sim 117 \mathrm{~cm}\end{array}$ & $\begin{array}{l}\text { Nozzle } \\
\text { Corner }\end{array}$ & $\begin{array}{l}\text { Nozzle } \\
\text { Weld }\end{array}$ & $\begin{array}{l}\text { Nozzle } \\
\text { Corner }\end{array}$ & $\begin{array}{l}\text { Nozzle } \\
\text { Weld }\end{array}$ \\
\hline $\begin{array}{l}\text { Neutron dpa rate } \\
{\left[\mathrm{x} 10^{-12} \mathrm{~s}^{-1}\right]}\end{array}$ & 2.22 & 1.92 & 0.215 & 34.6 & 2.25 \\
\hline $\begin{array}{l}\text { Gamma dpa rate } \\
{\left[\mathrm{x} 10^{-12} \mathrm{~s}^{-1}\right]}\end{array}$ & 2.54 & 1.98 & 1.93 & 6.55 & 2.33 \\
\hline $\begin{array}{l}\text { Total dpa rate } \\
{\left[\mathrm{x} 10^{-12} \mathrm{~s}^{-1}\right]}\end{array}$ & 4.76 & 3.90 & 2.15 & 41.1 & 4.58 \\
\hline $\begin{array}{l}\text { Ratio of total dpa rate for proposed } 9 \text { in. design to total dpa } \\
\text { rate for present 4 in. design }\end{array}$ & 10.5 & 2.13 \\
\hline
\end{tabular}

Note: Values shown are normalized values. Normalization factors were obtained by dividing the experimentally determined dpa rate by the calculated dpa rate at the dosimetry location. The resulting normalization factors are .638 for neutron dpa rate and 1.76 for gamma dpa rate. To obtain the unnormalized calculated values, the values shown should be divided by the normalization factor.

\subsection{HB-1 and -4 Model Results}

Models for HB-1, -3 , and -4 are based on the TORT three-dimensional discrete ordinates code. As discussed earlier, HB-1 and HB-4 are, in the present configuration, identical mirror images of each other. Since HB-1 will not be changed in the reactor upgrade, the model for the present HB-4 design suffices for HB-1.

Normalization of results for HB-4 and HB-1 was performed in a manner analogous to HB-2. Dosimetry results for HB-4 (present design) or HB-1 at key location 4 were available at two specimen positions located radially at $\sim 60^{\circ}$ (Position 2) and $\sim 22^{\circ}$ (Position 10), where the radial position is measured in a clockwise direction looking through the beam tube away from the core. ${ }^{14}$ Table 5 summarizes the data used to calculate the ratios of the neutron and gamma dpa rates to the calculated values at these locations. The average of the neutron and gamma ratios is used as the factor necessary to produce the correct normalized neutron and gamma dpa rates at locations close to the dosimetry points.

Figures 26 through 30 show the normalized neutron, gamma, and total iso-dpa rate plots and the neutron and gamma iso-flux ( $\mathrm{E}>1 \mathrm{MeV}$ ) plots for the HB-4,-1 (present design). Figures 31 through 35 show analogous results for the HB-4 new design.

Table 6 tabulates these normalized values for both present and new HB-4 designs. An additional region is included, referred to earlier as the annulus, which is located approximately one half 
way radially between the nozzle corner and the nozzle weld at the inside surface of the vessel wall.

Table 5. Determination of HB-4 (HB-1) normalization factors

\begin{tabular}{|l|l|l|}
\hline Key 4 Specimen Position & 2 & 10 \\
\hline XYZ Location (cm) (X is HB-4 axis) & $111.99,-11.04,6.73$ & $106.08,6.37,11.66$ \\
\hline Dosimetry Neutron dpa rate [ $\left.\mathrm{x} 10^{-12}\right]$ & 0.784 & 1.01 \\
\hline Calculated Neutron dpa rate [ $\left.\mathrm{x} 10^{-12}\right]$ & 1.02 & 1.05 \\
\hline Dosimetry/Calculated Neutron dpa Ratio & 0.766 & 0.966 \\
\hline $\begin{array}{l}\text { Dosimetry/Calculated Average Neutron dpa } \\
\text { Ratio [Normalization Factor] }\end{array}$ & 0.866 & 1.25 \\
\hline Dosimetry Gamma dpa rate [ $\left.\times 10^{-12}\right]$ & 1.25 & 1.29 \\
\hline Calculated Gamma dpa rate [ $\left.\times 10^{-12}\right]$ & 1.43 & 0.969 \\
\hline Dosimetry/Calculated Gamma dpa Ratio & 0.872 & \\
\hline $\begin{array}{l}\text { Dosimetry/Calculated Average Gamma dpa } \\
\text { Ratio [Normalization Factor] }\end{array}$ & 0.921 & \\
\hline
\end{tabular}

Table 6. Comparison of normalized dpa rates for HB-4 (HB-1) present and proposed HB-4 designs

\begin{tabular}{|c|c|c|c|c|c|c|c|}
\hline \multirow{2}{*}{\multicolumn{2}{|c|}{$\frac{\text { Design }}{\text { Location }}$}} & \multicolumn{3}{|c|}{ HB-4 (HB-1) Present Design } & \multicolumn{3}{|c|}{ HB-4 Proposed Design } \\
\hline & & Corner & Annulus & Weld & Corner & Annulus & Weld \\
\hline \multicolumn{2}{|c|}{$\begin{array}{l}\text { Location }(\mathrm{cm})(\mathrm{Z}=0) \\
\mathrm{X} \sim \\
\mathrm{Y} \sim\end{array}$} & $\begin{array}{l}106.0 \\
10.7\end{array}$ & $\begin{array}{l}103.5 \\
18.4\end{array}$ & $\begin{array}{l}102.2 \\
23.5\end{array}$ & $\begin{array}{l}106.0 \\
10.7\end{array}$ & $\begin{array}{l}103.5 \\
18.4\end{array}$ & $\begin{array}{l}102.2 \\
23.5\end{array}$ \\
\hline \multirow{3}{*}{$\begin{array}{l}\text { dpa rate } \\
{\left[\begin{array}{ll}\mathrm{X} & 10^{-12} \\
\left.\mathrm{~s}^{-1}\right]\end{array}\right.}\end{array}$} & neutron & 2.49 & 0.769 & 0.462 & 6.98 & 1.20 & 0.616 \\
\hline & gamma & 1.01 & 1.15 & 1.24 & 2.00 & 1.11 & 1.02 \\
\hline & total & 3.50 & 1.92 & 1.71 & 8.98 & 2.31 & 1.64 \\
\hline \multicolumn{5}{|c|}{$\begin{array}{l}\text { Ratio of total dpa rate for new HB- } 4 \text { design to total dpa } \\
\text { rate for present HB- } 4 \text { design }\end{array}$} & 2.57 & 1.20 & 0.96 \\
\hline
\end{tabular}

Notes:

1) Normalization factors were obtained by dividing the experimentally determined dpa value by the calculated dpa value at the HB-4 location. The resulting normalization factors are 0.866 for neutron dpa and 0.921 for gamma dpa.

2) Location values are mesh cell midpoints.

Only results for one side of the beam tube, those shown on the "shady" side of the beam tube, are given. These values are higher than those on the "sunny" section, since particles stream through the beam tube to arrive at this location and therefore pass through less shielding. Several observations can be made from these results. First, the dpa rates for the proposed, new HB-4 design are significantly less than those determined for the new HB-2 design. From a comparison 
of Tables 4 and 6, it is seen that the neutron dpa rate for the new HB-4 design is less than that for the new HB-2 design by a factor of $\sim 5$ at the nozzle corners. For the gamma dpa rate, the reduction is a factor of $\sim 3$. Similar reductions are observed at the nozzle welds. Although the proposed beam tubes do not differ drastically in size, HB-4 provides less of a direct channel for radiation particles since it is tangential to the core. Also, the relative effects of increasing the beam tube size in HB-4 are calculated to be less than for HB-2. At the nozzle corner, the increase in diameter causes the neutron dpa rate to change by a factor of $\sim 2.5$ instead of a factor of $\sim 18$ as calculated for HB-2. Essentially, the gamma dpa rate is unaffected except at the nozzle corner where it is changed by a factor of $\sim 2$. This is partially because of the local shielding of the cooling flange, which does not appear in the new model. Elsewhere, at the annulus and the weld, the gamma dpa rate is calculated to be slightly less in the model of the new design even though the tube diameter has been increased. Possible explanations are the increased shielding from the thicker tube walls in the proposed design model and the reduced density of the flange region between the two plates which allows slightly more gamma rays to penetrate to the annulus and weld locations in the present model. 


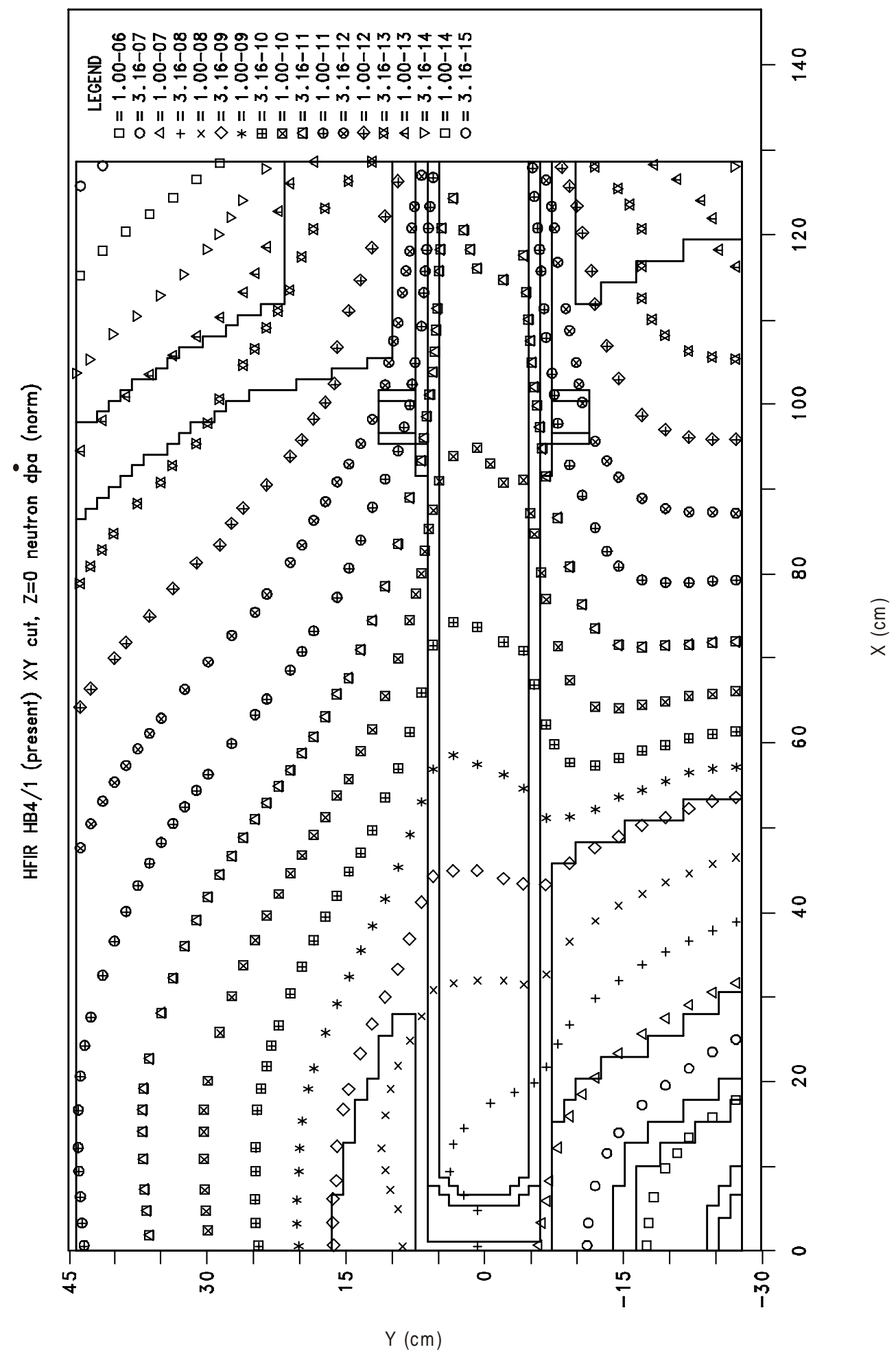

Figure 26. Neutron iso-dpa rate (neutrons $/ \mathrm{cm}^{2} / \mathrm{s}$ ) for HB-1 and HB-4 (present design; HB-4 shown; HB-1 is mirror image). 


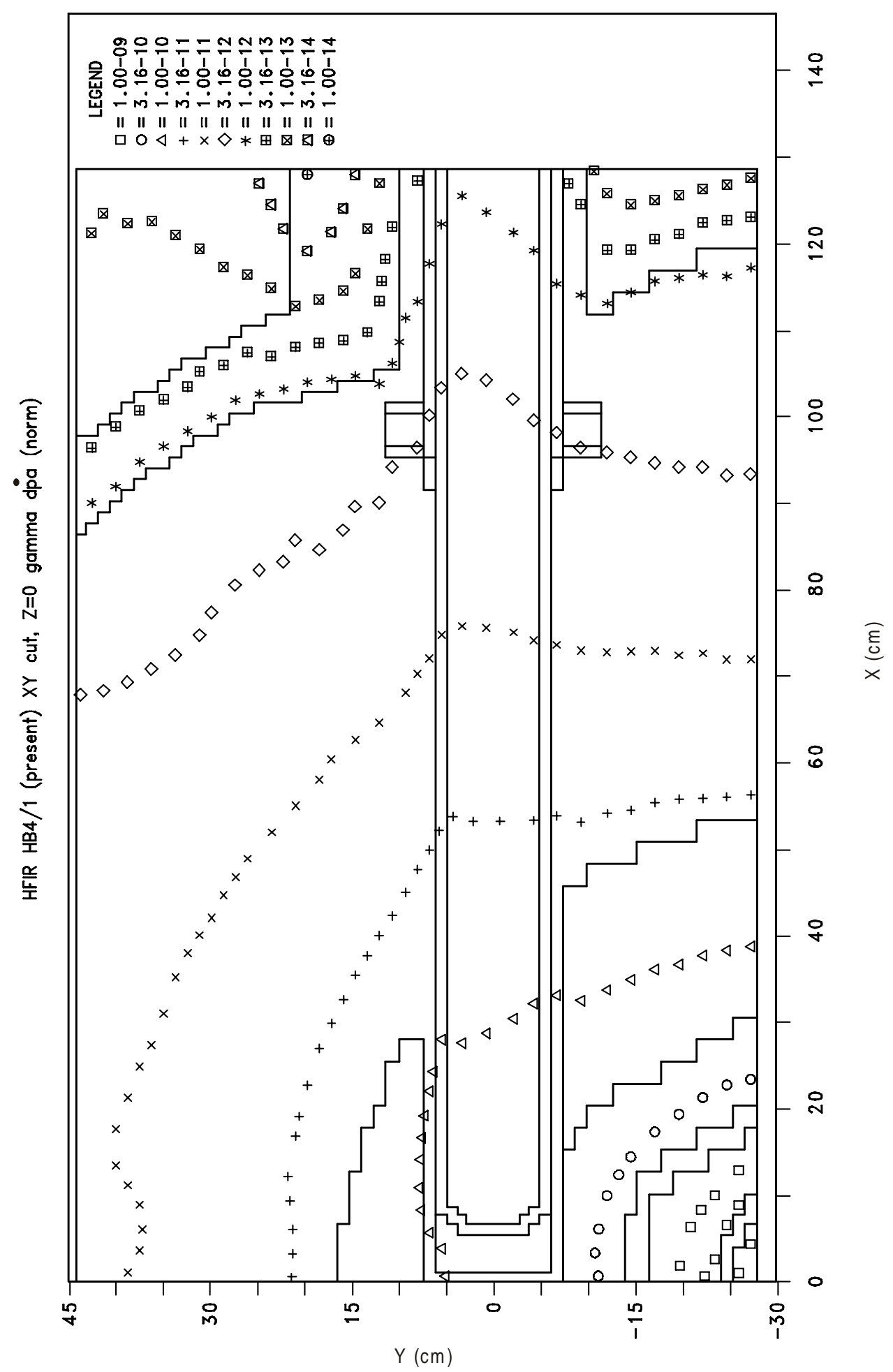

Figure 27. Gamma iso-dpa rate (displacements/atom/s) for HB-1 and HB-4 (present design; HB-4 shown; HB-1 is mirror image). 


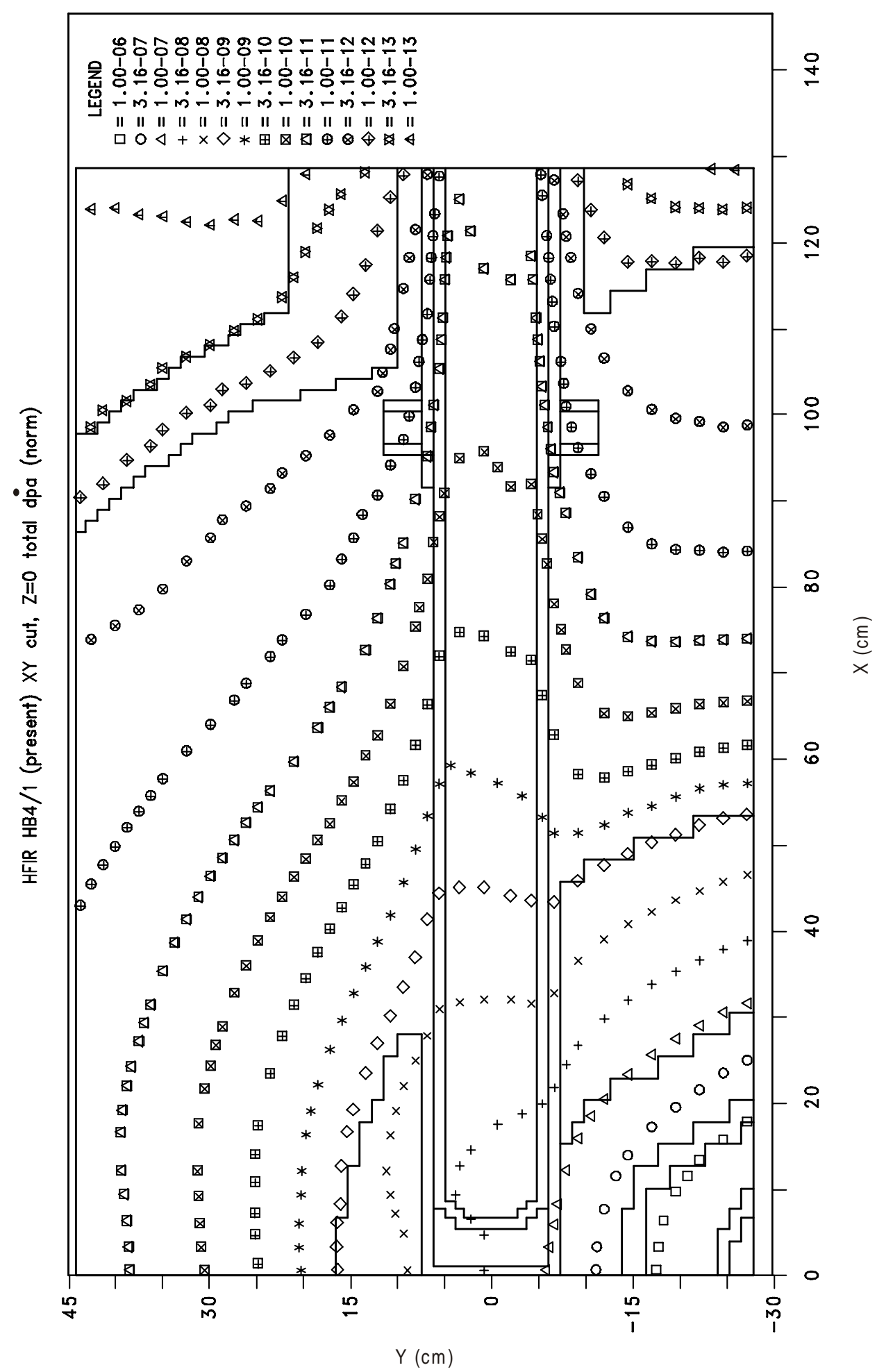

Figure 28. Total (neutron + gamma) iso-dpa rate (displacements/atom/s) for HB-1 and HB-4 (present design; HB-4 shown; HB-1 is mirror image). 


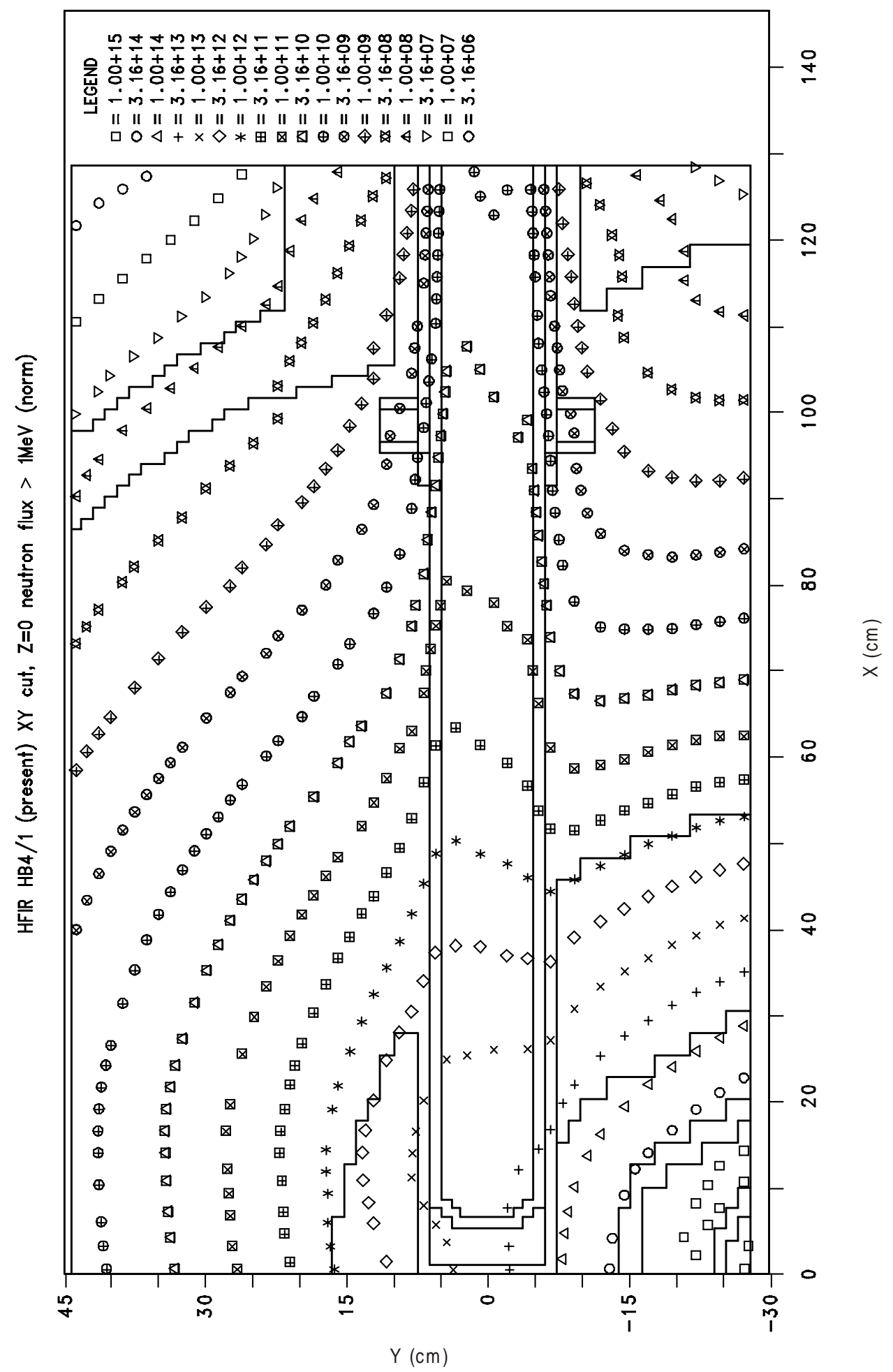

Figure 29. Neutron iso-flux (neutrons $\left./ \mathrm{cm}^{2} / \mathrm{s}\right)(\mathrm{E}>1 \mathrm{MeV})$ for HB-1 and HB-4 (present design; HB-4 shown; HB-1 is mirror image). 


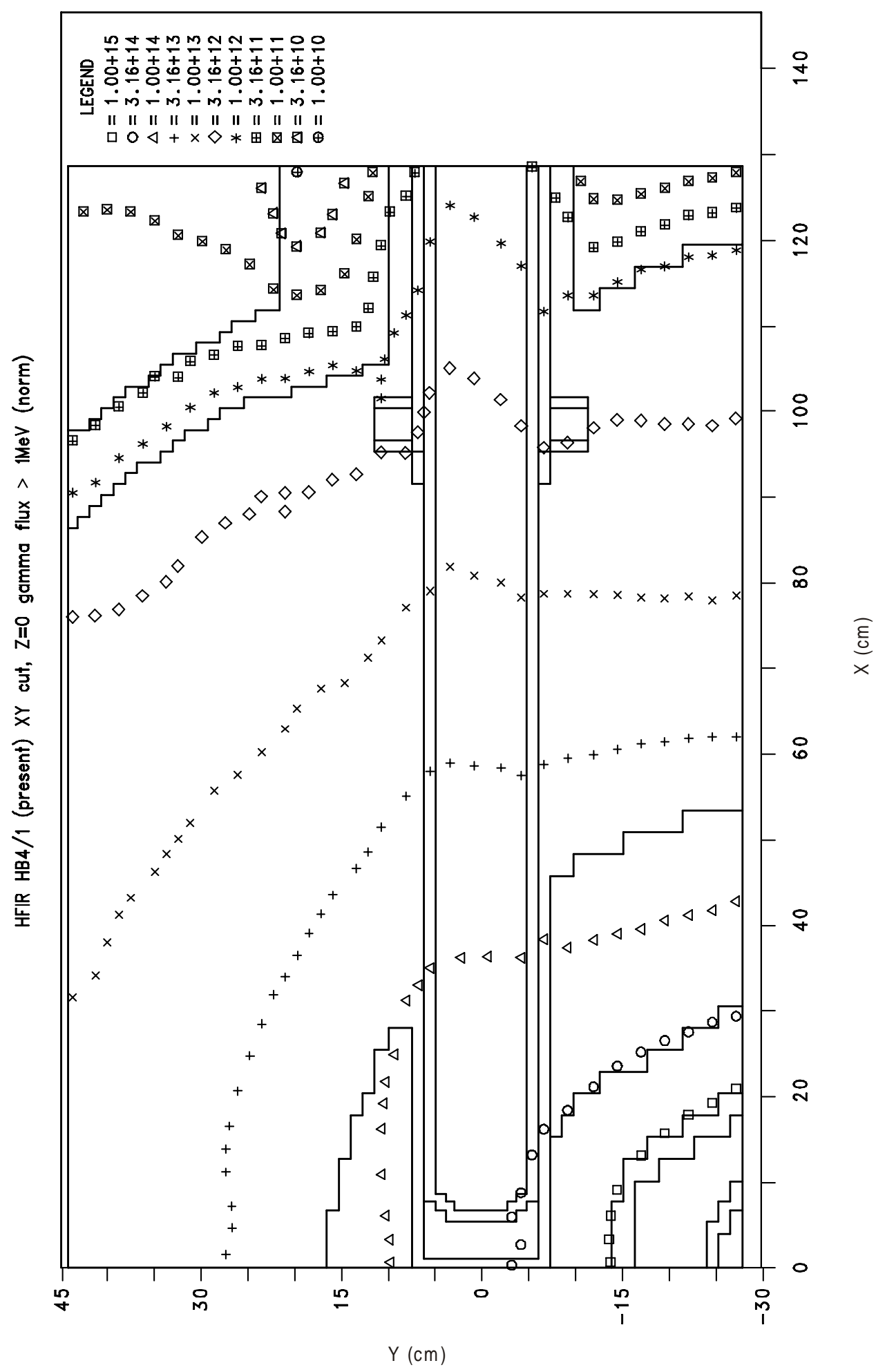

Figure 30. Gamma iso-flux (photons $\left./ \mathrm{cm}^{2} / \mathrm{s}\right)(\mathrm{E}>1 \mathrm{MeV}$ ) for HB-1 and HB-4 (present design; HB-4 shown; HB-1 is mirror image). 


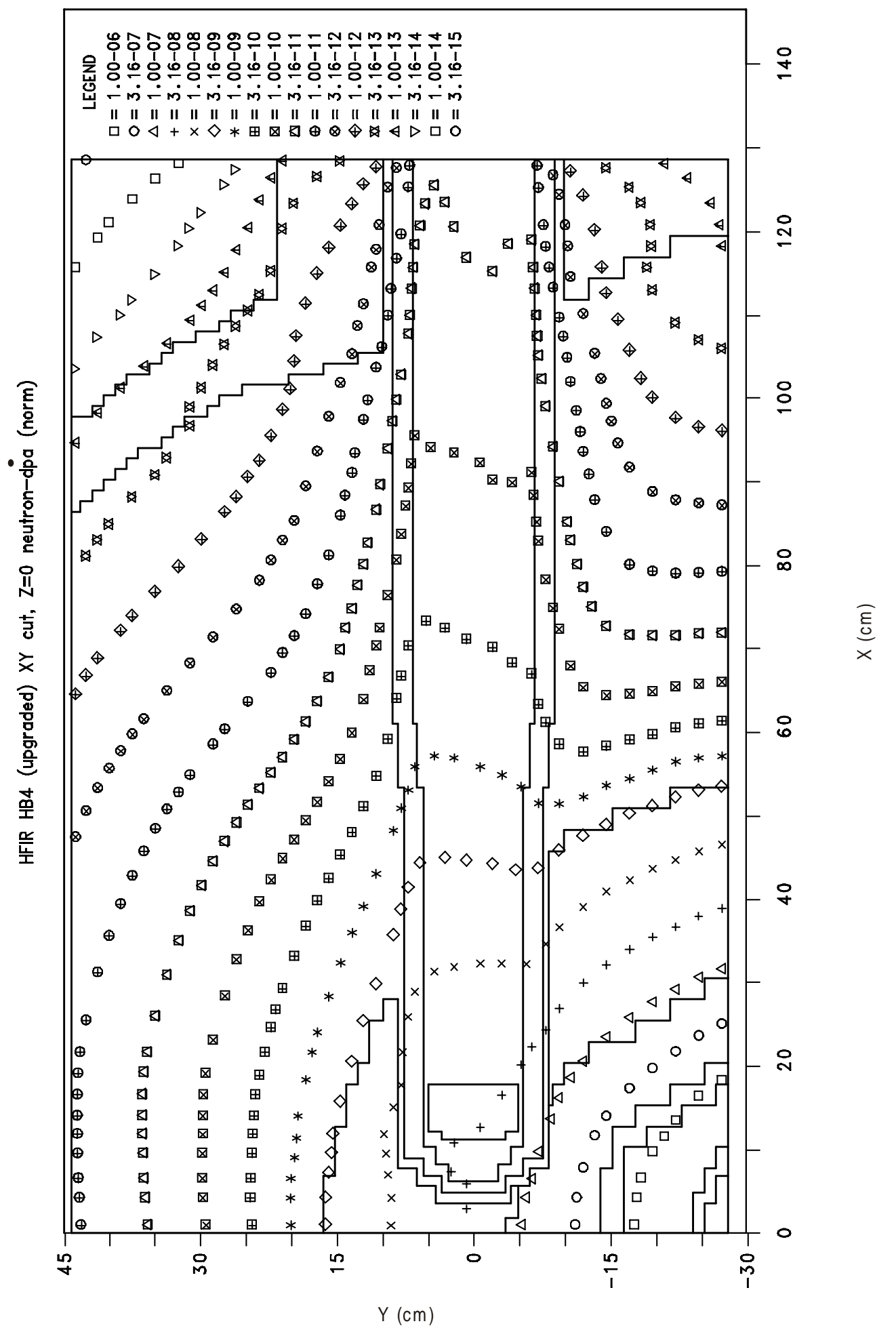

Figure 31. Neutron iso-dpa rate (displacements/atom/s) for HB-4 (new design). 


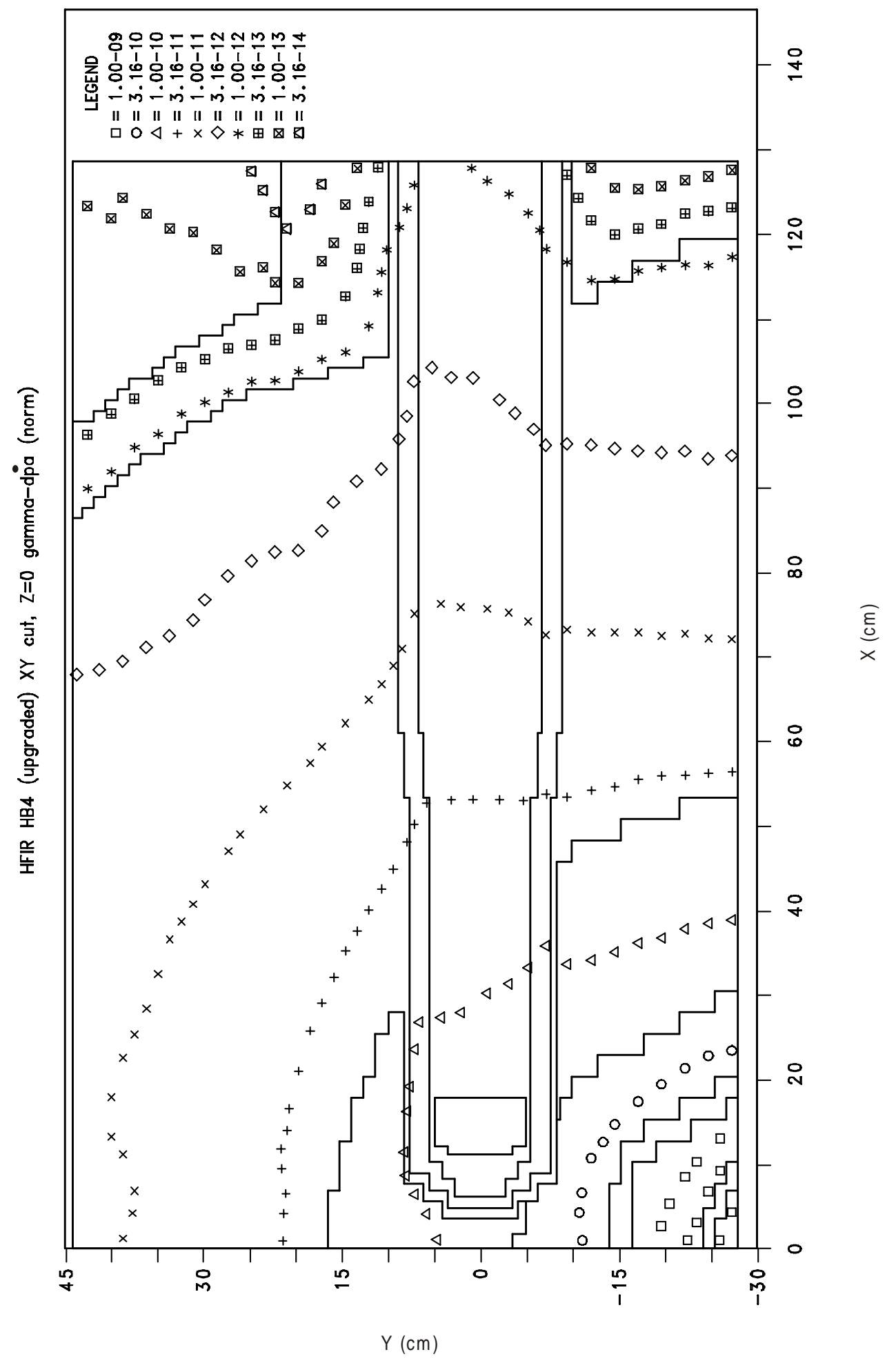

Figure 32. Gamma iso-dpa rate (displacements/atom/s) for HB-4 (new design). 


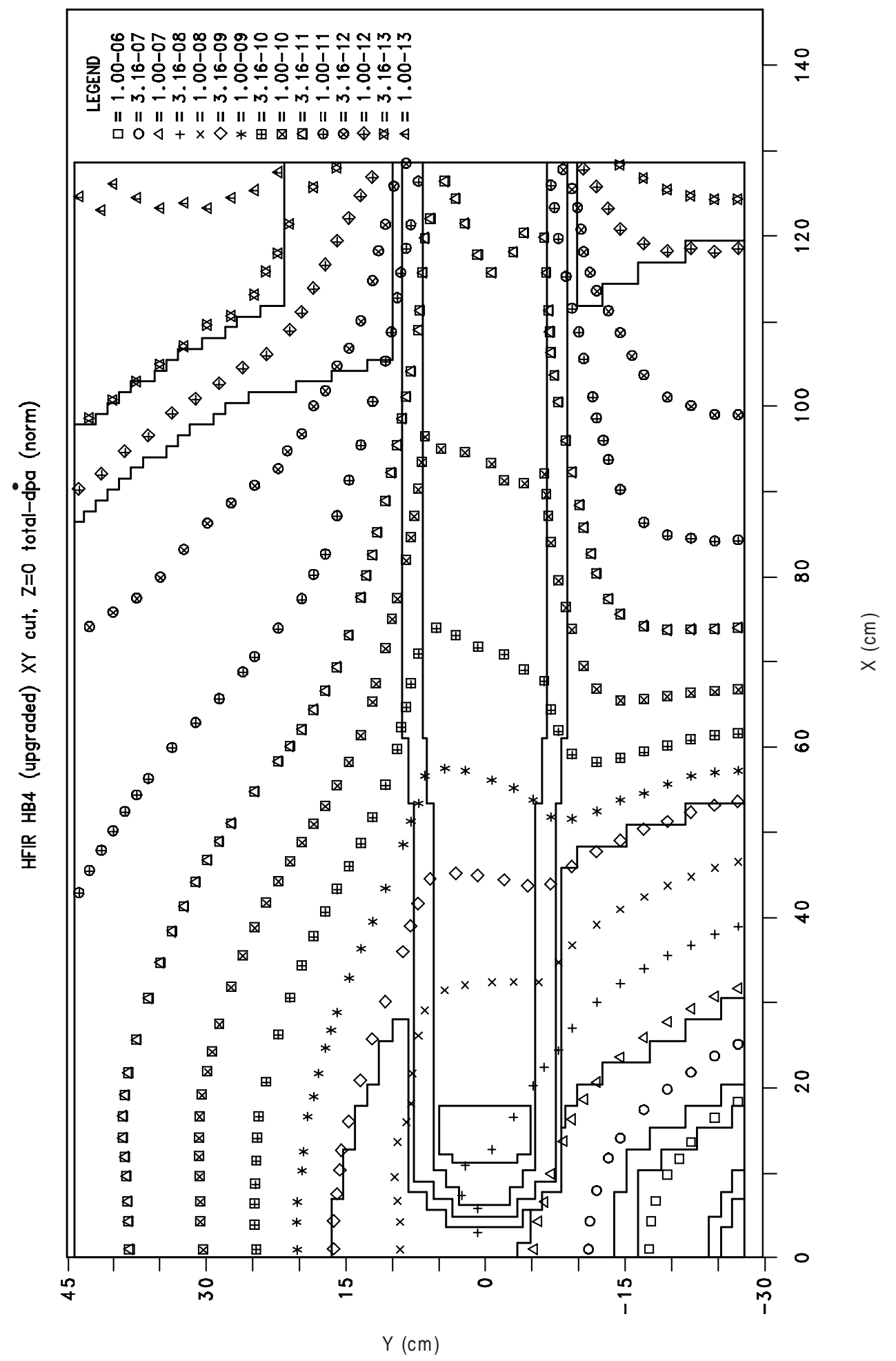

Figure 33. Total (neutron + gamma) iso-dpa rate (displacements/atom/s) for HB-4 (new design). 


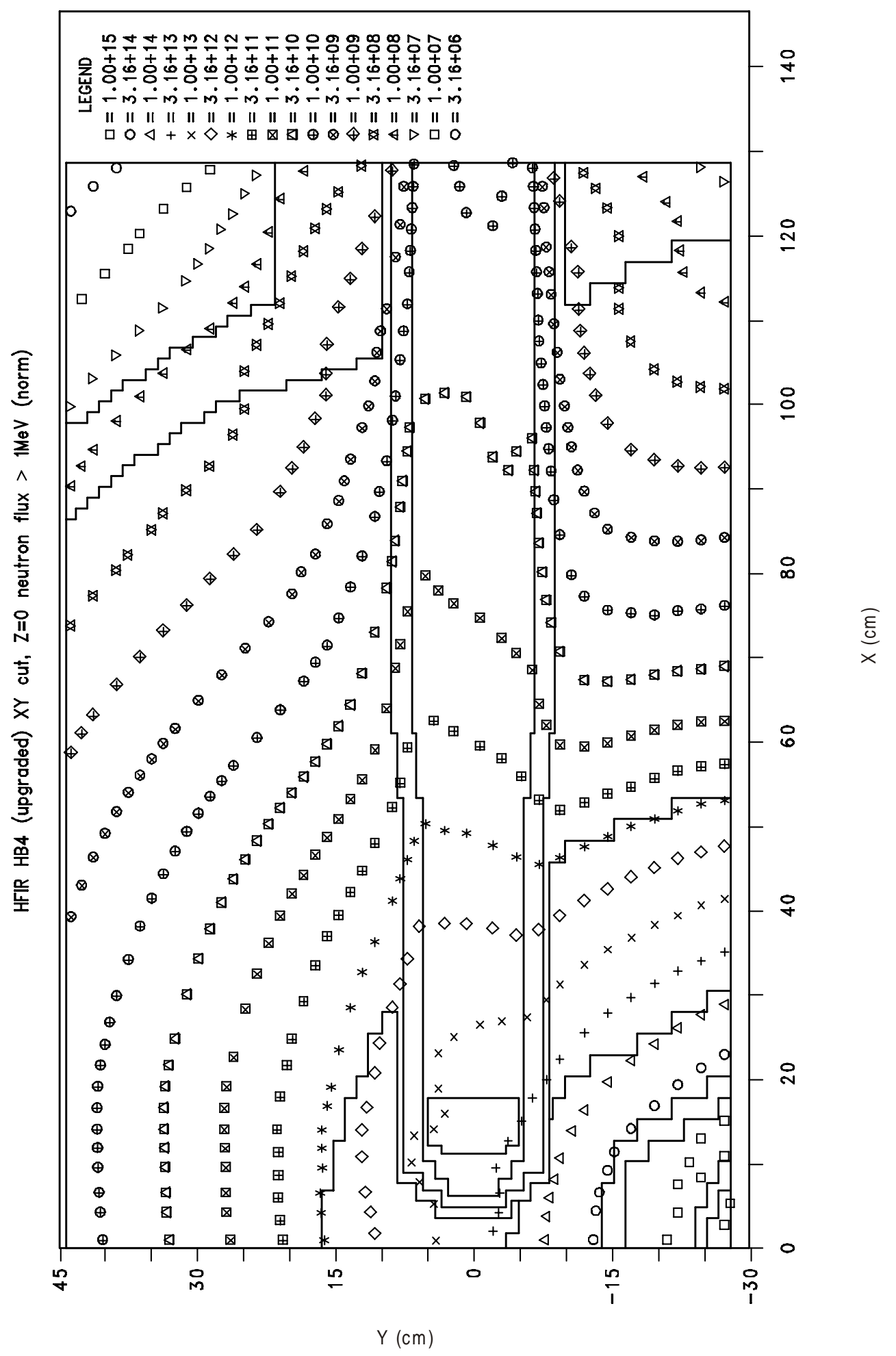

Figure 34. Neutron iso-flux (neutrons $\left./ \mathrm{cm}^{2} / \mathrm{s}\right)(\mathrm{E}>1 \mathrm{MeV})$ for $\mathrm{HB}-4$ (new design) 


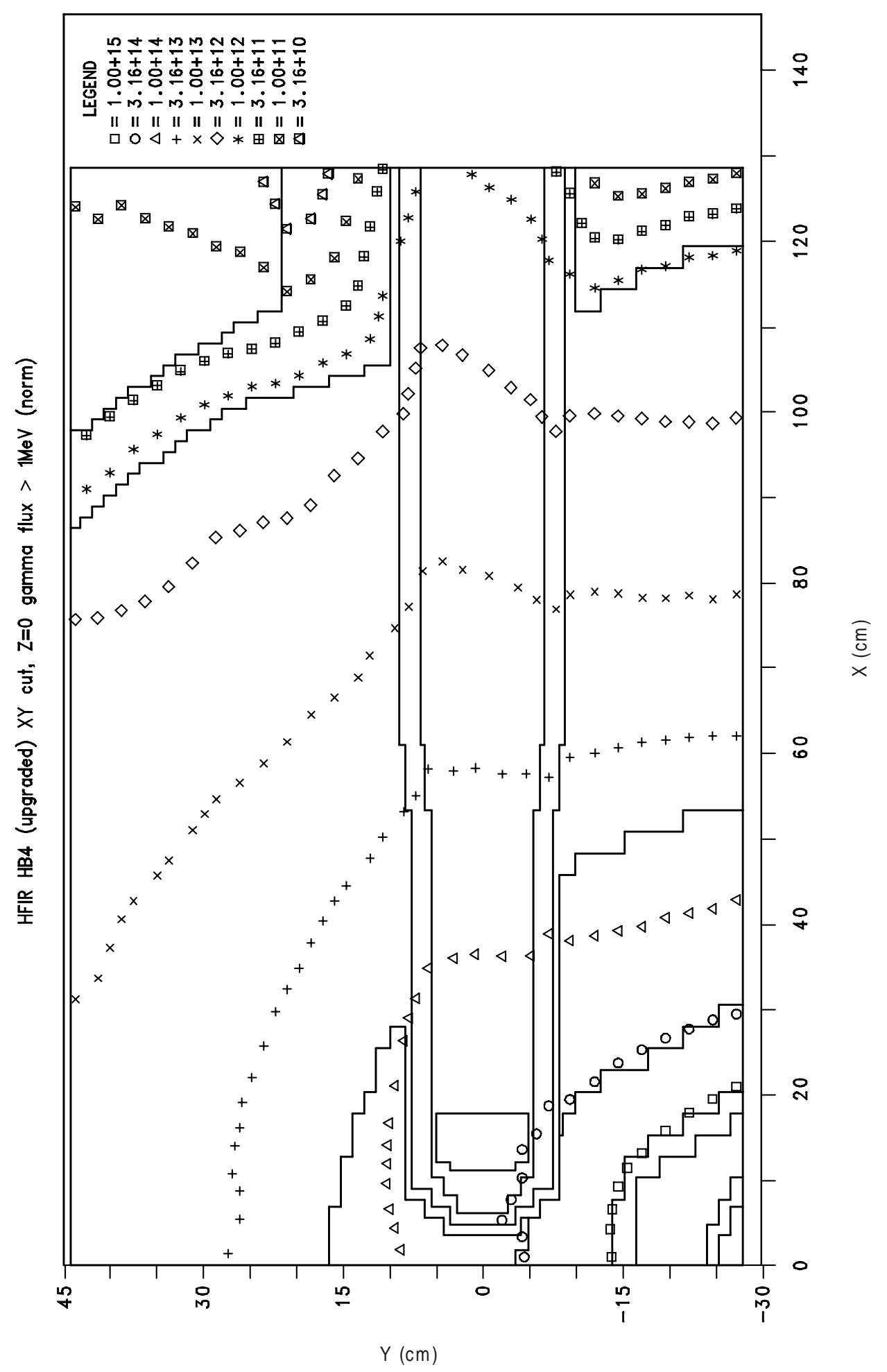

Figure 35. Gamma iso-flux (photons $\left./ \mathrm{cm}^{2} / \mathrm{s}\right)(\mathrm{E}>1 \mathrm{MeV})$ for HB-4 (new design) 


\subsection{HB-3 Model Results}

Currently there are no plans to modify HB-3. However, dpa calculations are required for all the beam tubes as a part of the complete updated assessment. Thus, a calculational model was developed for HB-3, the results of which can be compared to the other beam tube calculations. Unfortunately, there are no dosimetry based dpa results to use for normalization of the calculated results. A reasonable approach that was adopted was to combine (average) the normalization factors for HB-2 and HB-4. As a result, the normalization factors used for HB-3 are 0.752 for neutron dpa rate and 1.34 for gamma dpa rate. Table 7 summarizes results for the corner, annulus, and weld. Figures 36 through 40 show the normalized neutron, gamma, and total isodpa rate and the neutron and gamma iso-flux plots $(E>1 \mathrm{MeV})$ for the HB-3. A comparision of the iso-plots or the results in Tables 6 and 7 show that the dpa rates for HB-3 are somewhat higher than those for HB-1, HB-4 (present design).

Table 7 - Normalized dpa rate calculations for HB-3 design

\begin{tabular}{|c|c|c|c|c|c|c|c|}
\hline \multirow{2}{*}{\multicolumn{2}{|c|}{$\begin{array}{l}\text { Side of tube } \\
\text { Location }\end{array}$}} & \multicolumn{3}{|c|}{ "shady side" Results $(\mathrm{Y}>0)$} & \multicolumn{3}{|c|}{ "sunny side" Results $(\mathrm{Y}<0)$} \\
\hline & & Corner & Annulus & Weld & Corner & Annulus & Weld \\
\hline \multicolumn{2}{|c|}{$\begin{array}{l}\text { Location (midplane, } \mathrm{Z}=0 \text { ) } \\
\mathrm{X} \sim \\
\mathrm{Y} \sim\end{array}$} & $\begin{array}{r}113.0 \\
10.7\end{array}$ & $\begin{array}{r}111.1 \\
18.4\end{array}$ & $\begin{array}{r}108.0 \\
23.5\end{array}$ & $\begin{array}{r}120.0 \\
-10.7\end{array}$ & $\begin{array}{r}121.3 \\
-17.1\end{array}$ & $\begin{array}{r}121.3 \\
-22.2\end{array}$ \\
\hline \multirow{3}{*}{$\begin{array}{l}\text { dpa rate } \\
{\left[\mathrm{x} 10^{-12} \mathrm{~s}^{-1}\right]}\end{array}$} & Neutron & 4.25 & 1.08 & 0.587 & 2.65 & 6.41 & 0.246 \\
\hline & Gamma & 1.72 & 1.59 & 1.74 & 1.49 & 1.20 & 1.09 \\
\hline & Total & 5.97 & 2.67 & 2.32 & 4.14 & 1.84 & 1.33 \\
\hline
\end{tabular}

Notes:

1)Normalization factors were obtained by averaging the normalization factors for HB-2 and HB-4. The resulting normalization factors are 0.752 for neutron dpa rate and 1.34 for gamma dpa rate.

2) "Sunny side" refers to the area adjacent to the beam tube for which values along the Y-axis are negative. "Shady side" refers to the section where Y-axis values are positive.

3) Location values are mesh cell midpoints. 


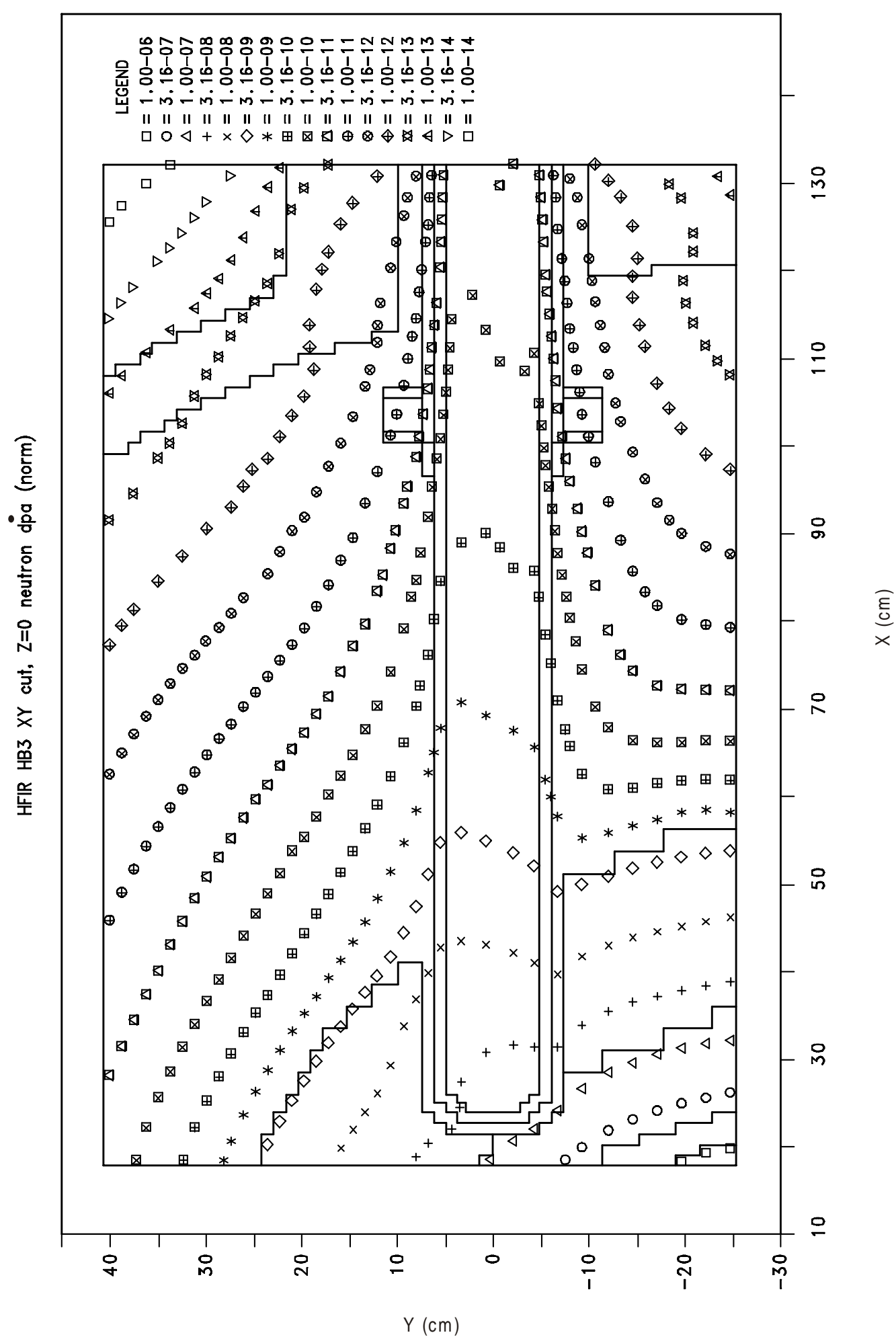

Figure 36. Neutron iso-dpa rate (displacements/atom/s) for HB-3 


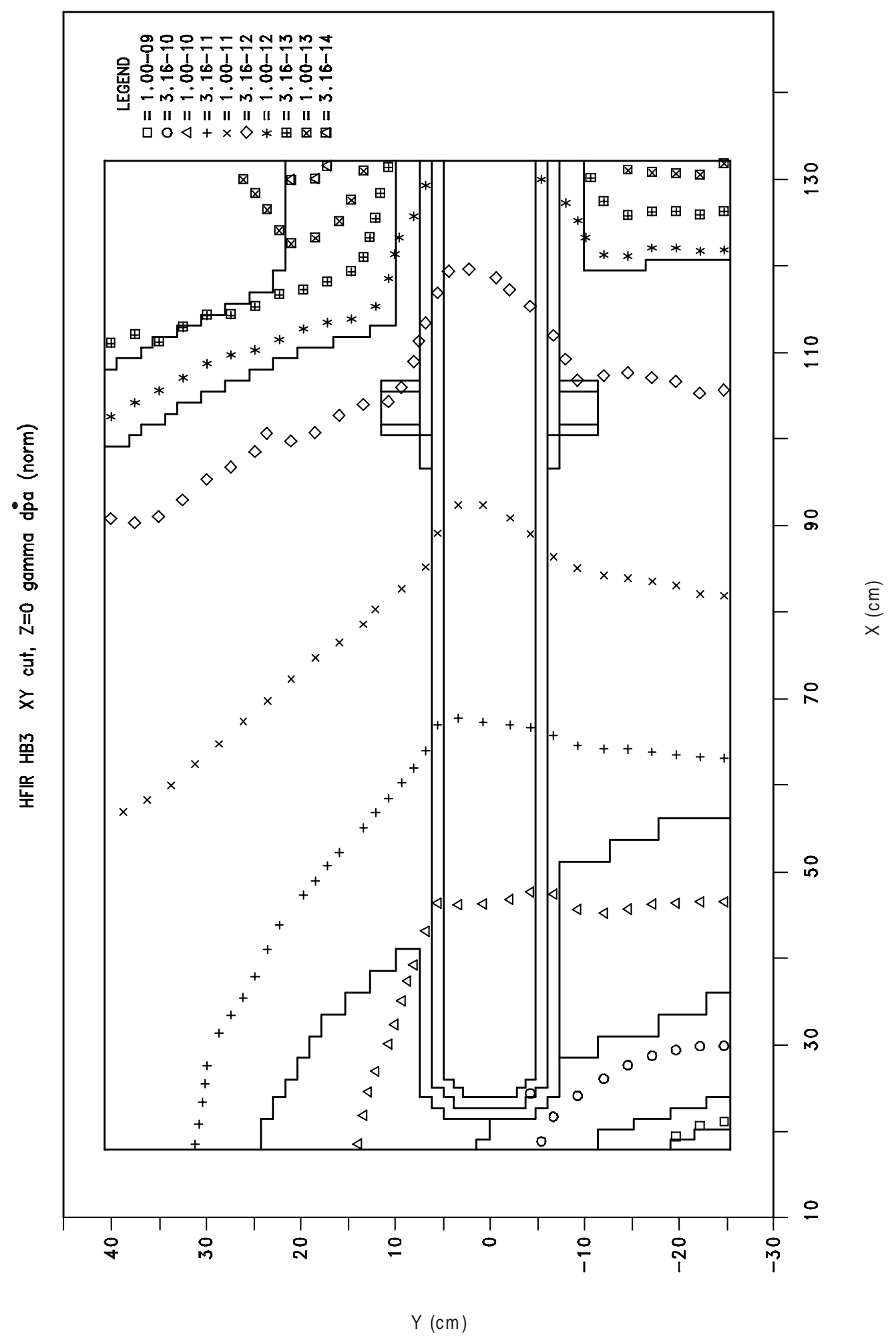

Figure 37. Gamma iso-dpa rate (displacements/atom/s) for HB-3 


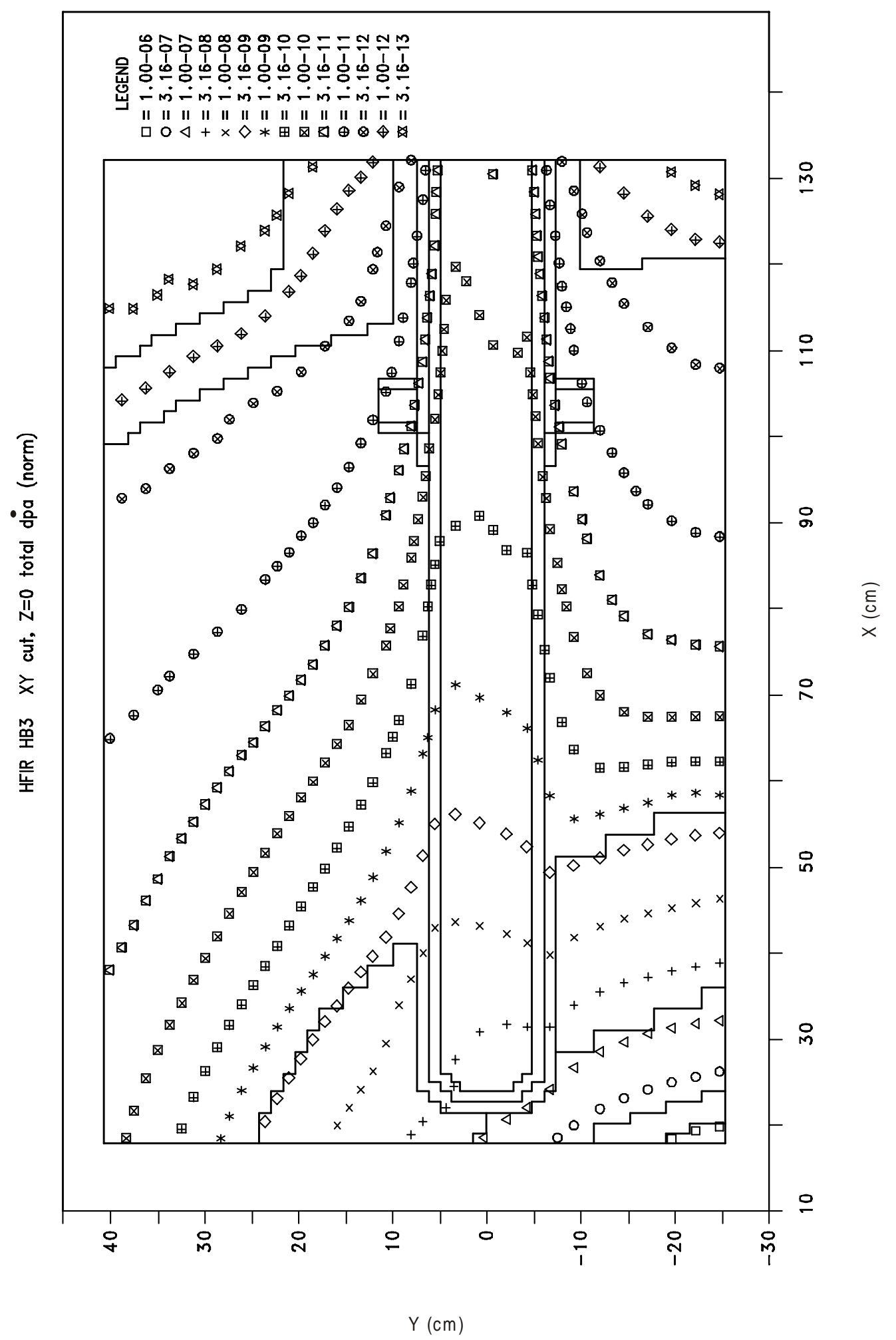

Figure 38. Total (neutron + gamma) iso-dpa rate (displacements/atom/s) for HB-3. 


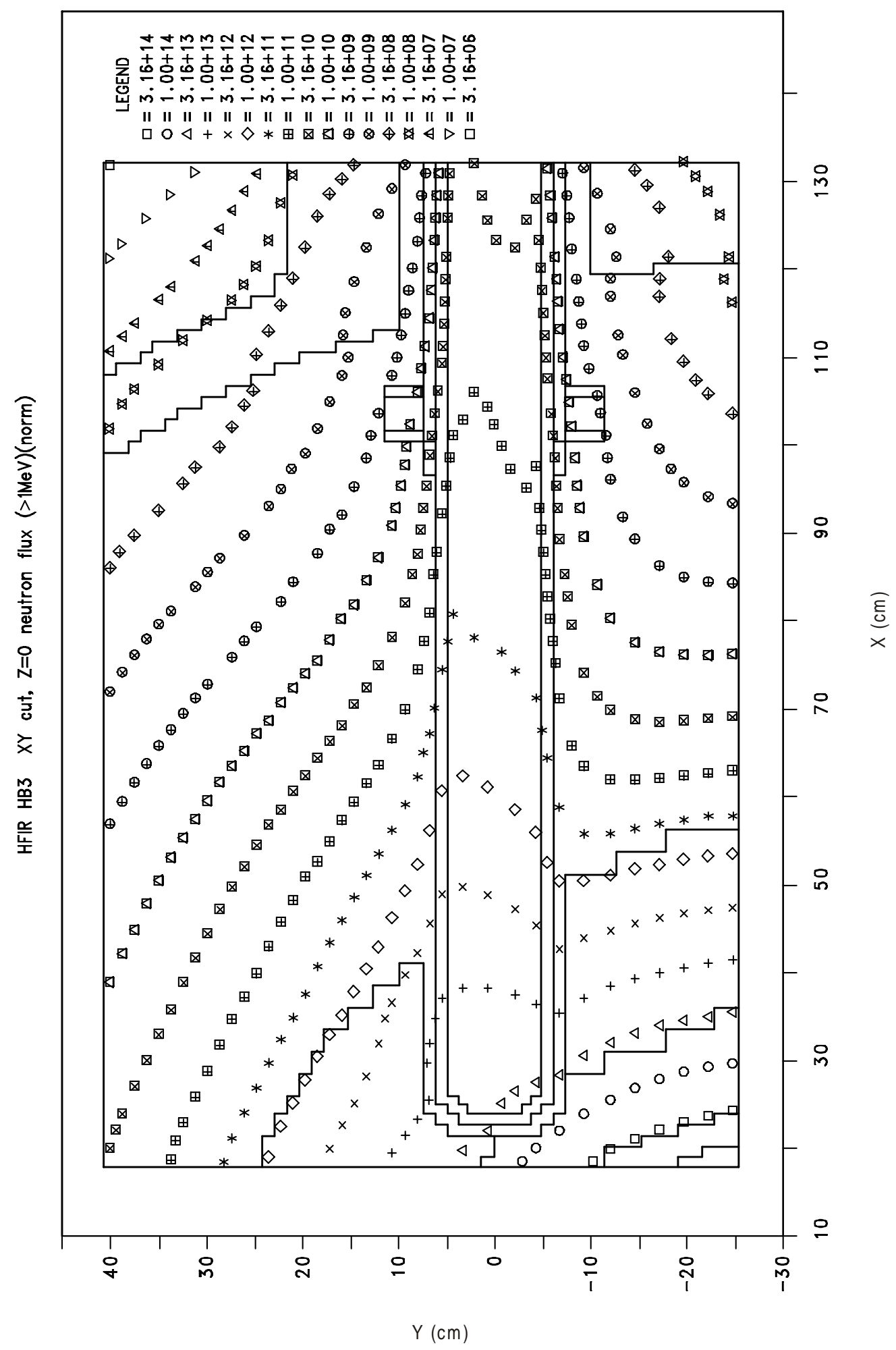

Figure 39. Neutron iso-flux (neutrons $\left./ \mathrm{cm}^{2} / \mathrm{s}\right)(\mathrm{E}>1 \mathrm{MeV})$ for $\mathrm{HB}-3$ 


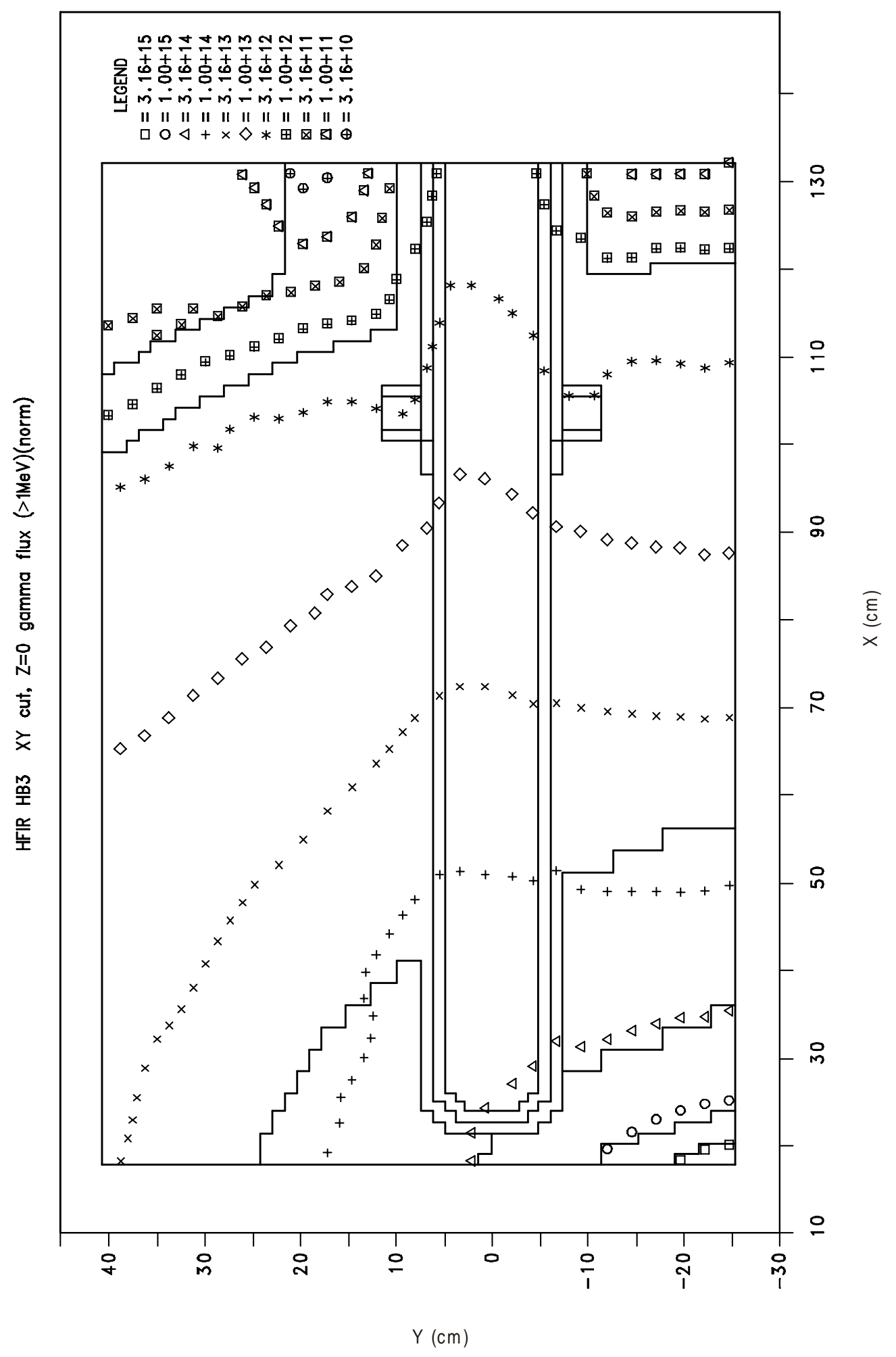

Figure 40. Gamma iso-flux (photons $\left./ \mathrm{cm}^{2} / \mathrm{s}\right)(\mathrm{E}>1 \mathrm{MeV})$ for HB-3. 



\section{DATA/CODE ARCHIVE}

Files for the discrete ordinates models have been archived at the HFIR facility and can be made available as necessary. In addition, code output, data files, and the software package have also been retained. Appendix D describes the archive directory and gives additional explanation for reproducing the results. 



\section{CONCLUSIONS}

This report has presented the results of calculations to obtain the fluxes and dpa rates used in recent life extension analyses for the HFIR vessel. These analyses were necessitated by proposed enlargements of beam tubes HB-2 and HB-4, which result in significantly increased radiation doses to the HFIR vessel, and by the motivation to develop state-of-the art calculational models for all of the HFIR beam tubes. Calculation models for each of the four beam tubes have been described (and are archived) and for each case iso-plots of dpa rates and neutron and gamma fluxes and selected tabulated results have been presented. Results have been shown to be consistent and have been normalized to the best dpa rate values available that were determined from measured dosimetry data. The primary purpose of this report is to provide detail and corroborating information supporting the radiation damage assessment reported in Reference 3. As a result, there is necessarily some duplication of information that was reported earlier in Reference 3. Sufficient details have been included to provide understanding and justification of the calculation approach used. 



\section{REFERENCES}

1. R. D. Cheverton, J. G. Merkle, and R. K. Nanstad, Evaluation of HFIR Pressure Vessel Integrity Considering Radiation Embrittlement, ORNL/TM-10444, Oak Ridge National Laboratory, April 1988.

2. I. Remec, J. A. Wang, F. B. K. Kam, and K. Farrell, "Effects of gamma-induced displacements on HFIR pressure vessel materials," J. of Nucl. Mater., 217, 258-268, 1994.

3. R. D. Cheverton, HFIR Vessel Life Extension with Enlarged HB-2 and HB-4 Beam Tubes, ORNL/TM-13698, Oak Ridge National Laboratory, December 1998.

4. R. L. Childs et al., "Neutron Dosimetry Analysis," from Evaluation of HFIR Pressure-Vessel Integrity Considering Radiation Embrittlement, Appendix E, ORNL/TM-10444, Oak Ridge National Laboratory, April 1988.

5. B. G. Carlson and G. I. Bell, "Solution of the Transport Equation by the $\mathrm{S}_{\mathrm{n}}$ Method," Proc. $Y$. N. Intern. Conf. Peaceful Uses At. Energy, 2" ${ }^{\text {nd }}$ Geneva P/2386, 1958.

6. B. G. Carlson and K. D. Lanthrop, Transport Theory - The Method of Discrete Ordinates, LA-3251-MS, Los Alamos National Laboratory, Rev. October 22, 1965.

7. DOORS3.1, RSICC Computer Code Collection, CCC-650, Radiation Safety Information Computational Center, Oak Ridge National Laboratory, 1996.

8. R. A. Lillie, "DTD: A Coupling Code for Two-Dimensional R-Z Cylindrical Geometries," presented at ANS Annual Meeting, Nashville, Tennessee, June 10-14, 1990.

9. C. Y. Fu and D. T. Ingersoll, VELM61 and VELM22: Multigroup Cross-Section Libraries for Sodium-Cooled Reactor Shield Analysis, ORNL/TM-10302, Oak Ridge National Laboratory, April 1987.

10. 1997 Annual Book of ASTM Standards, Sect. 12, Vol. 12.02, Nuclear (II), Solar, and Geothermal Energy, 1997.

11. N. P. Baumann, "Gamma-ray Induced Displacements in D2O Reactors," Proc. of the Seventh ASTM-EURATOM Symposium on Reactor Dosimetry," Strasbourg, France, August 27-31, 1990.

12. R. D. Cheverton and T. M. Sims, HFIR Core Nuclear Design, ORNL-4621, Oak Ridge National Laboratory, July 1971.

13. R. A. Lillie and J. C. Gehin, Oak Ridge National Laboratory, personal communication to E. D. Blakeman, Oak Ridge National Laboratory, April 1998. 
14. I. Remec, and F. B. Kam, Neutron Spectra at Different High Flux Isotope Reactor (HFIR) Pressure Vessel Surveillance Locations, NUREG/CR-6117, (ORNL/TM-12484), U.S. Nuclear Regulatory Commission, 1993. 


\section{APPENDIX A}

\section{QUALITY VERIFICATION}





\section{APPENDIX A}

\section{QUALITY VERIFICATION}

\section{A.1 General Remarks}

Models used in these calculations are based on the well established discrete ordinates methodology. The discrete ordinates codes, DORT and TORT, are current state-of-the art ORNL codes that have been used extensively on a world-wide basis for a vast number of applications. Although these codes have not been certified by quality assurance standards, they have been stringently tested and "fine-tuned" over a period of many years.

Validation of the specific models used in these calculations and the results obtained is based on the following considerations: 1) consistency between calculations at equivalent points, and 2) invariance of (or expected changes to) the models to changes in parameters. Crucial parameters for discrete ordinates models that can readily be examined in this case are mesh interval boundary spacing, and size of the beam tube model, the latter of which affects the location of the boundary source in this case. Other parameters that are of importance are the cross section set and group structure, Legendre expansion order, quadrature order, accuracy of model, and internal code convergence limits. It is not practical to vary every one of these quantities; in general, the user must rely on experience and advice to make the best initial selections of these latter quantities.

In these calculations, a reliable cross section set was selected and a sufficiently fine neutron and gamma group structure was selected. $\mathrm{A}_{3}$ Legendre expansion order was selected. Although some concern was raised that a higher order $\left(\mathrm{P}_{5}\right)$ was not used, an assessment determined that the $\mathrm{P}_{3}$ order was adequate. ${ }^{*}$ Worst case differences of $\sim 1 \%$ for neutron displacements per atom (dpa) and $\sim 2 \%$ for gamma dpa between $\mathrm{P}_{3}$ and $\mathrm{P}_{5}$ orders were calculated. Quadrature sets with sufficient angles to minimize ray effects were selected. As was discussed earlier, the quadrature was increased from $S_{10}$ to $S_{16}$ in the fixed source core calculation to investigate "lobes" that occurred due to ray effects from the $S_{10}$ quadrature. The new calculation was seen to reduced the lobes, but had a trivial effect on the results otherwise.

Because of the discretized geometrical mesh boundaries used, it is also not always practical within budgetary and/or run time limitations, or even possible to model complex systems with complete accuracy using the discrete ordinates approach. Curved surfaces modeled with a cartesian XYZ geometry always present a "staircase" effect, which cannot be made to exactly correspond to the actual configuration no matter how fine a mesh spacing is used. Again, experience and advice must prevail.

As a test of model consistency, each beam tube model should be compared with the fixed source core model at some point approximately the same in all models. Since the fixed source core

\footnotetext{
${ }^{*}$ Memorandum, E. D. Blakeman to J. R. Inger, $P_{5}$ Scattering Order Assessment in HFIR Beam Tube Calculations, October 3, 2000.
} 
model does not include beam tubes, this point should also be removed as far as possible from the beam tube in the beam tube models. A suitable point is at the surface of the inside vessel wall. As an approximation, the first midpoint of the first interval inside the vessel wall in each model is chosen. For the HB-2 RZ models, these points are chosen at the extreme right hand side of the plot (maximum radius) as far from the beam tube axis as possible on the model boundary. For the HB-4 (HB-1) and HB-3 XYZ models, these points should be at the maximum and minimum $\mathrm{Y}$ values along the model boundary at the surface of the vessel wall.

\section{A.2 Validation of Models}

\section{A.2.1 Validation of HB-2 Models}

As discussed above, a suitable point for comparison between the present and proposed HB-2 models and the fixed source core model is at the inside surface of the vessel wall (see Figure 4). For the two HB-2 models, these points are chosen at the maximum radius of the plot (extreme right hand side) as far from the beam tube axis as possible on the model boundary. They are each designated by a radius (-Y) and length (X) value measured along the beam tube radial and axial axes. Direct comparisons of dpa rate calculations without normalization are shown in Table A1. Results show a reasonable comparison; however, the beam tube results are consistently higher on the order of $\sim 40 \%$ (except for the neutron dpa for the enlarged tube design, which yields a factor of $\sim 2$ ). These results indicate that perturbations from the beamtube have not been entirely eliminated; that is, the model does not appear to be large enough such that the source is unaffected by the beam tube at the beam tube source boundary location for axial and radial extremes. This effect is somewhat more pronounced for the enlarged beam tube which would be expected to cause larger perturbation. In order to investigate the overall effects of this situation on the calculation of dpa rate at crucial points, i.e. the nozzle corner and weld, the model of the present 4 in. tube was increased by $7.62 \mathrm{~cm}(3 \mathrm{in}$.) in radius and the runs repeated. In this case, the difference between the core model and the beam tube at the inside vessel surface was reduced by $43 \%$ and $31 \%$ for the neutron and gamma dpa rates respectively, but the dpa rates at the nozzle corner and weld changed by a negligible amount $(<0.5 \%)$ for both neutrons and gammas. These results indicate that the original models are sufficient and that the differences that would be obtained by increasing the boundary dimensions in hopes of obtaining a completely unperturbed boundary flux are negligible at the main points of interest away from the source boundary region. The results also show that the results are not sensitive to perturbations in the boundary source on the radial perimeter of the model. It is clear that for the neutrons the dpa rate results primarily from neutrons that stream down the tube rather than from those that originate from the radial boundary. In the two-dimensional model used, the unavoidable curvature approximations of the Berylium reflector and the vessel wall would tend to produce error in the contribution from the source on the radial boundary. Since the results are evidently not sensitive to this error, the use of a two-dimensional approximation is supported.

A further concern with regard to model validity is the mesh spacing in either the axial or radial dimension. A mesh that is too coarse could obviously lead to incorrect results and/or poor convergence, while an overly fine mesh increases run times and computer storage requirements.

\footnotetext{
${ }^{*}$ The reader is referred to Section 5 for a thorough description of the coordinate system and separate plots for each beam tube. Several figures from Section 5 and 6 are referenced in this appendix.
} 
In order to test the selected mesh, the mesh spacing in the present HB-2 model was reduced in both dimensions by a factor of two, thus quadrupling the number of mesh cells. The original model contained 77 radial and 95 axial intervals (7,315 cells). Thus the fine mesh calculation contained 154 radial and 190 axial intervals (29,260 cells). In order to compare results from this calculation with those from the original model, it is necessary to average the results from four mesh cells from the finer mesh calculation for each mesh cell in the coarser calculation. Results indicate minimal differences. At the nozzle corner, for example, the worst case difference is $\sim 2 \%$ for the gamma dpa rate, while the neutron dpa rate differs by $\sim 0.5 \%$. The total dpa rate difference is $<1 \%$. Thus, it is concluded that the chosen mesh number and spacing is adequate for HB-2. Approximately the same mesh increments were used for the model for the new HB-2 design.

Table A1. Internal validation of HB-2 models by comparison of dpa rates calculated at approximately equivalent points near the reactor vessel inside surface

\begin{tabular}{|l|l|l|l|l|}
\hline Model & $\begin{array}{l}\text { Reactor Core Fixed } \\
\text { Source }\end{array}$ & $\begin{array}{l}\text { HB-2 Present 4 in. } \\
\text { Diameter }\end{array}$ & $\begin{array}{l}\text { HB-2 Proposed 9 in. } \\
\text { Diameter }\end{array}$ \\
\hline $\begin{array}{l}\text { Location(cm,cm) } \\
(\mathbf{R}, \mathbf{Z}) \text { or }(\mathbf{X}, \mathbf{Y})\end{array}$ & $\begin{array}{l}\mathrm{R}=120.0 \\
\mathrm{Z}=0\end{array}$ & $\begin{array}{l}\mathrm{X}=105.7 \\
-\mathrm{Y}=52.7\end{array}$ & $\begin{array}{c}\mathrm{X}=105.7 \\
-\mathrm{Y}=52.7\end{array}$ \\
\hline $\begin{array}{l}\text { dpa rate } \\
(\mathbf{d i s p} / \text { atom/s) }\end{array}$ & neutron & $8.38 \times 10^{-14}$ & $1.11 \times 10^{-13}(1.32)$ & $1.78 \times 10^{-13}(2.12)$ \\
\cline { 2 - 5 } & gamma & $9.40 \times 10^{-13}$ & $1.22 \times 10^{-12}(1.30)$ & $1.35 \times 10^{-12}(1.43)$ \\
\hline
\end{tabular}

Notes:

1)Values in parentheses show ratios to Reactor Core Fixed Source calculation values.

2) Locations depend on the selected model and are different for the fixed source and the beam tube models.

Refer to plots for orientation.

3) Locations are mesh cell midpoints.

Because HB-2 is aligned with the core radius vector, it is critical that an adequate angular quadrature be used to properly accommodate neutrons streaming along the tube axis. The quadrature set used is appropriate for this purpose. The set, shown in Figure A1 in DORT entry format, contains 147 angles, and is biased in the "upward" direction, i.e., there are 112 angles in the positive axial direction.

\section{A.2.2 Validation of HB-4 (HB-1) Models}

A similar internal validation of the HB-4 (HB-1) models (see Figures 8 and 9) was performed by comparing results at the inside vessel wall to results from the fixed source core model. In these cases midplane calculations on both sides of the beam tube at the maximum positive/negative values of Y (direction in reactor midplane perpendicular to the beam tube axis) at the surface of the vessel wall were used. Table A2 summarizes results. As for the HB-2 calculations, the 
neutron dpa rates for both beam-tube models at the maximum positive Y points ("shady" side) are notably higher than the core calculations. As before, this situation indicates that perturbations from the beam tube are still present at the boundaries. To further investigate this situation and validate the model that was used, the positive $\mathrm{Y}$ boundary was increased by $12.7 \mathrm{~cm}$ (5 in.)for the HB-4 proposed design case and the neutron dpa rate calculation repeated. Using the new enlarged model, the neutron dpa rate at the maximum positive $\mathrm{Y}$ value at the surface of the inside vessel wall is $\sim 2$ times the fixed source core model results, whereas in the original model the ratio is $\sim 3$. Thus, beam tube perturbations were reduced noticeably. However, results at the corner, annulus, and weld were found to be identical to those obtained earlier to within three significant digits. Thus, as in the case for HB-2, the expanded model reduced the perturbations from the beam-tube and improved the comparison with the fixed source core model at the boundary source location, but had negligible effect at the points of interest.

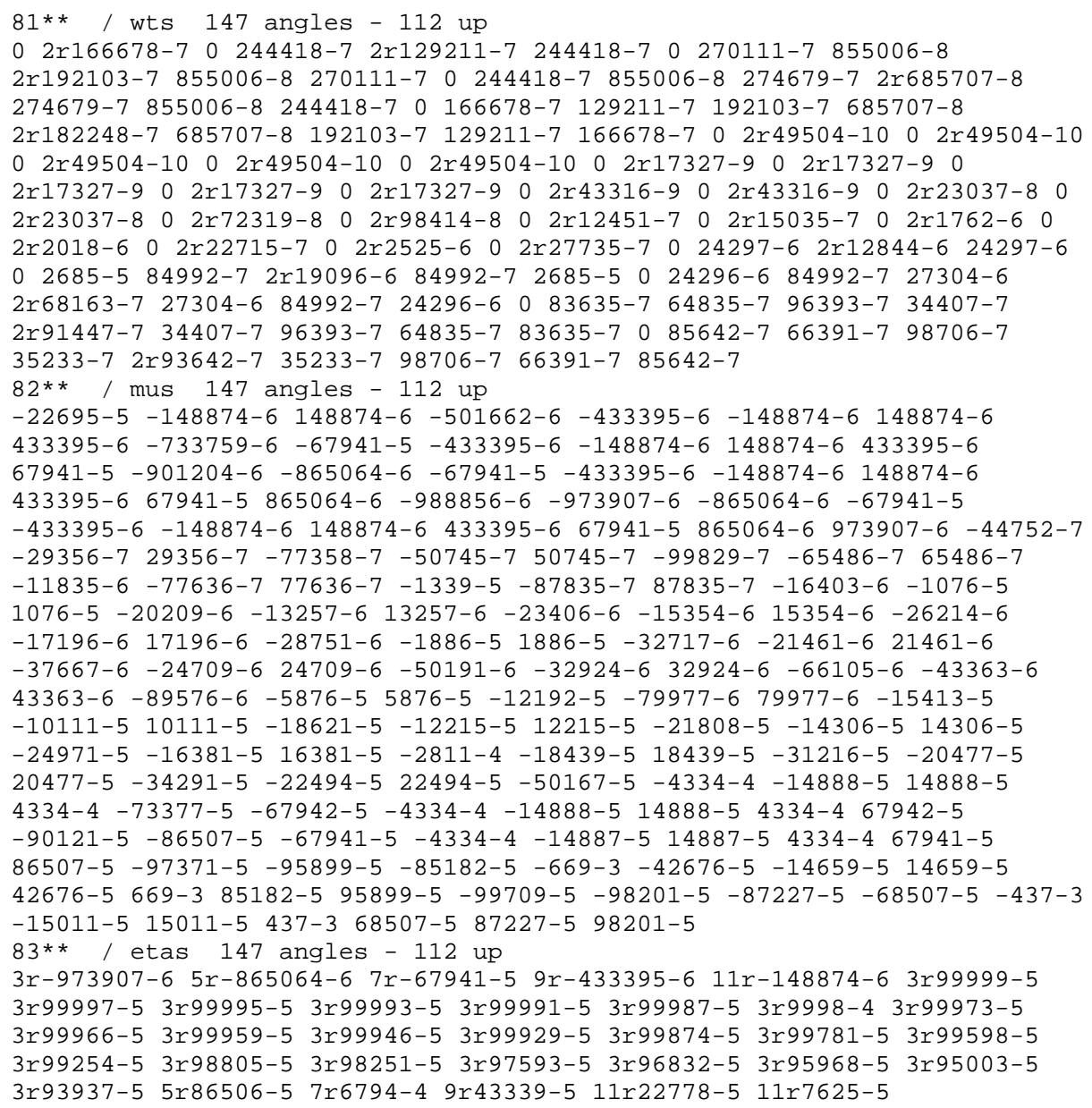

Figure A1. Upward biased 147 angle quadrature set 
Table A2. Internal validation of HB-4 (HB-1) models by comparison of dpa rates calculated at approximately equivalent points at the reactor vessel inside surface

\begin{tabular}{|c|c|c|c|c|c|c|}
\hline \multicolumn{2}{|l|}{ Model } & $\begin{array}{l}\text { Reactor } \\
\text { Core Fixed } \\
\text { Source }\end{array}$ & \multicolumn{2}{|c|}{$\begin{array}{l}\text { HB-4 (HB-1) Present } \\
\text { Design }\end{array}$} & \multicolumn{2}{|c|}{ HB-4 Proposed Design } \\
\hline \multicolumn{2}{|c|}{$\begin{array}{l}\text { Location: }(\mathbf{c m}, \mathrm{cm}) \\
(\mathrm{R}, \mathrm{Z}) \text { or }(\mathrm{X}, \mathrm{Y})\end{array}$} & $\begin{array}{l}\mathrm{R}=120.0 \\
\mathrm{Z}=0\end{array}$ & $\begin{array}{l}\text { "+ }{ }^{\prime} " \\
X=87.0 \\
Y=43.7\end{array}$ & $\begin{array}{l}\text { "- Y" } \\
X=120.6, \\
Y=-27.3\end{array}$ & $\begin{array}{l}"+Y " \\
X=87.0 \\
Y=42.5\end{array}$ & $\begin{array}{l}\text { "- Y" } \\
X=120.7 \\
Y=-27.3\end{array}$ \\
\hline \multirow{2}{*}{$\begin{array}{l}\text { dpa rate } \\
\text { (disp./ } \\
\text { atom/s) }\end{array}$} & neutron & $8.38 \times 10^{-14}$ & $\begin{array}{l}2.22 \times 10^{-13} \\
(2.65)\end{array}$ & $\begin{array}{l}9.56 \times 10^{-14} \\
(1.14)\end{array}$ & $\begin{array}{l}2.43 \times 10^{-13} \\
(2.90)\end{array}$ & $\begin{array}{l}9.56 \times 10^{-14} \\
(1.14)\end{array}$ \\
\hline & gamma & $9.40 \times 10^{-13}$ & $\begin{array}{l}1.61 \times 10^{-12} \\
(1.71)\end{array}$ & $\begin{array}{l}1.12 \times 10^{-12} \\
(1.19)\end{array}$ & $\begin{array}{l}1.69 \times 10^{-12} \\
(1.80)\end{array}$ & $\begin{array}{l}6.30 \times 10^{-13} \\
(0.67)\end{array}$ \\
\hline
\end{tabular}

Notes:

1) Values in parentheses show ratios to Reactor Core Fixed Source Calculation values.

2) $+Y$ and $-Y$ refer to locations at the reactor midplane at the vessel wall surface for maximum positive and negative. values of the $\mathrm{Y}$ coordinate, where the $\mathrm{Y}$ axis is perpendicular to the longitudinal axis $(\mathrm{X})$ of the beam tube.

3) Locations are mesh cell midpoints.

Because the core model was based on the DORT two-dimensional code and the HB-4 (HB-1) model on the TORT three-dimensional code, the above work supports the use of the two codes together to produce consistent results.

Sensitivity of the model to mesh spacing was also examined. A fine mesh model was developed in which the mesh intervals along the beam tube axis $(\mathrm{X})$ were reduced in spacing by a factor of 2 from the region between $17.8 \mathrm{~cm}$ and $99.1 \mathrm{~cm}$. This modification added 37 intervals to the model, increasing the number from 71 to 108 in the $\mathrm{X}$ dimension. Results were nearly identical to those with the original mesh. Figure A2 shows an iso-dpa rate plot of the total (neutron + gamma) dpa rate. A comparison with the same plot using the original mesh (Figure 33) shows the plots to be nearly identical. Scrutiny of the calculated values shows that the total dpa rate at the "shady side" ( $\mathrm{Y}>0$ ) weld is $\sim 2 \%$ higher and that at the shady side corner and annulus are $\sim 1 \%$ lower. Although the mesh was not varied in each dimension, it can be reasoned that because the mesh spacing is approximately the same in each dimension and the variation in the results is small when the mesh spacing in one dimension was drastically changed, the model has sufficiently fine mesh spacing. 


\section{A.2.3 Validation of HB-3 Model}

An internal comparison similar to that performed with the other beam tube models was also performed and is summarized in Table A3. Results are similar to those obtained for HB-4 (HB-1). That is, the neutron dpa rate values at the boundary are higher than the fixed source core values, especially for the positive $\mathrm{Y}$ location. Otherwise, there is reasonable agreement between the gamma dpa rate values. Because an increase in size of one of the HB-4 models had no effect at the points of interest, an enlarged model of HB-3 was not made and it was judged the present model is acceptable. Also because the mesh spacing in the HB-3 model is similar to that for HB-4 and the HB-4 model (new design) was shown to be insensitive to mesh spacing variation, the mesh spacing was not varied for HB-3.

Table A3. Internal validation of HB-3 model by comparison of dpa rates calculated at approximately equivalent points at the reactor vessel inside surface

\begin{tabular}{|c|c|c|c|c|}
\hline \multirow{2}{*}{\multicolumn{2}{|c|}{ Model }} & \multirow{2}{*}{$\begin{array}{l}\text { Reactor Core } \\
\text { Fixed Source }\end{array}$} & \multicolumn{2}{|c|}{ HB-3 Present Design } \\
\hline & & & “+Y” & "-Y" \\
\hline \multicolumn{2}{|c|}{$\begin{array}{l}\text { Location }(\mathbf{c m}, \mathbf{c m}) \\
(\mathbf{R}, \mathbf{Z}) \text { or }(\mathbf{X}, \mathbf{Y})\end{array}$} & $\begin{array}{l}\mathrm{R}=120.0 \\
\mathrm{Z}=0.0\end{array}$ & $\begin{aligned} X & =99.7 \\
Y & =40.0\end{aligned}$ & $\begin{array}{l}X=121.3 \\
Y=-24.8\end{array}$ \\
\hline \multirow[t]{2}{*}{$\begin{array}{l}\text { dpa rate } \\
\text { (disp./atom/s) }\end{array}$} & neutron & $8.38 \times 10^{-14}$ & $\begin{array}{l}2.32 \times 10^{-13} \\
(2.77)\end{array}$ & $\begin{array}{l}2.00 \times 10^{-13} \\
(2.38)\end{array}$ \\
\hline & gamma & $9.40 \times 10^{-13}$ & $\begin{array}{l}1.30 \times 10^{-12} \\
(1.38)\end{array}$ & $\begin{array}{l}8.35 \times 10^{-13} \\
(0.89)\end{array}$ \\
\hline
\end{tabular}

Notes:

1.Values in parentheses show ratios to Reactor Core Fixed Source calculation values.

2. Ymax and Ymin refer to locations at the reactor midplane at the vessel wall surface for maximum/minimum. values of the $\mathrm{Y}$ coordinate, where the $\mathrm{Y}$ axis is perpendicular to the longitudinal axis $(\mathrm{X})$ of the beam tube.

Ymax/Ymin are on opposite sides of the beam tube at the midplane location. 


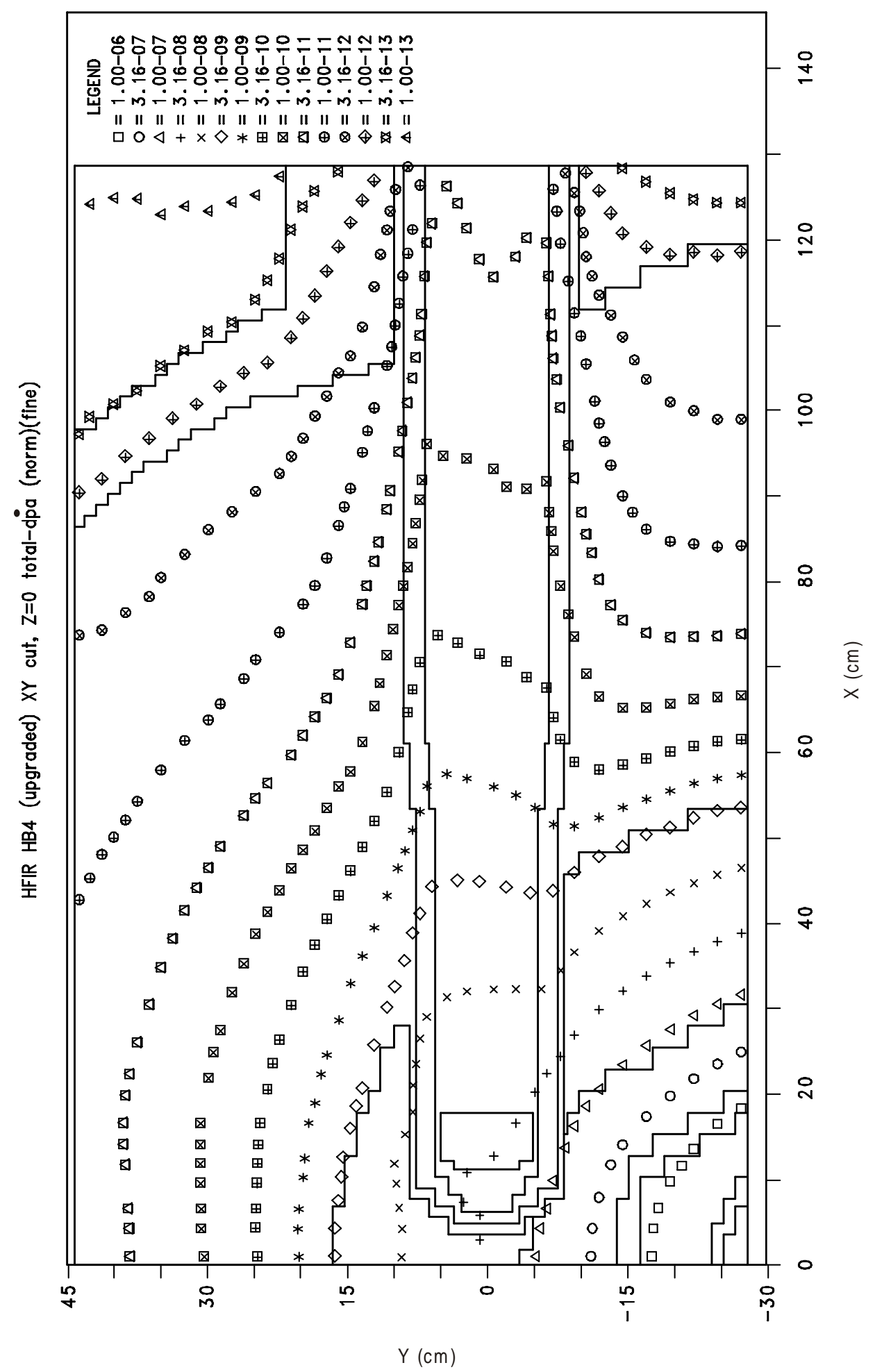

Figure A2. Total (neutron + gamma) iso-dpa rate (displacements/atom/s) for HB-4 (new design) with fine mesh on beam tube $(X)$ axis 



\section{APPENDIX B}

\section{CALCULATIONS USING BOC CONTROL PLATE POSITIONS}





\section{APPENDIX B}

\section{CALCULATIONS USING BOC CONTROL PLATE POSITIONS}

Calculations for this analysis were performed with end-of-cycle (EOC) reactor control plate positions (fully withdrawn) in the belief that this would provide the most conservative, i.e. largest flux and dpa rates at the points of interest, approach. For convenience, the beginning-ofcycle (BOC) fuel conditions were used since this avoids the use of burnup calculations and the inclusion of fission products and their cross sections. Some concern was raised during the analysis about the efficacy of this approach, since the control plates are not consistent with the fuel configuration and the configuration of the reactor changes considerably with changes in control plate positions. Therefore, some additional calculations were performed to address the sensitivity of the overall analysis to the control plate position.

Figure B1 shows an iso-plot of the total dpa rate for the fixed source case with the control plates inserted to the BOC position. The source for this calculation is normalized to the same value as in the EOC position case since the power level is assumed to be the same. A comparison with the EOC calculation (Figure 13) ${ }^{*}$ shows that the total dpa rate in the reactor midplane is nearly the same for the two cases, but becomes less for the BOC position case as the vertical distance from the midplane increases. Because the beam tubes are located in the vertical midplane, however, it is reasonable to expect that large differences would not be expected for beam tube calculations based on either EOC or BOC control plate condition cases..

To assess the quantitative effect of control plate position on the beam tube dpa rates, calculations were repeated for the $4 \mathrm{in}$. and $9 \mathrm{in}$. diameter HB-2 models using boundary sources based on the fixed source calculation with the control plates at the BOC position as discussed above. Figures B2 and B3 show the total iso-dpa plots for the two cases. For consistency, the values in the BOC plots have been normalized to the same values calculated earlier for the EOC control position case. Comparison of the new BOC plots with the original plots (Figures 18 and 23) shows there to be little difference between the EOC and BOC control position cases. Table B1 shows dpa rate data for specific locations. This data too is all normalized to the original normalization values determined previously ( 0.638 for neutron dpa and 1.76 for gamma dpa). As would be expected, the dpa rates for the BOC position cases are somewhat lower than those for the EOC postion cases. Values shown in [] indicate renormalized values that would be obtained if only the BOC position cases had been used at the outset. (In this case the normalization factors would be 0.659 and 2.123 for neutron and gamma dpa respectively.) It is seen that the renormalized BOC position values are almost identical to the original values for the present HB-2 design model and differ only very slightly $(\sim 2 \%)$ for the proposed new HB-2 design model. These results indicate that the results would have been approximately the same regardless of the control configuration used.

Because of the small differences seen with HB-2, similar model comparisons were not performed with HB-1,3,4.

\footnotetext{
${ }^{*}$ Figures from Section 6 are referenced in this appendix for comparison purposes.
} 
HFIR fs 84gp 100MW (unnorm BOC) total $n+g$ dpa

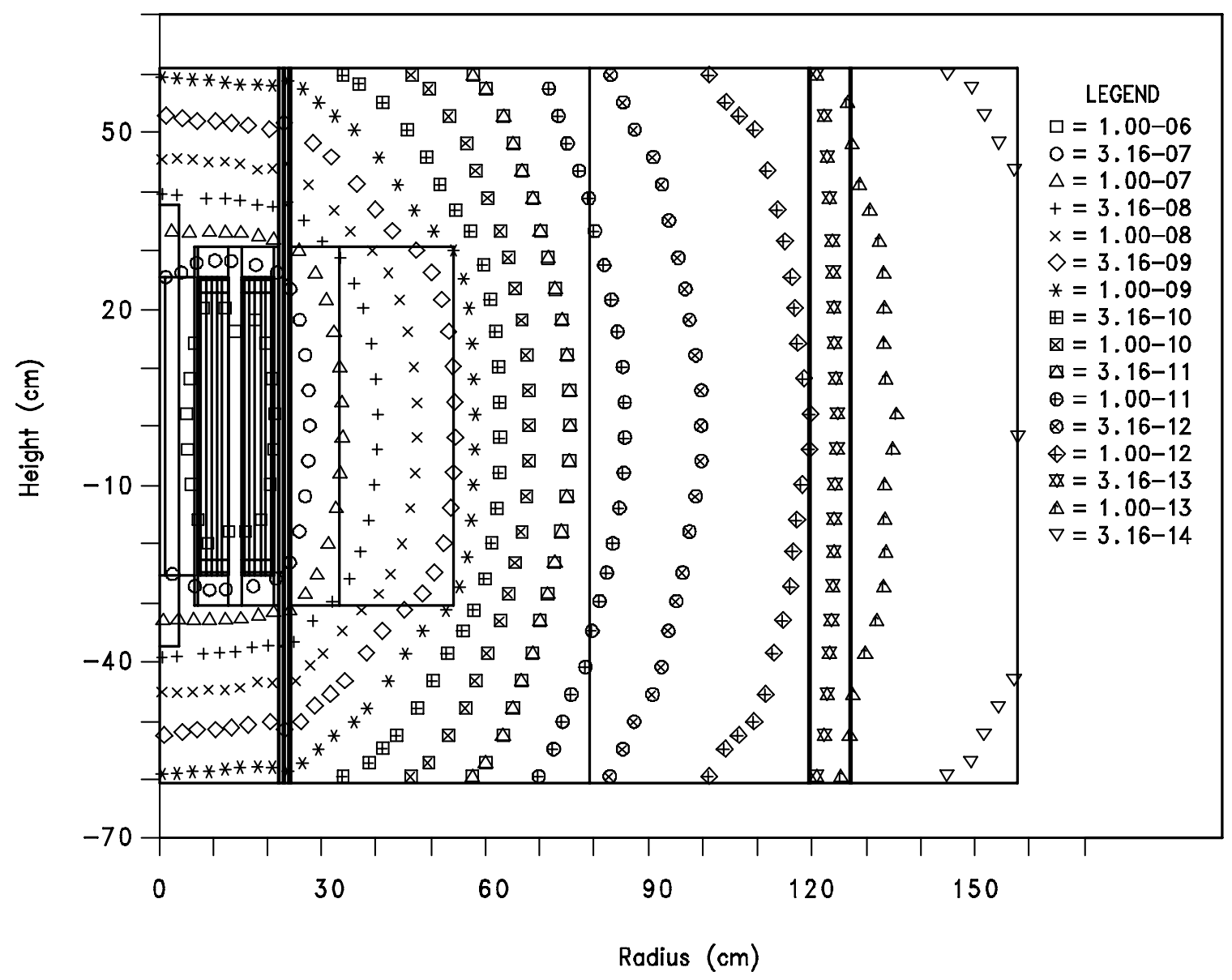

Figure B1. Total (neutron + gamma) iso-dpa rate (displacements/atom/s) for HFIR core fixed source model with BOC rod position. 
HFIR HB2 present (4 in.) $100 \mathrm{MW} 84 \mathrm{gp}$, total-dpa (norm)(BOC)

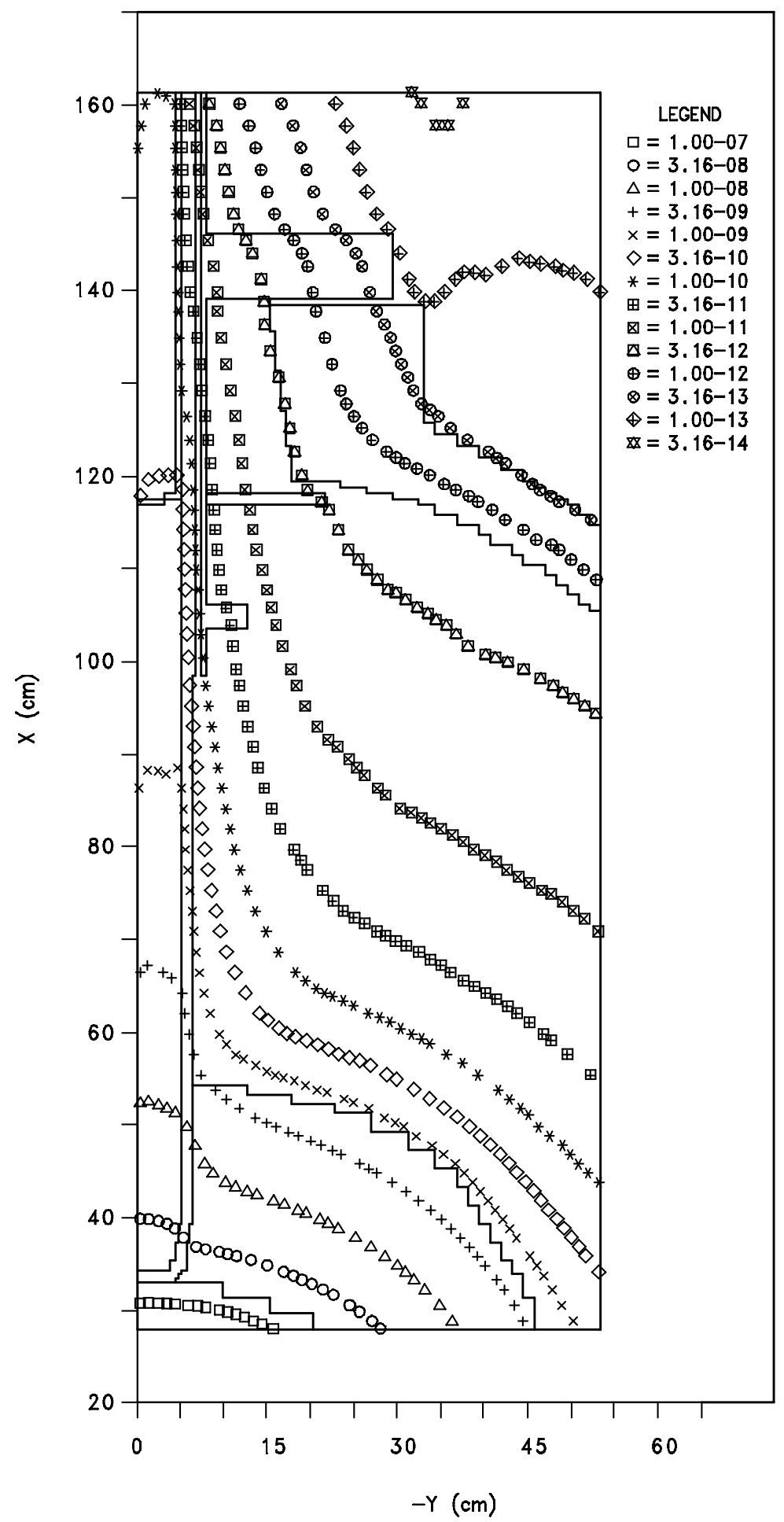

Figure B2. Total iso-dpa rate (displacements/atom/s) for HB-2 (present design) for BOC control plate positions 
HFIR HB2 upgraded (9 in.), $100 \mathrm{MW} 84 \mathrm{gp}$, tot.-dpa (norm)(BOC)

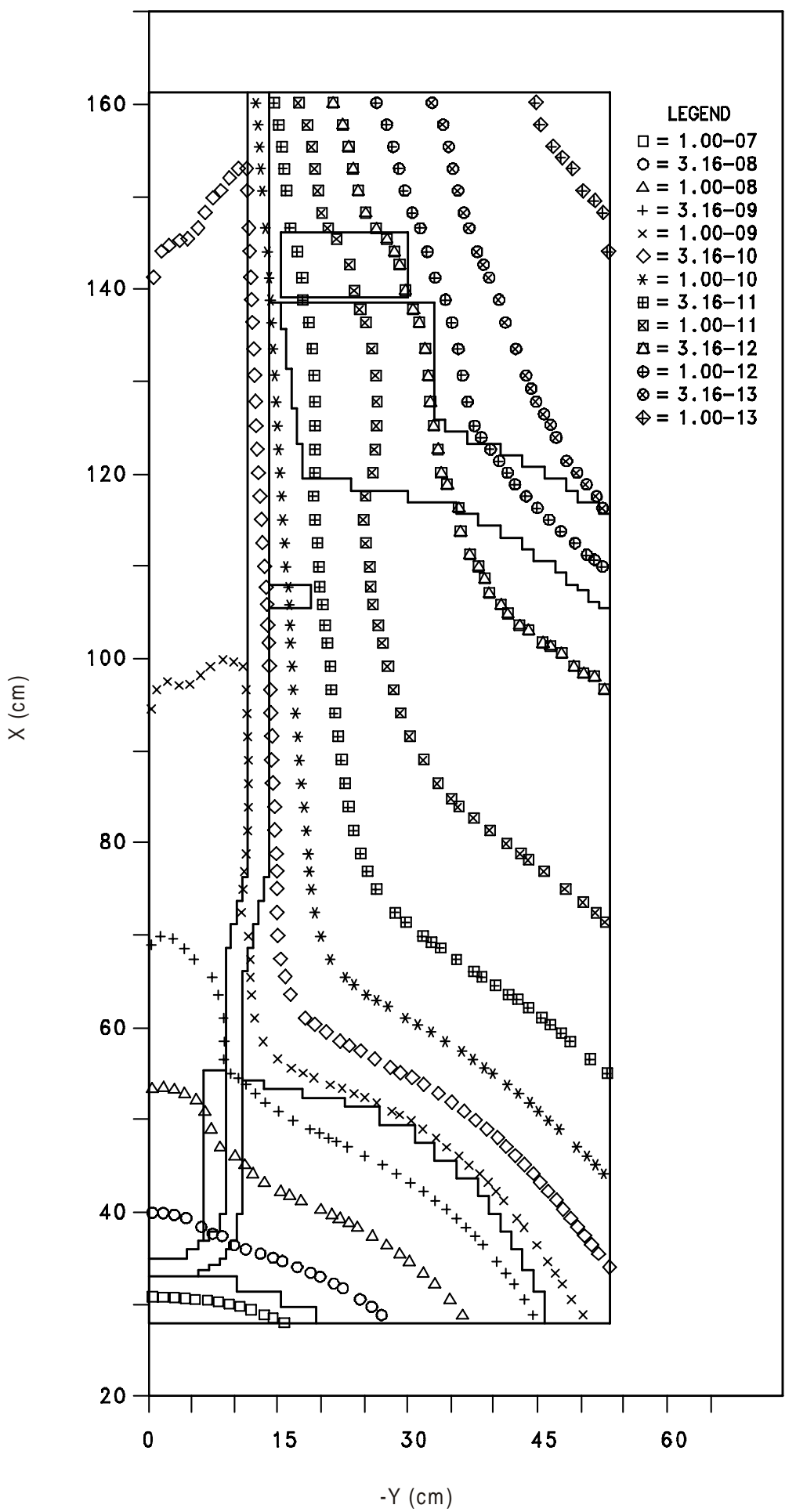

Figure B3. Total (neutron + gamma) iso-dpa rate (displacements/atom/s) for HB-2 (new design) for $\mathrm{BOC}$ control plate positions 
Table B1. Comparison of HB-2 models for BOC and EOC control plate positions

\begin{tabular}{|c|c|c|c|c|c|c|c|}
\hline \multirow[t]{3}{*}{ Design } & \multirow[t]{3}{*}{ Location } & \multicolumn{6}{|c|}{ dpa rate $\times 10^{-12}$ (displacements/atom/s) } \\
\hline & & \multicolumn{2}{|c|}{ Neutron } & \multicolumn{2}{|c|}{ Gamma } & \multicolumn{2}{|c|}{$\begin{array}{l}\text { Total (neutron + } \\
\text { gamma) }\end{array}$} \\
\hline & & BOC & EOC & BOC & EOC & BOC & EOC \\
\hline \multirow[t]{3}{*}{ Present } & $\begin{array}{l}\text { Key } 2 \\
\text { Dosimetry }\end{array}$ & $\begin{array}{l}2.15 \\
{[2.22]^{*}}\end{array}$ & 2.22 & $\begin{array}{l}2.11 \\
{[2.54]}\end{array}$ & 2.54 & $\begin{array}{l}4.26 \\
{[4.77]}\end{array}$ & 4.77 \\
\hline & $\begin{array}{l}\text { Nozzle } \\
\text { Corner }\end{array}$ & $\begin{array}{l}1.86 \\
{[1.92]}\end{array}$ & 1.92 & $\begin{array}{l}1.64 \\
{[1.98]}\end{array}$ & 1.98 & $\begin{array}{l}3.50 \\
{[3.90]}\end{array}$ & 3.90 \\
\hline & $\begin{array}{l}\text { Nozzle } \\
\text { Weld }\end{array}$ & $\begin{array}{l}0.218 \\
{[0.225]}\end{array}$ & 0.215 & $\begin{array}{l}1.59 \\
{[1.92]}\end{array}$ & 1.93 & $\begin{array}{l}1.80 \\
{[2.15]}\end{array}$ & 2.15 \\
\hline \multirow[t]{2}{*}{ New } & $\begin{array}{l}\text { Nozzle } \\
\text { Corner }\end{array}$ & $\begin{array}{l}32.6 \\
{[33.7]}\end{array}$ & 34.6 & $\begin{array}{l}5.35 \\
{[6.45]}\end{array}$ & 6.55 & $\begin{array}{l}37.9 \\
{[40.2]}\end{array}$ & 41.1 \\
\hline & $\begin{array}{l}\text { Nozzle } \\
\text { Weld }\end{array}$ & $\begin{array}{l}2.16 \\
{[2.23]}\end{array}$ & 2.25 & $\begin{array}{l}1.89 \\
{[2.28]}\end{array}$ & 2.33 & $\begin{array}{l}4.05 \\
{[4.51]}\end{array}$ & 4.58 \\
\hline
\end{tabular}

* Renormalized values for BOC. 



\section{APPENDIX C}

\section{MATERIAL COMPOSITION ATOMIC DENSITIES FOR HFIR MODELS}





\section{APPENDIX C}

\section{MATERIAL COMPOSITION ATOMIC DENSITIES FOR HFIR MODELS}

Table $\mathrm{C} 1$ tabulates the atomic densities for the material mixtures used for the models discussed in this report. Fuel, structural, and water mixtures are given.

Table C1. Atomic Densities for HFIR Model Mixtures

\begin{tabular}{|c|c|c|c|c|c|}
\hline \multirow[b]{3}{*}{$\begin{array}{l}\text { Element/ } \\
\text { Isotope }\end{array}$} & \multicolumn{5}{|c|}{ HFIR Number Densities (atoms/b.cm) } \\
\hline & \multicolumn{5}{|c|}{ Materials } \\
\hline & Water Pool & $\begin{array}{l}\text { Aluminum/ } \\
\text { water }\end{array}$ & $\begin{array}{c}\text { Side plates \& } \\
\text { water - } \\
\text { around fuel }\end{array}$ & $\begin{array}{c}\text { Side plates \& } \\
\text { water - } \\
\text { between fuel }\end{array}$ & $\begin{array}{c}\text { Side plates \& } \\
\text { water - } \\
\text { outside target }\end{array}$ \\
\hline $\mathbf{H}$ & $6.53753 \mathrm{E}-02$ & 3.26876E-02 & $1.07400 \mathrm{E}-02$ & $2.75000 \mathrm{E}-02$ & 3.97136E-02 \\
\hline \multicolumn{6}{|l|}{$\mathrm{Be}$} \\
\hline \multicolumn{6}{|l|}{${ }^{10} \mathbf{B}$} \\
\hline \multicolumn{6}{|l|}{${ }^{11} \mathbf{B}$} \\
\hline \multicolumn{6}{|l|}{ C } \\
\hline $\mathbf{O}$ & 3.26876E-02 & $1.63438 \mathrm{E}-02$ & $5.37000 \mathrm{E}-03$ & $1.37500 \mathrm{E}-02$ & $1.98568 \mathrm{E}-02$ \\
\hline Mg & & & 4.41062E-04 & $3.24732 \mathrm{E}-04$ & $2.10091 \mathrm{E}-04$ \\
\hline Al & & 3.01125E-02 & 4.80000E-02 & $3.53400 \mathrm{E}-02$ & $2.28639 \mathrm{E}-02$ \\
\hline $\mathbf{S i}$ & & & $1.90843 \mathrm{E}-04$ & $1.40508 \mathrm{E}-04$ & $9.09042 \mathrm{E}-05$ \\
\hline $\mathbf{T i}$ & & & $4.19625 \mathrm{E}-05$ & $3.08949 \mathrm{E}-05$ & $1.99880 \mathrm{E}-05$ \\
\hline $\mathrm{Cr}$ & & & $9.01992 \mathrm{E}-05$ & $6.64092 \mathrm{E}-05$ & 4.29647E-05 \\
\hline Mn & & & 3.65867E-05 & 2.69371E-05 & $1.74274 \mathrm{E}-05$ \\
\hline $\mathbf{F e}$ & & & $1.67959 \mathrm{E}-04$ & $1.23660 \mathrm{E}-04$ & $8.00041 \mathrm{E}-05$ \\
\hline \multicolumn{6}{|l|}{$\mathbf{N i}$} \\
\hline $\mathrm{Cu}$ & & & 8.43483E-05 & $6.21015 \mathrm{E}-05$ & 4.01777E-05 \\
\hline \multicolumn{6}{|l|}{${ }^{181} \mathrm{Ta}$} \\
\hline \multicolumn{6}{|l|}{${ }^{234} \mathbf{U}$} \\
\hline \multicolumn{6}{|l|}{${ }^{235} \mathbf{U}$} \\
\hline \multicolumn{6}{|l|}{${ }^{236} \mathbf{U}$} \\
\hline${ }^{238} \mathrm{U}$ & & & & & \\
\hline
\end{tabular}


Table C1. (continued)

\begin{tabular}{|c|c|c|c|c|c|}
\hline \multirow{2}{*}{$\begin{array}{c}\text { Element/ } \\
\text { Isotope }\end{array}$} & $\begin{array}{c}\text { Side plates \& } \\
\text { water - inside } \\
\text { target }\end{array}$ & $\begin{array}{c}\text { Target } \\
\text { extension }\end{array}$ & $\begin{array}{c}\text { Removal } \\
\text { beryllium }\end{array}$ & $\begin{array}{c}\text { Permanent } \\
\text { beryllium }\end{array}$ & $\begin{array}{c}\text { Side plates \& } \\
\text { water -control } \\
\text { areas }\end{array}$ \\
\hline $\mathbf{H}$ & $3.97136 \mathrm{E}-02$ & $3.83500 \mathrm{E}-02$ & $3.28000 \mathrm{E}-03$ & $9.94000 \mathrm{E}-04$ & $3.14070 \mathrm{E}-03$ \\
\hline $\mathbf{B e}$ & & & $1.17000 \mathrm{E}-01$ & $1.20800 \mathrm{E}-01$ & \\
\hline${ }^{\mathbf{1 0}} \mathbf{B}$ & & & & & \\
\hline${ }^{\mathbf{1}} \mathbf{B}$ & & & & & \\
\hline $\mathbf{C}$ & & & & & \\
\hline $\mathbf{O}$ & $1.98568 \mathrm{E}-02$ & $1.92000 \mathrm{E}-02$ & $1.64000 \mathrm{E}-03$ & $4.97000 \mathrm{E}-04$ & $1.57030 \mathrm{E}-03$ \\
\hline $\mathbf{M g}$ & $1.38719 \mathrm{E}-04$ & & & & \\
\hline $\mathbf{A l}$ & $1.50965 \mathrm{E}-02$ & $2.36000 \mathrm{E}-02$ & $5.52000 \mathrm{E}-04$ & $5.60000 \mathrm{E}-04$ & $5.74010 \mathrm{E}-02$ \\
\hline $\mathbf{S i}$ & $6.00220 \mathrm{E}-05$ & & & & \\
\hline $\mathbf{T i}$ & $1.31976 \mathrm{E}-05$ & & & & \\
\hline $\mathbf{C r}$ & $2.83686 \mathrm{E}-05$ & & & & \\
\hline $\mathbf{M n}$ & $1.15069 \mathrm{E}-05$ & & & & \\
\hline $\mathbf{F e}$ & $5.28249 \mathrm{E}-05$ & & & & \\
\hline $\mathbf{N i}$ & & & & & \\
\hline $\mathbf{C u}$ & $2.65284 \mathrm{E}-05$ & & & & \\
\hline${ }^{\mathbf{1 8 1}} \mathbf{T a}$ & & & & & \\
\hline${ }^{\mathbf{2 3 4}} \mathbf{U}$ & & & & & \\
\hline${ }^{\mathbf{2 3 5}} \mathbf{U}$ & & & & & \\
\hline${ }^{\mathbf{2 3 6}} \mathbf{U}$ & & & & & \\
\hline${ }^{\mathbf{2 3 8}} \mathbf{U}$ & & & & & \\
\hline
\end{tabular}


Table C1. (continued)

\begin{tabular}{|c|c|c|c|c|c|}
\hline & \multicolumn{5}{|c|}{ HFIR Number Densities (atoms/b.cm) } \\
\hline & \multicolumn{5}{|c|}{ Materials } \\
\hline $\begin{array}{c}\text { Element/ } \\
\text { Isotope }\end{array}$ & $\begin{array}{c}\text { Tantalum } \\
\text { control }\end{array}$ & $\begin{array}{l}\text { Inner fuel } \\
\text { zone } 51 \text { - } \\
\text { midplane }\end{array}$ & $\begin{array}{l}\text { Inner fuel } \\
\text { zone } 52 \text { - } \\
\text { midplane }\end{array}$ & $\begin{array}{l}\text { Inner fuel } \\
\text { zone } 53 \text { - } \\
\text { midplane }\end{array}$ & $\begin{array}{l}\text { Inner fuel } \\
\text { zone } 54 \text { - } \\
\text { midplane }\end{array}$ \\
\hline H & $2.77000 \mathrm{E}-03$ & $3.26876 \mathrm{E}-02$ & $3.26876 \mathrm{E}-02$ & $3.26876 \mathrm{E}-02$ & $3.26876 \mathrm{E}-02$ \\
\hline \multicolumn{6}{|l|}{ Be } \\
\hline${ }^{10} \mathbf{B}$ & & 2.15244E-05 & $2.01781 \mathrm{E}-05$ & $1.56525 \mathrm{E}-05$ & $1.01038 \mathrm{E}-05$ \\
\hline${ }^{11} \mathbf{B}$ & & $8.71738 \mathrm{E}-05$ & $8.17215 \mathrm{E}-05$ & $6.33926 \mathrm{E}-05$ & 4.09204E-05 \\
\hline C & & $2.71745 \mathrm{E}-05$ & $2.54749 \mathrm{E}-05$ & $1.97613 \mathrm{E}-05$ & $1.27561 \mathrm{E}-05$ \\
\hline $\mathbf{O}$ & $1.38500 \mathrm{E}-03$ & $1.68740 \mathrm{E}-02$ & $1.69403 \mathrm{E}-02$ & $1.71631 \mathrm{E}-02$ & $1.74363 \mathrm{E}-02$ \\
\hline Mg & & $2.39816 \mathrm{E}-04$ & $2.41743 \mathrm{E}-04$ & $2.48221 \mathrm{E}-04$ & $2.56163 \mathrm{E}-04$ \\
\hline Al & 4.17246E-21 & $2.60988 \mathrm{E}-02$ & $2.63085 \mathrm{E}-02$ & 2.70134E-02 & $2.78778 \mathrm{E}-02$ \\
\hline $\mathrm{Si}$ & & $1.03766 \mathrm{E}-04$ & $1.04600 \mathrm{E}-04$ & $1.07402 \mathrm{E}-04$ & $1.10839 \mathrm{E}-04$ \\
\hline $\mathbf{T i}$ & & $2.28160 \mathrm{E}-05$ & $2.29993 \mathrm{E}-05$ & $2.36156 \mathrm{E}-05$ & $2.43713 \mathrm{E}-05$ \\
\hline $\mathrm{Cr}$ & & $4.90435 \mathrm{E}-05$ & $4.94375 \mathrm{E}-05$ & $5.07623 \mathrm{E}-05$ & $5.23866 \mathrm{E}-05$ \\
\hline Mn & & $1.98931 \mathrm{E}-05$ & $2.00529 \mathrm{E}-05$ & 2.05903E-05 & $2.12491 \mathrm{E}-05$ \\
\hline $\mathrm{Fe}$ & & $9.13234 \mathrm{E}-05$ & $9.20572 \mathrm{E}-05$ & $9.45241 \mathrm{E}-05$ & $9.75487 \mathrm{E}-05$ \\
\hline \multicolumn{6}{|l|}{$\mathrm{Ni}$} \\
\hline $\mathrm{Cu}$ & & 4.58644E-05 & $4.62329 \mathrm{E}-05$ & $4.74718 \mathrm{E}-05$ & $4.89908 \mathrm{E}-05$ \\
\hline${ }^{181} \mathrm{Ta}$ & $1.45550 \mathrm{E}-02$ & & & & \\
\hline${ }^{234} \mathbf{U}$ & & $1.98304 \mathrm{E}-06$ & $2.23093 \mathrm{E}-06$ & $3.06425 \mathrm{E}-06$ & $4.08595 \mathrm{E}-06$ \\
\hline${ }^{235} \mathbf{U}$ & & $1.85331 \mathrm{E}-04$ & $2.08498 \mathrm{E}-04$ & $2.86378 \mathrm{E}-04$ & 3.81864E-04 \\
\hline${ }^{236} \mathbf{U}$ & & $7.95070 \mathrm{E}-07$ & 8.94457E-07 & $1.22856 \mathrm{E}-06$ & $1.63820 \mathrm{E}-06$ \\
\hline${ }^{238} \mathbf{U}$ & & $1.07307 \mathrm{E}-05$ & $1.20720 \mathrm{E}-05$ & $1.65813 \mathrm{E}-05$ & 2.21099E-05 \\
\hline
\end{tabular}


Table C1. (contintued)

\begin{tabular}{|c|c|c|c|c|c|}
\hline \multirow{2}{*}{$\begin{array}{c}\text { Element/ } \\
\text { Isotope }\end{array}$} & $\begin{array}{c}\text { Inner fuel } \\
\text { zone 55 - } \\
\text { midplane }\end{array}$ & $\begin{array}{c}\text { Inner fuel } \\
\text { zone 56 - } \\
\text { midplane }\end{array}$ & $\begin{array}{c}\text { Inner fuel } \\
\text { zone 57 - } \\
\text { midplane }\end{array}$ & $\begin{array}{c}\text { Inner fuel } \\
\text { zone 58 - } \\
\text { midplane }\end{array}$ & $\begin{array}{c}\text { Inner fuel } \\
\text { zone 59 - } \\
\text { midplane }\end{array}$ \\
\cline { 2 - 6 } $\mathbf{H}$ & $3.26876 \mathrm{E}-02$ & $3.26876 \mathrm{E}-02$ & $3.26876 \mathrm{E}-02$ & $3.26876 \mathrm{E}-02$ & $3.26876 \mathrm{E}-02$ \\
\hline $\mathbf{B e}$ & & & & & \\
\hline${ }^{\mathbf{1 0}} \mathbf{B}$ & $6.56156 \mathrm{E}-06$ & $5.91348 \mathrm{E}-06$ & $9.05531 \mathrm{E}-06$ & $1.23965 \mathrm{E}-05$ & $1.28733 \mathrm{E}-05$ \\
\hline${ }^{\mathbf{1 1}} \mathbf{B}$ & $2.65743 \mathrm{E}-05$ & $2.39496 \mathrm{E}-05$ & $3.66740 \mathrm{E}-05$ & $5.02056 \mathrm{E}-05$ & $5.21369 \mathrm{E}-05$ \\
\hline $\mathbf{C}$ & $8.28397 \mathrm{E}-06$ & $7.46577 \mathrm{E}-06$ & $1.14323 \mathrm{E}-05$ & $1.56505 \mathrm{E}-05$ & $1.62526 \mathrm{E}-05$ \\
\hline $\mathbf{O}$ & $1.76107 \mathrm{E}-02$ & $1.76426 \mathrm{E}-02$ & $1.74880 \mathrm{E}-02$ & $1.73235 \mathrm{E}-02$ & $1.73000 \mathrm{E}-02$ \\
\hline $\mathbf{M g}$ & $2.61233 \mathrm{E}-04$ & $2.62161 \mathrm{E}-04$ & $2.57663 \mathrm{E}-04$ & $2.52881 \mathrm{E}-04$ & $2.52199 \mathrm{E}-04$ \\
\hline $\mathbf{A l}$ & $2.84295 \mathrm{E}-02$ & $2.85305 \mathrm{E}-02$ & $2.80411 \mathrm{E}-02$ & $2.75206 \mathrm{E}-02$ & $2.74464 \mathrm{E}-02$ \\
\hline $\mathbf{S i}$ & $1.13033 \mathrm{E}-04$ & $1.13434 \mathrm{E}-04$ & $1.11488 \mathrm{E}-04$ & $1.09419 \mathrm{E}-04$ & $1.09124 \mathrm{E}-04$ \\
\hline $\mathbf{T i}$ & $2.48536 \mathrm{E}-05$ & $2.49419 \mathrm{E}-05$ & $2.45140 \mathrm{E}-05$ & $2.40590 \mathrm{E}-05$ & $2.39941 \mathrm{E}-05$ \\
\hline $\mathbf{C r}$ & $5.34233 \mathrm{E}-05$ & $5.36131 \mathrm{E}-05$ & $5.26934 \mathrm{E}-05$ & $5.17154 \mathrm{E}-05$ & $5.15759 \mathrm{E}-05$ \\
\hline $\mathbf{M n}$ & $2.16697 \mathrm{E}-05$ & $2.17466 \mathrm{E}-05$ & $2.13736 \mathrm{E}-05$ & $2.09769 \mathrm{E}-05$ & $2.09203 \mathrm{E}-05$ \\
\hline $\mathbf{F e}$ & $9.94792 \mathrm{E}-05$ & $9.98326 \mathrm{E}-05$ & $9.81199 \mathrm{E}-05$ & $9.62989 \mathrm{E}-05$ & $9.60390 \mathrm{E}-05$ \\
\hline $\mathbf{N i}$ & & & & & \\
\hline $\mathbf{C u}$ & $4.99603 \mathrm{E}-05$ & $5.01378 \mathrm{E}-05$ & $4.92777 \mathrm{E}-05$ & $4.83631 \mathrm{E}-05$ & $4.82326 \mathrm{E}-05$ \\
\hline${ }^{\mathbf{1 8 1}} \mathbf{T a}$ & & & & & \\
\hline${ }^{\mathbf{2 3 4} \mathbf{U}}$ & $4.73819 \mathrm{E}-06$ & $4.85752 \mathrm{E}-06$ & $4.27901 \mathrm{E}-06$ & $3.66379 \mathrm{E}-06$ & $3.57599 \mathrm{E}-06$ \\
\hline${ }^{\mathbf{2 3 5}} \mathbf{U}$ & $4.42822 \mathrm{E}-04$ & $4.53974 \mathrm{E}-04$ & $3.99907 \mathrm{E}-04$ & $3.42411 \mathrm{E}-04$ & $3.34205 \mathrm{E}-04$ \\
\hline${ }^{\mathbf{2 3 6}} \mathbf{U}$ & $1.89971 \mathrm{E}-06$ & $1.94755 \mathrm{E}-06$ & $1.71560 \mathrm{E}-06$ & $1.46894 \mathrm{E}-06$ & $1.43374 \mathrm{E}-06$ \\
\hline${ }^{\mathbf{2 3 8}} \mathbf{U}$ & $2.56394 \mathrm{E}-05$ & $2.62851 \mathrm{E}-05$ & $2.31546 \mathrm{E}-05$ & $1.98256 \mathrm{E}-05$ & $1.93504 \mathrm{E}-05$ \\
\hline
\end{tabular}


Table C1. (continued)

\begin{tabular}{|c|c|c|c|c|c|}
\hline \multirow{2}{*}{$\begin{array}{c}\text { Element/ } \\
\text { Isotope }\end{array}$} & $\begin{array}{c}\text { Outer fuel } \\
\text { zone 60 - } \\
\text { midplane }\end{array}$ & $\begin{array}{c}\text { Outer fuel } \\
\text { zone 61 - } \\
\text { midplane }\end{array}$ & $\begin{array}{c}\text { Muterials fuel } \\
\text { zone 62 - } \\
\text { midplane }\end{array}$ & $\begin{array}{c}\text { Outer fuel } \\
\text { zone 63 - } \\
\text { midplane }\end{array}$ & $\begin{array}{c}\text { Outer fuel } \\
\text { zone 64 - } \\
\text { midplane }\end{array}$ \\
\hline $\mathbf{H}$ & $3.26876 \mathrm{E}-02$ & $3.26876 \mathrm{E}-02$ & $3.26876 \mathrm{E}-02$ & $3.26876 \mathrm{E}-02$ & $3.26876 \mathrm{E}-02$ \\
\hline $\mathbf{B e}$ & & & & & \\
\hline${ }^{\mathbf{1 0}} \mathbf{B}$ & & & & & \\
\hline${ }^{\mathbf{1 1}} \mathbf{B}$ & & & & & \\
\hline $\mathbf{C}$ & & & & & \\
\hline $\mathbf{O}$ & $1.74139 \mathrm{E}-02$ & $1.75578 \mathrm{E}-02$ & $1.79686 \mathrm{E}-02$ & $1.82590 \mathrm{E}-02$ & $1.81998 \mathrm{E}-02$ \\
\hline $\mathbf{M g}$ & $1.14207 \mathrm{E}-04$ & $1.14671 \mathrm{E}-04$ & $1.15996 \mathrm{E}-04$ & $1.16933 \mathrm{E}-04$ & $1.16742 \mathrm{E}-04$ \\
\hline $\mathbf{A l}$ & $1.24289 \mathrm{E}-02$ & $1.24794 \mathrm{E}-02$ & $1.26236 \mathrm{E}-02$ & $1.27256 \mathrm{E}-02$ & $1.27048 \mathrm{E}-02$ \\
\hline $\mathbf{S i}$ & $4.94161 \mathrm{E}-05$ & $4.96169 \mathrm{E}-05$ & $5.01902 \mathrm{E}-05$ & $5.05954 \mathrm{E}-05$ & $5.05129 \mathrm{E}-05$ \\
\hline $\mathbf{T i}$ & $1.08656 \mathrm{E}-05$ & $1.09098 \mathrm{E}-05$ & $1.10358 \mathrm{E}-05$ & $1.11249 \mathrm{E}-05$ & $1.11068 \mathrm{E}-05$ \\
\hline $\mathbf{C r}$ & $2.33558 \mathrm{E}-05$ & $2.34507 \mathrm{E}-05$ & $2.37217 \mathrm{E}-05$ & $2.39132 \mathrm{E}-05$ & $2.38742 \mathrm{E}-05$ \\
\hline $\mathbf{M n}$ & $9.47364 \mathrm{E}-06$ & $9.51213 \mathrm{E}-06$ & $9.62205 \mathrm{E}-06$ & $9.69973 \mathrm{E}-06$ & $9.68390 \mathrm{E}-06$ \\
\hline $\mathbf{F e}$ & $4.34907 \mathrm{E}-05$ & $4.36674 \mathrm{E}-05$ & $4.41720 \mathrm{E}-05$ & $4.45286 \mathrm{E}-05$ & $4.44560 \mathrm{E}-05$ \\
\hline $\mathbf{N i}$ & & & & & \\
\hline $\mathbf{C u}$ & $2.18419 \mathrm{E}-05$ & $2.19306 \mathrm{E}-05$ & $2.21840 \mathrm{E}-05$ & $2.23631 \mathrm{E}-05$ & $2.23266 \mathrm{E}-05$ \\
\hline${ }^{\mathbf{1 8 1}} \mathbf{T a}$ & & & & & \\
\hline${ }^{\mathbf{2 3 4}} \mathbf{U}$ & $4.00218 \mathrm{E}-06$ & $4.54026 \mathrm{E}-06$ & $6.07667 \mathrm{E}-06$ & $7.16248 \mathrm{E}-06$ & $6.94119 \mathrm{E}-06$ \\
\hline${ }^{\mathbf{2 3 5}} \mathbf{U}$ & $3.74035 \mathrm{E}-04$ & $4.24323 \mathrm{E}-04$ & $5.67913 \mathrm{E}-04$ & $6.69390 \mathrm{E}-04$ & $6.48709 \mathrm{E}-04$ \\
\hline${ }^{\mathbf{2 3 6}} \mathbf{U}$ & $1.60461 \mathrm{E}-06$ & $1.82035 \mathrm{E}-06$ & $2.43635 \mathrm{E}-06$ & $2.87168 \mathrm{E}-06$ & $2.78296 \mathrm{E}-06$ \\
\hline${ }^{\mathbf{2 3 8}} \mathbf{U}$ & $2.16566 \mathrm{E}-05$ & $2.45683 \mathrm{E}-05$ & $3.28822 \mathrm{E}-05$ & $3.87577 \mathrm{E}-05$ & $3.75603 \mathrm{E}-05$ \\
\hline
\end{tabular}


Table C1. (continued)

\begin{tabular}{|c|c|c|c|c|}
\hline \multirow{2}{*}{$\begin{array}{c}\text { Element/ } \\
\text { Isotope }\end{array}$} & $\begin{array}{c}|c| \\
\text { Outer fuel } \\
\text { zone 65 - } \\
\text { midplane }\end{array}$ & $\begin{array}{c}\text { Outer fuel } \\
\text { zone 66 - } \\
\text { midplane }\end{array}$ & $\begin{array}{c}\text { Outer fuel } \\
\text { zone 67 - } \\
\text { midplane }\end{array}$ & $\begin{array}{c}\text { Outer fuel } \\
\text { zone 68 - } \\
\text { midplane }\end{array}$ \\
\hline $\mathbf{H}$ & $3.26876 \mathrm{E}-02$ & $3.26876 \mathrm{E}-02$ & $3.26876 \mathrm{E}-02$ & $3.26876 \mathrm{E}-02$ \\
\hline $\mathbf{B e}$ & & & & \\
\hline${ }^{\mathbf{1 0}} \mathbf{B}$ & & & & \\
\hline${ }^{\mathbf{1 1}} \mathbf{B}$ & & & & \\
\hline $\mathbf{C}$ & & & & \\
\hline $\mathbf{O}$ & $1.78798 \mathrm{E}-02$ & $1.74339 \mathrm{E}-02$ & $1.71379 \mathrm{E}-02$ & $1.70502 \mathrm{E}-02$ \\
\hline $\mathbf{M g}$ & $1.15710 \mathrm{E}-04$ & $1.14271 \mathrm{E}-04$ & $1.13317 \mathrm{E}-04$ & $1.13034 \mathrm{E}-04$ \\
\hline $\mathbf{A l}$ & $1.25925 \mathrm{E}-02$ & $1.24359 \mathrm{E}-02$ & $1.23321 \mathrm{E}-02$ & $1.23013 \mathrm{E}-02$ \\
\hline $\mathbf{S i}$ & $5.00663 \mathrm{E}-05$ & $4.94439 \mathrm{E}-05$ & $4.90309 \mathrm{E}-05$ & $4.89084 \mathrm{E}-05$ \\
\hline $\mathbf{T i}$ & $1.10086 \mathrm{E}-05$ & $1.08717 \mathrm{E}-05$ & $1.07809 \mathrm{E}-05$ & $1.07540 \mathrm{E}-05$ \\
\hline $\mathbf{C r}$ & $2.36632 \mathrm{E}-05$ & $2.33690 \mathrm{E}-05$ & $2.31738 \mathrm{E}-05$ & $2.31159 \mathrm{E}-05$ \\
\hline $\mathbf{M n}$ & $9.59829 \mathrm{E}-06$ & $9.47897 \mathrm{E}-06$ & $9.39979 \mathrm{E}-06$ & $9.37631 \mathrm{E}-06$ \\
\hline $\mathbf{F e}$ & $4.40630 \mathrm{E}-05$ & $4.35152 \mathrm{E}-05$ & $4.31517 \mathrm{E}-05$ & $4.30439 \mathrm{E}-05$ \\
\hline $\mathbf{N i}$ & & & & \\
\hline $\mathbf{C u}$ & $2.21293 \mathrm{E}-05$ & $2.18542 \mathrm{E}-05$ & $2.16716 \mathrm{E}-05$ & $2.16175 \mathrm{E}-05$ \\
\hline${ }^{\mathbf{1 8 1}} \mathbf{T a}$ & & & & \\
\hline${ }^{\mathbf{2 3 4}} \mathbf{U}$ & $5.74454 \mathrm{E}-06$ & $4.07674 \mathrm{E}-06$ & $2.97001 \mathrm{E}-06$ & $2.64177 \mathrm{E}-06$ \\
\hline${ }^{\mathbf{2 3 5}} \mathbf{U}$ & $5.36873 \mathrm{E}-04$ & $3.81004 \mathrm{E}-04$ & $2.77571 \mathrm{E}-04$ & $2.46894 \mathrm{E}-04$ \\
\hline${ }^{\mathbf{2 3}} \mathbf{U}$ & $2.30319 \mathrm{E}-06$ & $1.63451 \mathrm{E}-06$ & $1.19078 \mathrm{E}-06$ & $1.05918 \mathrm{E}-06$ \\
\hline${ }^{\mathbf{2 3 8} \mathbf{U}}$ & $3.10850 \mathrm{E}-05$ & $2.20601 \mathrm{E}-05$ & $1.60713 \mathrm{E}-05$ & $1.42952 \mathrm{E}-05$ \\
\hline
\end{tabular}


Table C1. (continued)

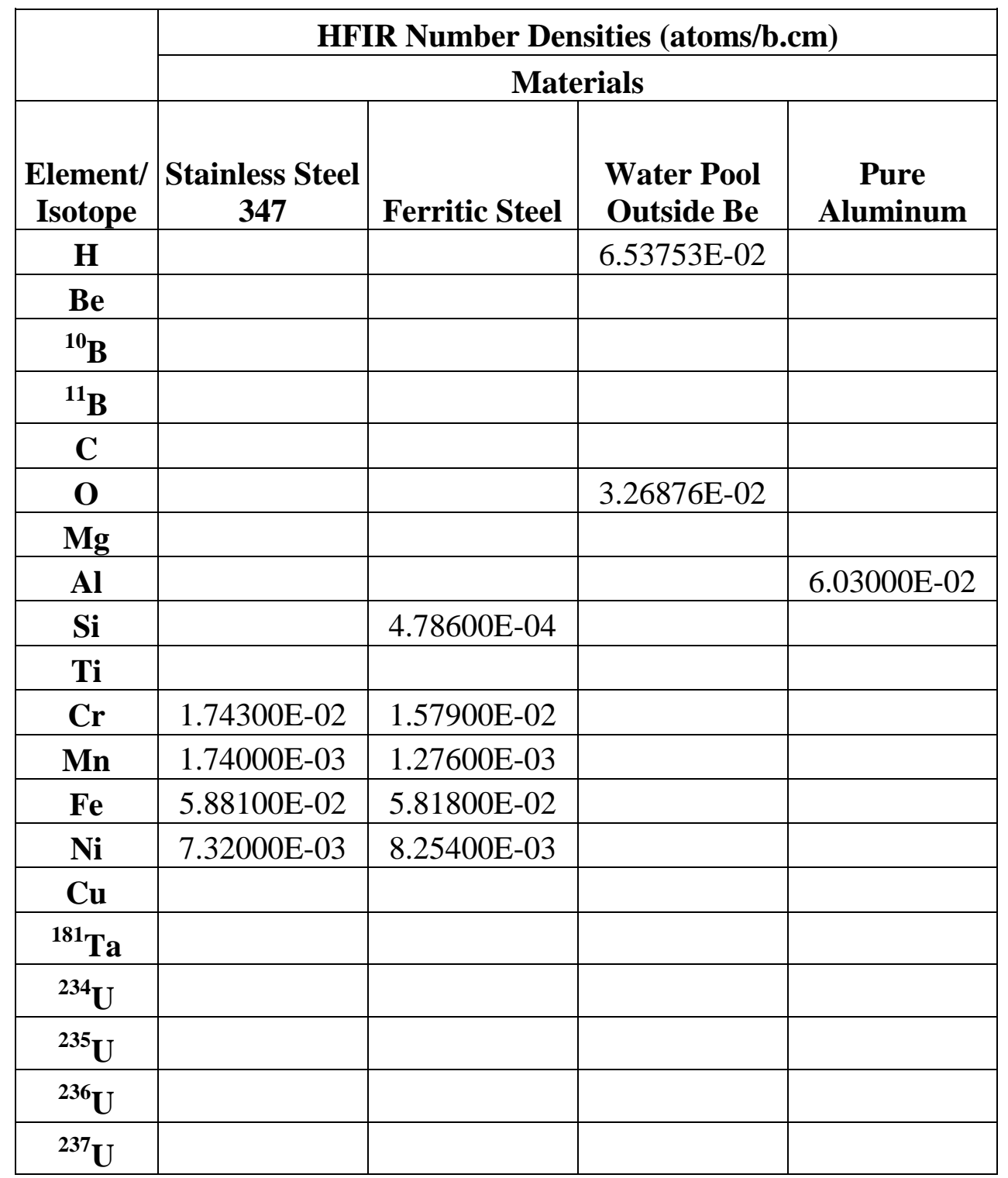


Table C1. (continued)

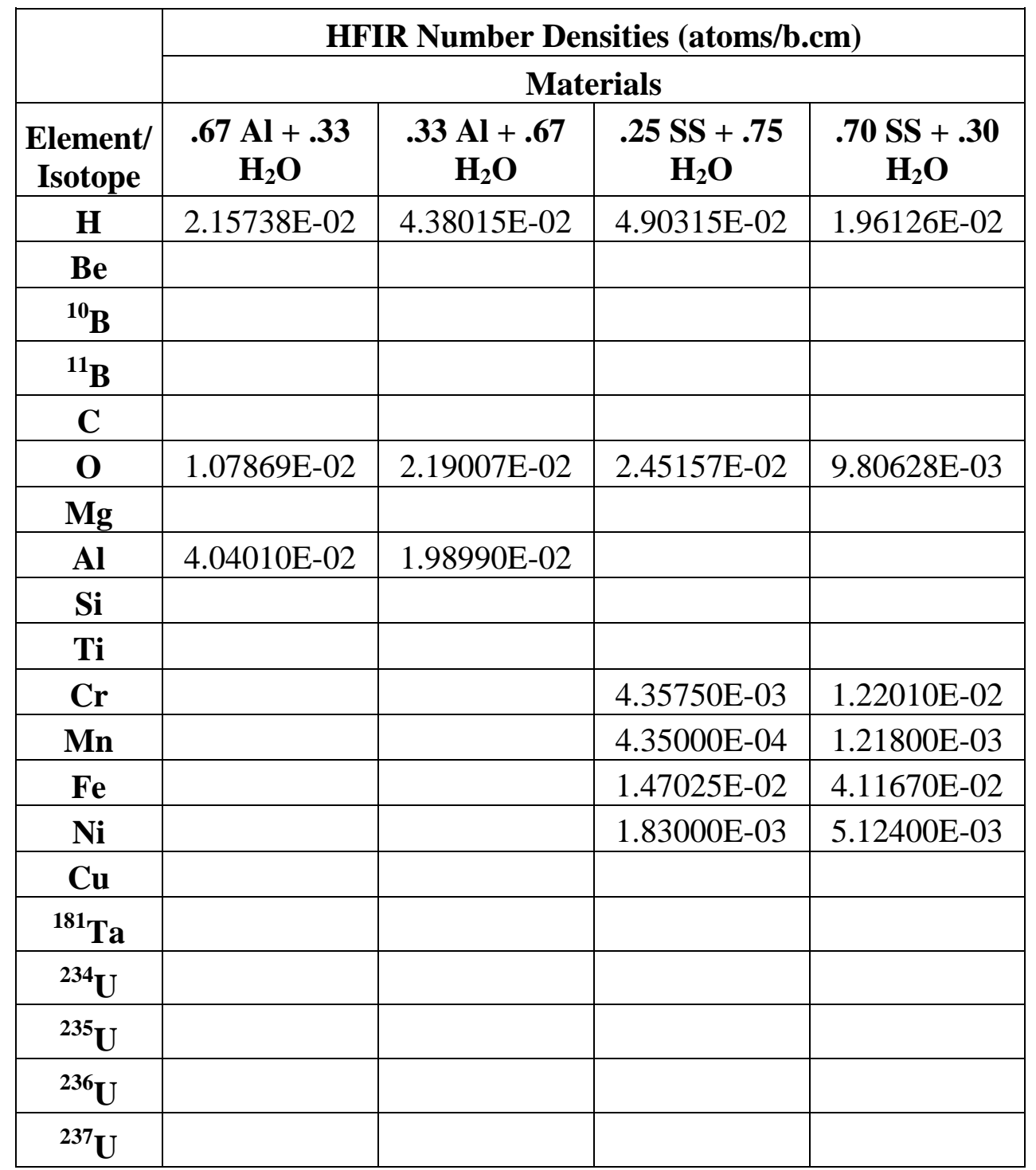




\section{APPENDIX D}

\section{GUIDE TO CALCULATION MODELS FOR HFIR BEAM TUBES AND DATA ARCHIVAL STORAGE}





\section{APPENDIX D}

\section{GUIDE TO CALCULATION MODELS FOR HFIR BEAM TUBES AND DATA ARCHIVAL STORAGE}

\section{D1. Introduction}

This document is an overview of the code input and output files used to perform dpa rate and fast flux calculations for the HFIR beam tubes. Models of the present and proposed new designs are listed for each beam tube. Archival of this information for future purposes is discussed.

\section{D2. Glossary Of File Name Segments}

Filenames for the various runs are long and comprised of numerous segments separated by ".", that describe the run. In addition, there are comments within the file itself that describe the preliminary runs that must be made and input/output data files. Filename terms are explained in Table D1.

\section{D3. Primary DORT/TORT Model Files}

Input files for the main DORT/TORT runs used in this analysis are listed in Table D2. A brief explanation of each file is given. The files are located in the directory structure given in Figure D1. It is anticipated that the system on which the files are maintained may change periodically. HFIR personnel should be contacted for further information.

The 84 group VELM (61 neutron, 23 gamma) library is located in the xsections directory.

\section{D4. Archival Code Storage}

Codes used for this analysis are members of the ORNL DOORS computer code system. A distributed CD-ROM containing the current version of this system (Vers 3.2) has been obtained and will be retained for archival purposes. In addition, source and executable files have been placed on permanent removable storage.

\section{D5. Archival Data Storage}

Data storage to be archived includes discrete ordinates model input text files and output text files, binary output files, and the cross section library. The input text files are primarily in the form of UNIX script files and are stored in the directory "models" under the appropriate subdirectory. Models for HB-1 are stored with HB-4 models since they are mirror images. These files automate the execution process but would have to be tailored to reflect requirements for specific computers. For example, if a different directory structure were used, the input would have to reflect this structure. In general, these changes are simple. The actual code (i.e. TORT, DORT, etc.) input section would not need to be changed, however. 


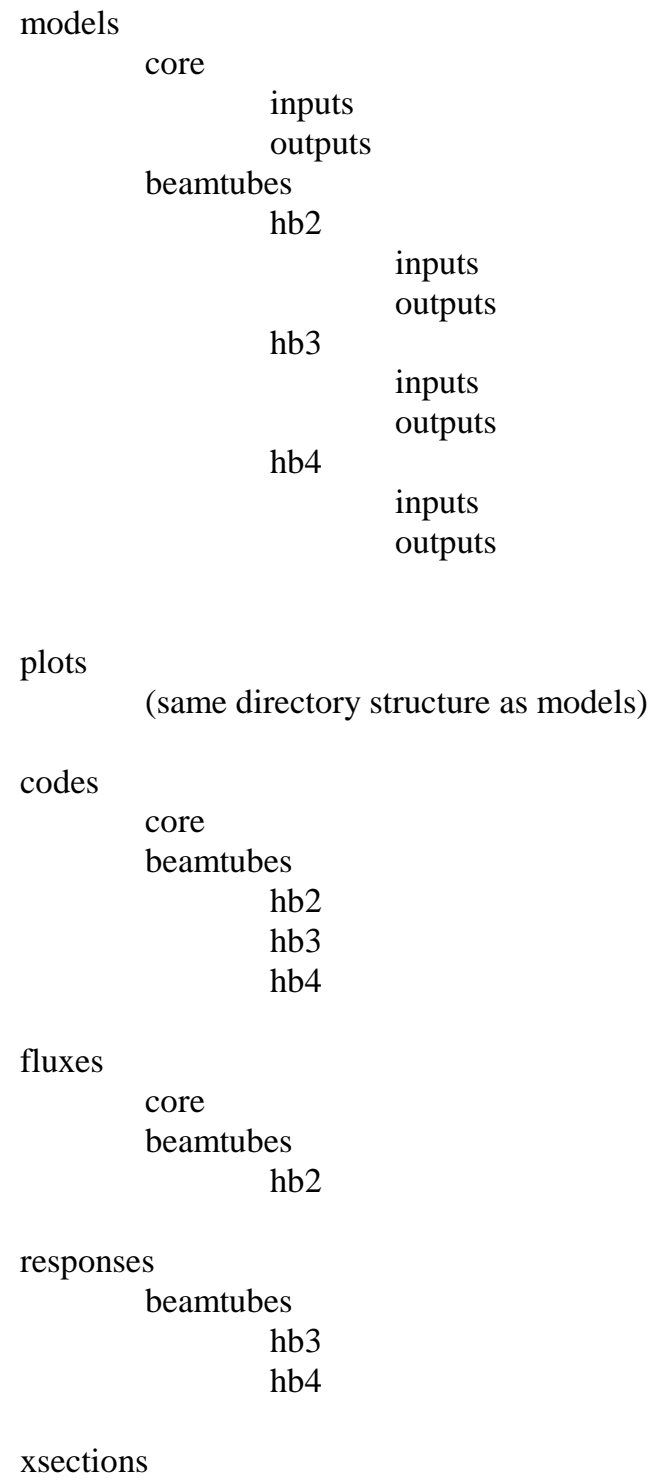

Figure D1. Directory structure for beam line calculations for HFIR vessel life extension analysis."

\footnotetext{
${ }^{*}$ hb4 directories also used for hb1.
} 
Code output files include text files and binary files. The text files present the code output but do not include fluxes or calculated activities and are also stored in the models directory for the appropriate "output" subdirectory. The fluxes or calculated activities are output as binary files. For the two-dimensional (DORT) calculations, the neutron and gamma, energy dependent flux moments have been retained. For this project, the flux moments files end with the suffix "p3flx" (except for the fixed source calculation, in which case they begin with "p3flx"). The flux moment file names contain identifying phrases and are documented by the input in the appropriate DORT file. For the fixed source core calculations, directional flux files are also retained. They begin with the prefix "dirflx". Flux files for the two-dimensional runs are stored in the "fluxes" directory under the appropriate subdirectory.

For the three-dimensional (TORT) codes, the calculated activity responses, including neutron dpa rate, gamma dpa rate, total dpa rate, neutron and gamma fast fluxes (> $1 \mathrm{MeV}$ ) have been retained. These files end with the suffix "res". The activity responses are fluxes weighted with the appropriate cross sections and integrated over the group energies. It is practical to save them instead of flux moments or scalar fluxes for the three-dimensional calculations, because of the enormous size (by today's standards) of the three-dimensional flux files. A disadvantage, however, of only keeping the integrated values is that if a different activity must be calculated, it is necessary to rerun the TORT model with input added to include the specified activity. The activity response files are stored in the "responses" directory under the appropriate subdirectory.

A number of small FORTRAN codes have also been developed and are archived as well. These codes are used to add fluxes or responses from the neutron + prompt gamma run and the delayed gamma run to produce a combined neutron and total gamma flux or response file. The fluxes or responses are also normalized in the final file. These codes are well commented and clearly indicate the situation for which they are used. They are relatively simple and use a standard FORTRAN. Therefore it is not necessary to archive a separate FORTRAN compiler with them. These files are stored in the "codes" directory. 
Table D1. Explanation of filename terms

\begin{tabular}{|c|c|}
\hline Term & Description \\
\hline hfr84kjvk & DORT eigenvalue model for HFIR core \\
\hline hfr84fsjvk & DORT fixed source model for HFIR core \\
\hline dtd8424jvp & $\begin{array}{l}\text { Dtd (dort to dort) model for hb2 } 4 \text { inch diameter model. } \\
\text { Calculates source for DORT models }\end{array}$ \\
\hline dtd8429jvp & $\begin{array}{l}\text { Dtd (dort to dort) model for hb2 } 9 \text { inch diameter model. } \\
\text { Calculates source for DORT models }\end{array}$ \\
\hline dfr84vis* & VISA runs for all beam tubes \\
\hline dfr84hb24 & DORT model for hb2 4 inch diameter present design \\
\hline dfr84hb29 & DORT model for hb2 9 inch diameter modified design \\
\hline v2 & $\begin{array}{l}\text { Revised neutron and gamma source used in all runs after } \\
4 / 99 \\
\text { (Note: some isoplot runs do not include v2 in the title. It is } \\
\text { assumed that in the latest runs, the v2 fluxes/activities are } \\
\text { used.) }\end{array}$ \\
\hline tort & TORT discrete ordinates code model \\
\hline torsed & TORSED code to write boundary source for TORT \\
\hline xtorid & XTORID code to write 2D plot data for ISPL3D code \\
\hline ispl3d & Ispl3d plotting routines for HB3,4 TORT models \\
\hline $\mathrm{hb}^{*}(*=2,3,4)$ & HFIR beam tubes $2,3,4(1)$ \\
\hline new & $\begin{array}{l}\text { Calculations for the present design of hb4 (1), where "new" } \\
\text { originally referred to a new model. The author apologizes } \\
\text { for any confusion this may cause since the "new" beam tube } \\
\text { design for HB-2 and HB-4 is referred to elsewhere. The } \\
\text { keywork "mod" is used for the proposed modified design. }\end{array}$ \\
\hline $\bmod$ & $\begin{array}{l}\text { Calculations for the modified/new design of hb2 or hb4 } \\
\text { (there is no modified design for } \mathrm{hb} 1 \text { or } \mathrm{hb} 3 \text { ) }\end{array}$ \\
\hline new1 & $\begin{array}{l}\text { Calculations for hb3 (there is no modified design). Again, } \\
\text { this originally referred to a new model, not a new design. } \\
\text { This should not cause confusion, however, since there is no } \\
\text { new design. }\end{array}$ \\
\hline $\mathrm{dg}$ & Model for which the source is entirely delayed gammas \\
\hline fs & $\begin{array}{l}\text { In a TORT beam-tube model or run related to a TORT } \\
\text { model, a .fs. run contains a fixed source contribution from } \\
\text { the fuel included in the model as well as a boundary source } \\
\text { from the earlier fixed source calculation }\end{array}$ \\
\hline nofs & $\begin{array}{l}\text { In a TORT beam-tube model or run related to a TORT } \\
\text { model, a *.nofs.* run contains only the boundary source } \\
\text { from the core fixed source calculation The nofs runs for } \\
\text { HB- } 1,3,4 \text { were replaced with fs runs in which a source in the } \\
\text { fueled region in the model was included. }\end{array}$ \\
\hline gheat & $\begin{array}{l}\text { TORT and associated models for HB3 and HB } 4 . \\
\text { Calculation of gamma heating responses }\end{array}$ \\
\hline
\end{tabular}




\begin{tabular}{|c|c|}
\hline highz & $\begin{array}{l}\text { TORT and associated models for HB } 4 \text { in which model } \\
\text { height has been increased to } \sim 25.4 \mathrm{~cm} \text { (from original model) }\end{array}$ \\
\hline total.norm & $\begin{array}{l}\text { In isoplot routines for HB2,3,4 in which DORT or TORT } \\
\text { responses have been normalized and the gamma and } \\
\text { delayed gamma responses added. Normalizations were } \\
\text { changed } \sim 4 / 99 \text {. Several fortran codes are used to add TORT } \\
\text { responses for neutron \& prompt gamma runs and delayed } \\
\text { gamma runs to get the total normalized response. }\end{array}$ \\
\hline dpaRatio & $\begin{array}{l}\text { Ratio of neutron to total gamma dpa. Calculated from } \\
\text { TORT response files for hb3 \& hb4 using fortran codes, } \\
\text { respadd3_dpaRatio.f (hb3) or respadd4*_dpaRatio.f for hb4 } \\
\text { present and modified designs. }\end{array}$ \\
\hline res & Suffix for TORT response file \\
\hline scflx & Suffix for TORT scalar flux file \\
\hline boc & $\begin{array}{l}\text { In general, runs were performed with BOC fuel conditions } \\
\text { and EOC control surface positions. Runs that include "boc" } \\
\text { have BOC control and fuel conditions. }\end{array}$ \\
\hline fine & $\begin{array}{l}\text { Mesh has been made finer (i.e. number of mesh intervals } \\
\text { increased) for sensitivity analysis. }\end{array}$ \\
\hline expanded & $\begin{array}{l}\text { Model increased in size to investigate boundary source } \\
\text { perturbation effects. }\end{array}$ \\
\hline
\end{tabular}


Table D2. List of main DORT/TORT code inputs by beam tube design

\begin{tabular}{|l|l|l|l|}
\hline HB\# & Des & DORT/TORT code file(s) & Comments \\
\hline 2 & $\mathrm{P}$ & $\begin{array}{l}\text { hfr84hb24.v2.sh1 } \\
\text { hfr84hb24.dg.v2.sh1 }\end{array}$ & Base Case \\
\hline 2 & $\mathrm{P}$ & $\begin{array}{l}\text { hfr84hb24.expanded.v2.sh1 } \\
\text { hfr84hb24.dg.expanded.v2.sh1 }\end{array}$ & $\begin{array}{l}\text { Enlarged model to examine } \\
\text { perturbations from source }\end{array}$ \\
\hline 2 & $\mathrm{P}$ & $\begin{array}{l}\text { hfr84hb24.v2.boc.sh1 } \\
\text { hfr84hb24.dg.v2.boc.sh1 }\end{array}$ & BOC conditions \\
\hline 2 & $\mathrm{~N}$ & $\begin{array}{l}\text { hfr84hb29.v2.sh1 } \\
\text { hfr84hb29.dg.v2.sh1 }\end{array}$ & Base Case \\
\hline 2 & $\mathrm{~N}$ & $\begin{array}{l}\text { hfr84hb29.v2.boc.sh1 } \\
\text { hfr84hb29.dg.v2.boc.sh1 }\end{array}$ & Base Case \\
\hline $1(4)$ & $\mathrm{P}$ & $\begin{array}{l}\text { tort.new.hb4.fs.highz.v2.sh1 } \\
\text { tort.new.hb4.fs.dg.highz.v2.sh1 }\end{array}$ & Base Case \\
\hline 4 & $\mathrm{~N}$ & $\begin{array}{l}\text { tort.mod.hb4.fs.highz.v2.sh1 } \\
\text { tort.mod.hb4.fs.dg.highz.v2.sh1 } \\
\text { tort.mod.hb4.fs.highz.v2.fine.sh1 } \\
\text { tort.mod.hb4.fs.dg.highz.v2.fine.sh1 }\end{array}$ & Fine mesh in X direction \\
\hline 3 & $\mathrm{P}$ & $\begin{array}{l}\text { tort.new1.hb3.fs.v2.sh1 } \\
\text { tort.new1.hb3.fs.dg.v2.sh1 }\end{array}$ & Base Case \\
\hline
\end{tabular}

Notes:

1) script in the codes contain names of flux/response files. Comments contain explanations for the use of the code. Also, see glossary of terms.

2) $\mathrm{P}=$ present, $\mathrm{N}=$ new under Des (Design) column.

3) files come in pairs because of separate delayed gamma run. 
INTERNAL DISTRIBUTION

1-5. E. D. Blakeman

6. W. K. Brown

7. J. A. Bucholz

8. S. E. Burnette

9. S. J. Chang

10. R. D. Cheverton

11. D. H. Cook

12. R. E. Daniels

13. T. L. Dickson

14. H. R. Fair

15. M. B. Farrar

16. G. F. Flanagan

17. M. L. Gildner

18. R. E. Hale

19. R. M. Harrington

20. R. W. Hobbs

21. J. R. Inger

22. D. T. Ingersoll

23. S. K. Iskander

24. M. W. Kohring
25. M. A. Kuliasha

26. J. E. Lee

27. R. A. Lillie

28. M. A. Linn

29. R. S. McKeehan

30. L. D. Merryman

31. R. H. Morris

32. J. V. Pace III

33. L. D. Proctor

34. I. Remec

35. J. B. Roberto

36. R. B. Rothrock

37. C. O. Slater

38. R. M. Stinnett

39-40. RRD-DCC

41. Central Research Library

42. Laboratory Records-RC

43. Laboratory Records

(for submission to OSTI) 